UCRL-CR-132260

S/C- B337552

\title{
Final Report for NIF Chamber Dynamics Studies
}

\author{
P. F. Peterson \\ J. M. Scott
}

September 1, 1998

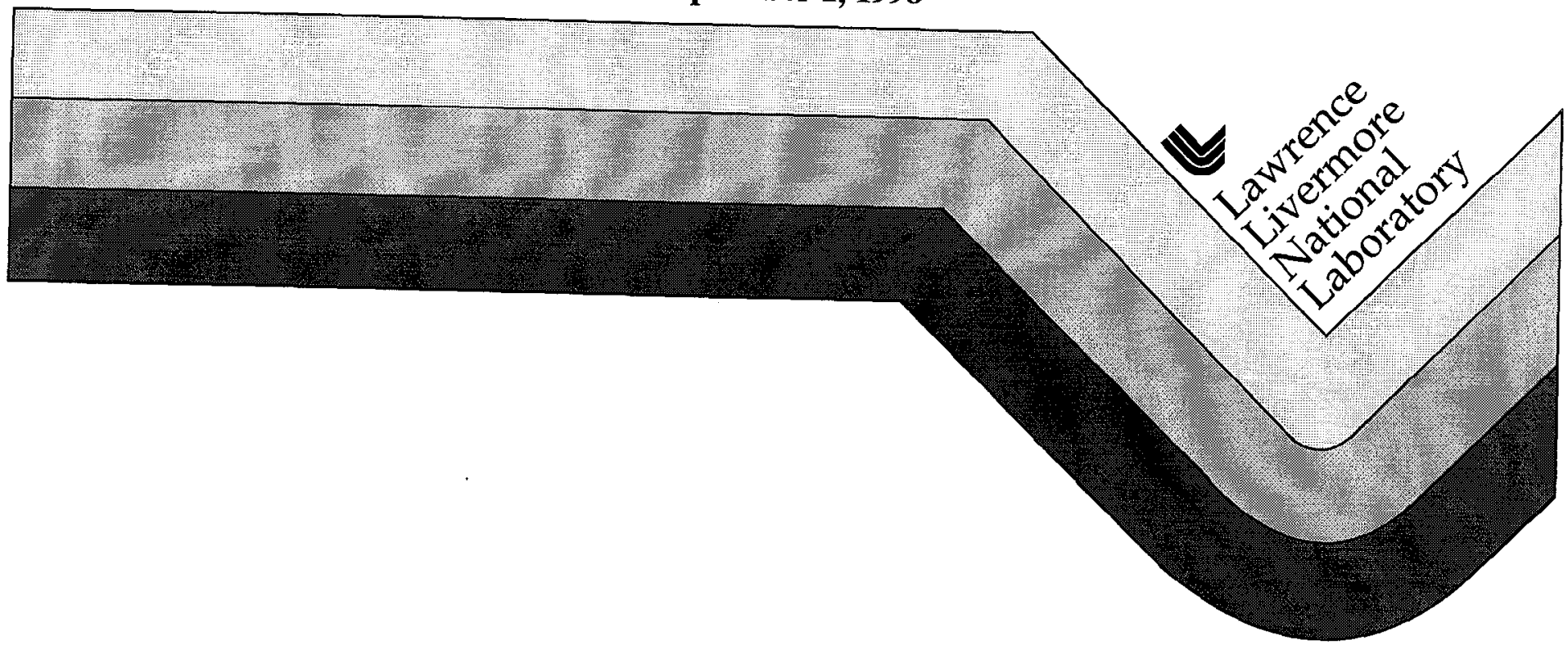




\section{DISCLAIMER}

Work performed under the auspices of the U.S. Department of Energy by Lawrence Livermore National Laboratory under contract number W-7405-ENG-48.

This document was prepared as an account of work sponsored by an agency of the United States Government. Neither the United States Government nor the University of California nor any of their employees, makes any warranty, express or implied, or assumes any legal liability or responsibjlity for the accuracy, completeness, or usefulness of any information, apparatus, product, or process disclosed, or represents that its use would not infringe privately owned rights. Reference herein to any specific commercial products, process, or service by trade name, trademark, manufacturer, or otherwise, does not necessarily constitute or imply its endorsement, recommendation, or favoring by the United States Government or the University of California. The views and opinions of authors expressed herein do not necessarily state or reflect those of the United States Government or the University of California, and shall not be used for advertising or product endorsement purposes. 


\title{
Final Report for NIF Chamber Dynamics Studies
}

\author{
Per F. Peterson and John M. Scott
}

Work Accomplished Under Contract LLNL B337552

April 1, 1997 - September 30, 1998

September 1998

Thermal Hydraulics Group

University of California--Berkeley

Dept. of Nuclear Engineering

Berkeley, CA 94720-1730 


\section{Introduction}

The National Ignition Facility (NIF), a $1.8 \mathrm{MJ}, 192$ laser beam facility, will have anticipated fusion yields of up to $20 \mathrm{MJ}$ from D-T pellets encased in a gold hohlraum target. The energy emitted from the target in the form of x rays, neutrons, target debris kinetic energy, and target shrapnel will be contained in a $5 \mathrm{~m}$. radius spherical target chamber. Various diagnostics will be stationed around the target at varying distances from the target. During each shot, the target will emit $x$ rays that will vaporize nearby target facing surfaces including those of the diagnostics, the target positioner, and other chamber structures. This ablated vapor will be transported throughout the chamber, and will eventually condense and deposit on surfaces in the chamber, including the final optics debris shields.

The research at the University of California at Berkeley relates primarily to the NIF chamber dynamics. The key design issues are the ablation of the chamber structures, transport of the vapor through the chamber and the condensation or deposition processes of those vaporized materials. An understanding of these processes is essential in developing a concept for protecting the final optics debris shields from an excessive coating $(>10 \AA)$ of target debris and ablated material, thereby prolonging their lifetime between change-outs. At Berkeley, we have studied the physical issues of the ablation process and the effects of varying materials, the condensation process of the vaporized material, and design schemes that can lower the threat posed to the debris shields by these processes. The work or portions of the work completed this year have been published in several papers and a dissertation [1-5].

\section{References}

1. Scott, J. M., Peterson, P. F., Burnham, A. K. "Experimental and Analytical Studies of Louvered First-Wall Systems for NIF", ANS 13th Topical Meeting Technology of Fusion Energy, June 1998 (to be published in Fusion Technology).

2. Scott, J. M., Peterson, P. F. "Chamber-Protection Issues for Near-Target Experiments in NIF", ANS 13th Topical Meeting Technology of Fusion Energy, June 1998 (to be published in Fusion Technology).

3. Burnham, A. K., Gerassimenko, M., Scott, J. M., et. al. "Constraints on Target Chamber First Wall and Target Designs That Will Enable NIF Debris Shields To Survive", SSLA-ICF, June 1998

4. Whitman, P., Burnham, A., Norton, M., Genin, F., Scott, J. M., et al. "Management of Unconverted Light for the National Ignition Facility Target Chamber", SSLA-ICF, June 1998

5. Scott, J. M. "X-ray Ablated Plumes in Inertial Confinement Fusion Reactors", Ph.D. Dissertation, U. C. Berkeley, Sept. 1998. 


\section{Summary of Contract Tasks Completed May 1, 1998-Sept. 30, 1998}

1) Continuing work on the design and operation of ablation/condensation experiments on NOVA to support the NIF target chamber development. These experiments will help characterize the contamination threat from the first wall to the NIF final optics assemblies. The results from these experiments will serve as a benchmark for the TSUNAMI code.

Additional support and experiments have included study of louvered designs for the NIF first wall and beam dumps. The experiments provided data for benchmarking of the combined TSUNAMI/ABLATOR code. Comparison of the experimental data with calculation showed good agreement.

2) Support for long-term characterization of potential target chamber materials. Long term exposure of potential target chamber materials such as boron carbide in the NOVA target chamber are performed on a rolling basis. Analysis of these samples will help determine if these materials are suitable for use in the NIF target chamber.

Several long term exposure experiments were performed to characterize the long term behavior of NIF target chamber candidate materials including boron carbide and fused silica. In addition the study of the louvered design for the first wall helped to characterized the long term impact of remobilization from candidate first wall materials like boron carbide and stainless steel.

3) TSUNAMI analysis of the NIF louvered first wall design. We will provide an analysis of the louvered first wall design in attempt to quantify the amount of material that will be mobilized from first wall.

Analysis of the first wall design showed that up to $90 \%$ of the debris plume can be captured with the louvered dogleg configuration. The results of the analysis were reported in an LLNL memoramdum.

4) Initial TSUNAMI analysis of contamination mitigation for the final optics debris shields. It has been proposed to provide a puff of gas from the final optics debris shields towards the target chamber after a shot on NIF. The purpose of the puff of gas will be to prevent low kinetic energy vapor from depositing on the debris shields.

Additional TSUNAMI analysis was provided for the analysis of previous experiments including the modeling of an aluminum ablation plume where the ablation plume seems to have interacted with oncoming target debris. No analysis was provided specifically for the final optics debris shields.

5) Continuing work on advanced chamber protection concepts such as the frost-coated minichamber.

Work was completed on the study of debris mitigation by the mini-chamber showing an $85 \%$ capture rate. Additionally, John participated with the NIF target positioner working group to help develop a design that can withstand expected $x$-ray fluences of $1-2 \mathrm{~kJ} / \mathrm{cm}^{2}$ with the release of 
a minimal amount of material. The technical issues associated with the NIF target positioner are similar to those faced by the mini-chamber.

6) Participation in relevant workshops and conferences.

The results of this work were published and presented in relevant conferences and meetings. 


\section{Table of Contents}

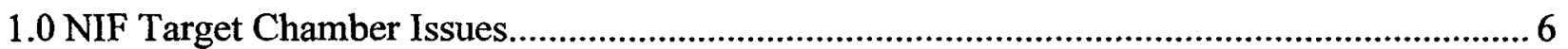

2.0 Long-term exposure of fused silica and borosilicate glass on NOVA....................................... 10

3.0 Long-term exposure of $\mathrm{B}_{4} \mathrm{C}$ to the Nova target chamber environment.................................... 19

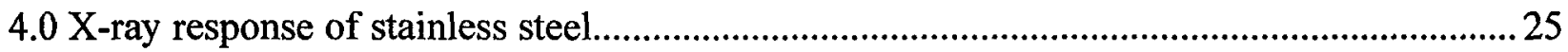

5.0 Louvered geometry experiments with NIF first wall materials .................................................. 35

6.0 Capture fraction calculations for the NIF first wall ................................................................ 49

7.0 Variability of material response to NOVA x-ray emissions....................................................5

8.0 Variation of NIF target chamber material response with x-ray spectrum ................................65 


\subsection{NIF Target Chamber Issues}

The NIF target chamber is a 10 -m diameter aluminum sphere that will serve as the vacuum chamber in which experiments with the $1.8-\mathrm{MJ}$ laser will be conducted. Figure 1 shows the target chamber with various penetrations for diagnostics and beam ports. Approximately, $90 \%$ of the inside surface of the target chamber will be covered with first wall panels and laser beam dumps. The remaining $10 \%$ consists of laser beam ports and diagnostic ports. The primary function of the first wall is to prevent damage to the final optics debris shields due to the ablation of material from the first wall surface primarily from target X-ray emissions. The debris shields are the critical elements in the laser system that will determine the shot and maintenance frequency of the NIF. They are located at the interface between the final optics assemblies (FOA) and the target chamber and serve as protection from target chamber emissions including debris and $\mathrm{X}$ rays. In addition to the first wall requirement, the beam dumps must also absorb unconverted $1 \omega(1.06 \mu \mathrm{m})$ and $2 \omega(0.53 \mu \mathrm{m})$ light with a minimal release of mass. The FOA's contain frequency conversion crystals that take $1 \omega$ and convert it to $3 \omega(0.35 \mu \mathrm{m})$ light. The conversion process is only $60 \%$ efficient and residual $1 \omega$ and $2 \omega$ light enter the target chamber. The $3 \omega$ light shines on target and the unconverted light is diffracted around the target and is absorbed in beam dumps opposite the locations where laser light enters the chamber. Figure 2 gives a list of threats that the first wall and beam dumps must endure. These include other threats besides those already mentioned such as neutrons and shrapnel. Shrapnel consists of target debris that has not been completely vaporized, that is molten or solid, and has a great enough velocity to damage exposed surfaces. The neutron threat is concerned with the issue of activation of materials present in the chamber.

For a considerable period of time during the development of the target chamber, the beam dumps and first wall panels were going to be of different design, but evaluation of various beam designs showed that the design for the first wall panel could also serve as the design of the beam dump. Therefore, any further references to the 'first wall' in this section includes the beam dumps because both the first wall and beam dumps are required to withstand the same X-ray fluence.

During any given experiment in the NIF a small target approximately $1 \mathrm{~g}$. in mass will be heated and vaporized reaching temperatures on the order of $10^{6}$ or $10^{7} \mathrm{~K}$ in an effort to research ICF target physics and other high energy density physics phenomena. The interaction of these targets with the laser light will generate $X$ rays and vaporized debris that will deposit on various surfaces in the chamber. The X-ray fluence from the target is sufficient to vaporize thin layers of target facing materials in the chamber that will condense on target chamber surfaces along with the vaporized target debris. Some of this vaporized matcrial will condense on the debris shields. Consequently, the debris shield contamination rate will need to be below a maximum level for an appropriate amount of time commensurate with the established cleaning schedule for the target chamber. 
The first wall of the NIF target chamber will be a source of contamination for the FOA debris shields. Unlike Nova, where the X-ray fluence from targets at the first wall is $\sim .05 \mathrm{~J} / \mathrm{cm}^{2}$, the expected X-ray fluence on NIF approaches $\sim 2 \mathrm{~J} / \mathrm{cm}^{2}$ for $20-\mathrm{MJ}$ target yields ${ }^{1}$. With respect to the X-ray fluence level, the Nova first wall is a sink for material that deposits on its surface. On NIF, the X-ray fluence will be sufficiently high to remove first wall material and deposited contaminants. Therefore, the first wall will be a source of ablation debris that can travel through the target chamber and deposit on the FOA debris shields. Since $90 \%$ of the aluminum target chamber surface area will consist of first wall panels, it is critical to choose a material that is not easily mobilized by target X-ray emissions. Additionally, it would be advantageous to have a first wall design that provides a sink for mobilized material in the target chamber.

Current levels for the allowable contamination rate on the debris shields ${ }^{2}$ are in the range of $1 \mu \mathrm{g} / \mathrm{cm}^{2} / \mathrm{shot}$. This rate is partitioned between various contaminants including vaporized target debris, ablated near-target materials, laser ablated beam dump material, first wall material, and remobilized deposits from the first wall. The first wall has the possibility to consume a large portion of this budget because of its large surface area, $\sim 300 \mathrm{~m}^{2}$.

Mitigating the threat from the first wall will require the use of an X-ray resistant first wall material. Additionally, a first-wall design consisting of flat panels would need periodic cleaning because the surface deposits would become a large source of remobilized debris per shot. Consequently, it would beneficial to develop passive cleaning methods that do not need lengthy periodic maintenance to meet the allowable optics contamination rate. The combination of an appropriate X-ray resistant material with a geometry that effectively retards material transport should keep FOA debris shield contamination rate at a level compatible with the established resources.

Though the conditions that the NIF first wall must endure are not as significant a threat as that posed to a ICF target chambers designed to produce energy, the threats faced by the NIF can give us insight to the target chamber dynamics issues that need to be addressed in a next generation facility. Some future facilities propose lasers as the drivers for the fuel pellets in which case some of the lessons learned from NIF can readily be applied when it comes to issues associated with optics contamination. The design of NIF has been important for the early stages in the development of models that will eventually be applied to a next generation ICF facility.

The focus of this report will be on experiments performed in an effort to pursue the selection of a material and a geometrical design for the first wall panels. These experiments included long-term exposure of materials to the Nova target chamber and the response of materials to Nova target emissions. Various materials were tested for both the first wall and the beam dump design. Additionally, model calculations will be compared to these experiments where applicable and predictions for NIF will be provided. The report is broken down into individual sections with their own references and figures. 


\section{References}

1. Anderson, A. T., "X-ray Ablation Measurements for ICF Appliations", Ph.D. Dissertation, University of California--Berkeley, 1996.

2. Burnham, A. K., Gerassimenko, M., Scott, J. M., et. al. "Constraints on Target Chamber First Wall and Target Designs That Will Enable NIF Debris Shields To Survive", SSLA-ICF, June 1998 


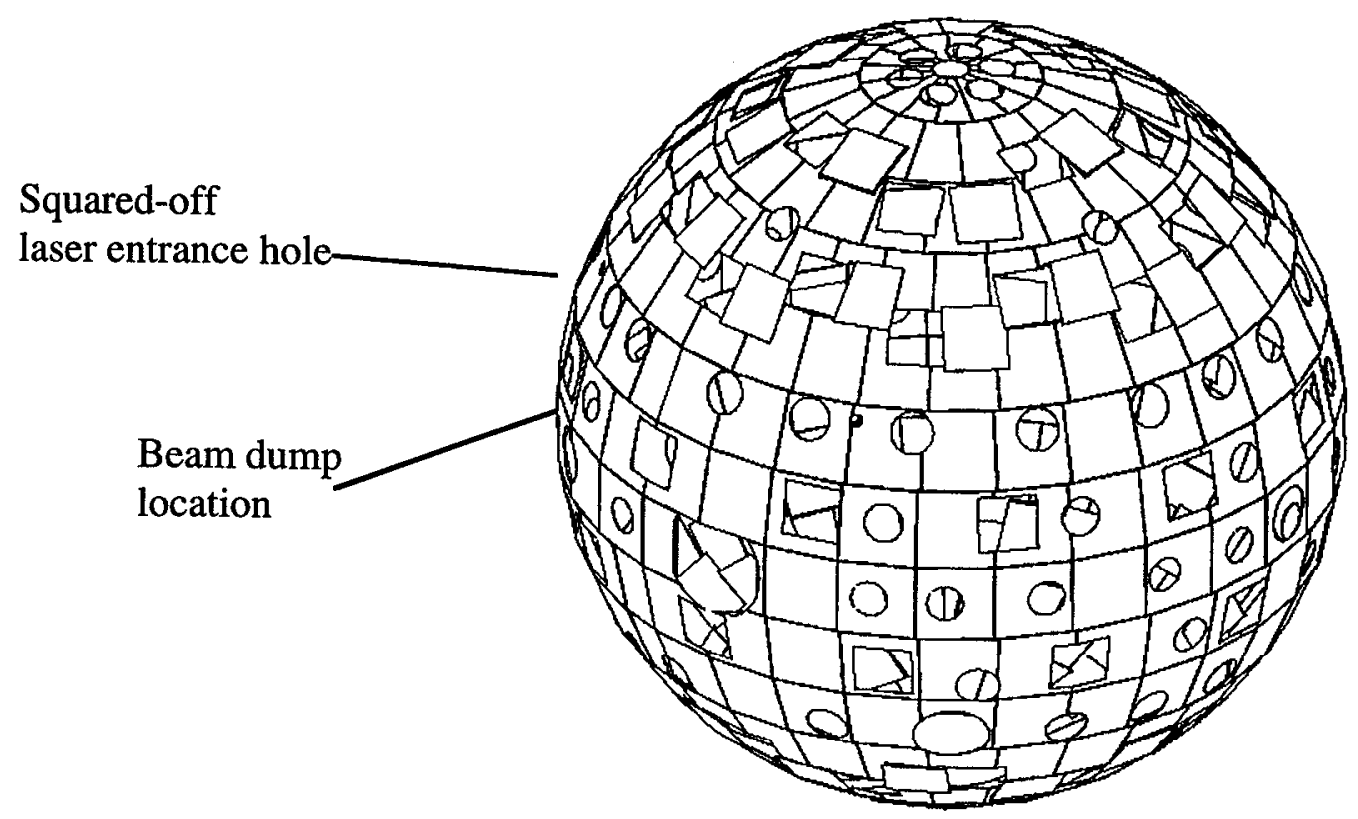

Fig. 1--Layout of the first wall panels on the aluminum target chamber.
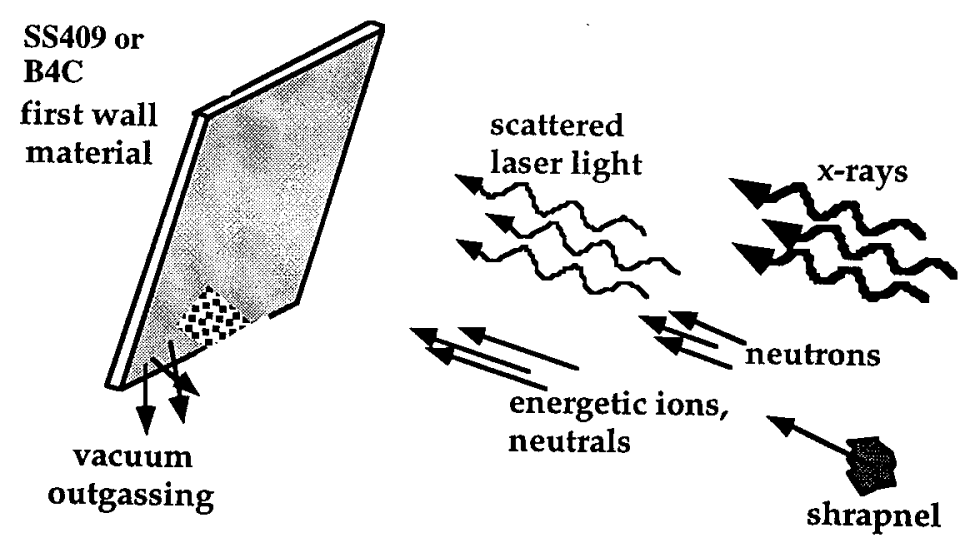

Fig. 2--Threats to the NIF first wall 


\subsection{Long-term exposure of fused silica and borosilicate glass on NOVA}

Fused silica and borosilicate glasses have been proposed as potential materials for use as the NIF target chamber beam dumps. The removal of fused silica by $\mathrm{x}$-ray emissions from NOVA targets is discussed in a previous memo ${ }^{1}$ from Anderson and Burnham. In that memo, they discussed removal based on a few exposures to NOVA. For a single exposure or a few exposures, the goal is to measure removal by $\mathrm{x}$ rays; but for a long-term exposure, measurable removal of material will occur from both $\mathrm{x}$ rays and shrapnel damage. Shrapnel consists of target debris that has not been completely vaporized, that is molten or solid, and that has a great enough velocity to damage exposed surfaces. Damage from shrapnel can easily be witnessed on the fused silica blast shields used in the NOVA target chamber. It is expected on NIF that some portion of the material debris will be in the form of shrapnel. ${ }^{2}$ A long-term exposure aids in the characterization of the material response to the $\mathrm{x}$-ray and shrapnel threat.

\section{Experiment}

The glass samples were mounted in a fixture, sketched in Fig. 1, approximately $4.5^{\prime \prime} \times 4.5^{\prime \prime}$ in size. The position of each of the samples is listed, because they remained constant throughout the entire experiment. They are held in place by stainless straps that are secured to the fixture with a screw and nut. The experimental fixture itself is mounted to copper activation tube no. 1 inside the NOVA target chamber. This position is chosen because of its proximity to the target and its location $25^{\circ}$ off the hohlraum axis. Experiments measuring material removal by $\mathrm{x}$ rays were located on SIM5, also $25^{\circ}$ off the hohlraum axis. The experiment mounts to the face of the copper activation tube, leaving the samples' front surfaces approximately $42 \mathrm{~cm}$ from target chamber center. At this distance, the samples receive a nominal x-ray fluence of $0.9 \mathrm{~J} / \mathrm{cm}^{2}$ for scale-1 hohlraums driven by a 1-ns pulse. Determination of this fluence is discussed in a previous memo. ${ }^{3}$

A total of eight $1 " \times 2$ " samples were exposed over a six-week period to a total of 83 NOVA shots. The eight samples consisted of four pairs of identical materials, fused silica from General Electric, fused silica from Corning, Pyrex, and Tempax from Schott. The exposure period occurred over various weeks from Oct. 13, 1997 to Dec. 18, 1997. Table 1 summarizes the shot data for each of the shots for the duration of the exposure. Before their exposure, the samples were polished to a $0.1-\mu \mathrm{m}$ finish in order to facilitate measuring the material removal by profilometry. After polishing, a portion of the sample was masked, and the unmasked portion was bead blasted to roughen the surface. It is likely that if glass were chosen as the beam dump material, its functional form would consist of bead-blasted panels. After bead blasting, we are left with a sample with some portion retaining the polished finish, but the majority, about $95 \%$, of the sample had a roughened surface. 


\section{Results}

Material removal from the samples was measured both by profilometry with a Tencor alpha-step 200 and by weighing the samples with a Mettler AE163 scale. The profilometry measurement provides the data regarding the amount of removal material by vaporization from $\mathrm{x}$ rays, while weighing the samples accounts for the loss both by shrapnel and by vaporization. In this manner, the weight loss due to shrapnel losses can be obtained by the difference in each measurement. Damage from larger pieces of shrapnel tends to manifest itself as 'dings' or craters on the surface of the samples, easily seen by the naked eye. The damage sites look similar to the damage from a BB hitting a car windshield. Damage from shrapnel occurs on a microscopic basis as well. A damage site from micro-shrapnel on a polished surface is pictured in Fig. 2.

Figure 3 shows a typical view of the polished surface after the exposure. Optical microscope photographs of the bead-blasted surfacc werc not possible due to the roughness generated by the beadblasting. On the polished surface, many craters as well as shrapnel damage sites can be seen. Metal splats from the most recent exposures to target debris are visible. The metals tend to be $\mathrm{Cu}$ and $\mathrm{Al}$ from shine shields and near-target surfaces. Typically, craters are seen with some surrounded by a splat of target debris material and others not surrounded by a splat of material. These craters are due to liquid drops of copper or aluminum impinging on the surface of the sample. The craters with splats of target debris are due to the most recent shots the samples have experienced. As they are exposed to subsequent shots, the splats are vaporized by exposure to target $x$ rays, leaving just the crater behind. Previous results from two- and threeexposure surfaces (from a sample that was part of a few exposure experiment) suggest that the liquid drops form a crater on the surface without cracks radiating from the crater. In Fig. 4, we can see splats with a crater in the center as well as craters with no material around them. On these few exposure surfaces, there are no cracks radiating from the craters. It is likely that the cracks radiating from the craters on long-term exposure surfaces are formed by repeated melting and solidifying of the surface around the craters. Since the melt layer is on the order of a micron and the crater depth is greater, the hole formed by the crater in the melt layer will act as a stress concentrator as the material solidifies. Also observable in Fig. 4 are silhouettes of metal splats that have been removed. There are many silhouettes on the three-exposure surface. Apparently, when a metal splat is removed, on a subsequent exposure it also removes some of the underlying material, leaving an impression from the metal splat. The possibility of the impression forming when the splat impacts the surfaces was ruled out, when the metal from a one-exposure surface was removed from the surface by acid and revealed no silhoucttes.

Table 2 summarizes the weight measurements and profilometry data obtained after the six-week exposure period. Note that the profilometry measurement is converted into an equivalent weight loss. Though the measured weight loss seems to vary greatly, measurements for half of the samples are affected by mass loss not directly attributable to target emissions. The unexposed corners of some of the samples have cracked off, adding to the weight loss. It is not precisely clear exactly why the corners of some of the samples were lost. Some of the corners could have been cracked when the samples were placed in the fixture. The samples were 
taken out and placed back in the fixture twice during the period of exposure to obtain midexposure measurements. It is possible that tightening the straps multiple times over the edges of the samples weakened the corners and made them very easy to break off. Six of the samples had corners broken off, but for two of the samples, Corning \#2 and Tempax \#2, the broken off material could be collected and weighed. A profilometer measurement is not provided for the sample labeled Corning \#2 because the corner containing the polished portion of the sample had broken off. The four samples, GE \#1, Corning \#1, Pyrex \#1, and Pyrex \#2, were those that were affected by corners breaking off. Correcting the mass loss from the corners is difficult because of the irregular shape of the removed corner. Therefore, the numbers listed in the total loss column of Table 2 do include the mass loss from the unexposed corners. Consequently, the mass loss due to shrapnel alone is not calculated for these samples.

\section{Discussion}

From Table 2, there was virtually no weight loss from the samples during the first two weeks of exposures. It was not until the final four weeks of exposure that there was significant weight loss from the samples. There was a measurable ablation step from the samples due to exposure to the target $x$ rays during the first two-week period, but the equivalent mass amounted to approximately $1 \mathrm{mg}$ in most of the cases. It was not until the last four weeks that corners were accidentally removed and the majority of the shrapnel losses occurred. As a check for consistency, the removal of fused silica for this long-term exposure can be compared to data from a few exposure experiments. ${ }^{4}$ Assuming that shot energies over $10 \mathrm{~kJ}$ produce significant ablation, the fused silica samples averaged $0.48 \mu \mathrm{m}$ of removal over 69 shots or $7 \times 10^{-3} \mu \mathrm{m} / \mathrm{shot}$. This fits reasonably within previously obtained data. For fused silica at $1 \mathrm{~J} / \mathrm{cm}^{2}$, we would expect $\sim .01 \mu \mathrm{m}$ of removal.

From the results, shrapnel losses from only three of the eight samples can reliably be made. The shrapnel loss is an order of magnitude greater than the loss by x-ray ablation. The results suggest that the damage threat from shrapnel is significantly greater than the threat from $x$ rays, but we must scale the results to NIF geometry to properly assess the potential threat. Taking the best data and averaging the results from the shrapnel loss over the area of the samples and the number of shots, gives an average rate of $2.5 \times 10^{-5} \mathrm{~g} / \mathrm{cm}^{2} / \mathrm{shot}$ removal rate for the experiments on NOVA. Scaling this result to NIF by accounting for the surface area of the beam dumps, the difference in mass between a NOVA target and NIF target (assuming that shrapnel is proportional to target mass), and the distance from the target gives $0.25 \mathrm{~g}$ of glass dust generated per NIF shot. If this number is recalculated by averaging the data from all eight samples, then $1.7 \mathrm{~g}$. of glass dust is generated per NIF shot. This gives a range of $0.25-1.7 \mathrm{~g}$ as the estimated removal rate of the beam dump by shrapnel.

For x-ray ablation, assuming the nominal fluence at the NIF first wall is nearly that from these experiments, which is a reasonable assumption given that the expected fluence on the NIF first wall is $1-2 \mathrm{~J} / \mathrm{cm}^{2}$ and the target chamber beam dumps will likely consist of louvers at a $60^{\circ}$ 
tilt to the target, the estimated mass removed from the beam dumps would be $0.5 \mathrm{~g}$ per NIF shot, if we average the results over all the samples. Since the beam dump would be louvered, we could expect at least half of this material to be captured on the back side of adjacent louvers, leaving $0.25 \mathrm{~g}$ to travel into the chamber. Unlike the material vaporized by $\mathrm{x}$ rays, shrapnel-initiated debris will not be captured onto the back side of louvers. The damage sites from shrapnel imply that solid pieces of material are removed from the surface. These solid bits of material are unlikely to stick to the back side of a louver unless they have a high enough velocity to implant themselves. If they do have a high velocity, they would still have to remove some material from the louver surface when they impact it. From these experiments, we witness shrapnel damage significantly greater then x-ray ablation damage, but scaling the results to NIF shows that the damage threat from $x$ rays and shrapnel is of the same order.

Once material is removed by vaporization due to $\mathrm{x}$ rays or by shrapnel damage, concern lies in the threat this material poses on subsequent shots. Glass dust generated from shrapnel becomes an issue if it falls into line of sight of target chamber center, where it may have repeated exposure to target $\mathrm{x}$ rays. This threat may be reduced via a beam dump with a louvered design. It is likely that dust from shrapnel can fall out of view of target chamber center behind an adjacent louver of a beam dump. This would be true for the beam dumps on the lower half of the target chamber. For the beam dumps on the upper half of the chamber, the dust would simply fall down to the bottom of the chamber. Using the calculated figures, the beam dumps on the upper half would probably 'rain' approximately $0.13 \mathrm{~g}$ of dust onto the lower half of the target chamber. The use of a louvered first wall would mitigate this threat; a large percentage of the 'rain' could be caught behind first wall louvers, keeping it out of sight of target $\mathrm{x}$ rays.

Glass vaporized by $\mathrm{x}$ rays will condense on surfaces in the chamber, including the first wall. Results from recent experiments studying remobilization of target chamber contaminants suggest that metals deposited onto first wall materials effectively act as the first wall when exposed to $\mathrm{x}$ rays. If glass is deposited on the first wall along with other metal contaminants from target debris and near target surfaces, it will likely be removed on later shots and deposit elsewhere in the chamber. Providing a sink for this remobilized material, such as a louvered first wall, will provide surfaces for deposition of this material out of sight of target chamber center. Without a substantial sink, we could expect a large fraction of the vaporized beam dump material to be remobilized per shot, allowing a greater chance for contamination of the final optics debris shields.

It is important to note that these experiments characterize the mass loss to the beam dumps expected from $\mathrm{x}$ rays and shrapnel, and not the mass loss from the beam dumps' function as absorbers of unconverted laser light. It is expected that the mass loss from laser light ablation for a fused silica beam dump is $2.2 \mathrm{~g} / \mathrm{shot}^{5}{ }^{5}$ If we assume a louvered geometry beam dump captures half of this material, the removal rate is reduced to $1.1 \mathrm{~g} / \mathrm{shot}$, or about twice the combined threat from shrapnel and $x$ rays. 


\section{Conclusion}

Four $1 " \times 2$ " samples of fused silica and four $1 " \times 2$ " samples of borosilicate glass, candidate materials for the NIF target chamber beam dumps, were exposed to a total of 83 NOVA shots over a six-week period to obtain a measure of their long-term behavior in an environment similar to the expected NIF target chamber operating conditions. The samples were located approximately $42 \mathrm{~cm}$ from target chamber center on NOVA. The samples were weighed to measure their mass difference before and after exposure. Profilometry was performed to measure the mass loss due to $\mathrm{x}$-ray ablation. The difference between the two measurements provided information on the damage due to shrapnel. We found that for these NOVA experiments, the shrapnel damage was responsible for the majority of the weight loss of the samples. Scaling the results from NOVA conditions to the expected NIF parameters shows that the expected mass loss from shrapnel damage is of the same order as the expected loss from $\mathrm{x}$-ray ablation, i.e., approximately $0.25 \mathrm{~g} / \mathrm{shot}$ for each mechanism, for a total of $0.5 \mathrm{~g} / \mathrm{shot}$. The expected mass loss from laser light ablation is $1.1 \mathrm{~g}$. Therefore, for glass beam dump materials, the contamination rate expected from absorbing unconverted light is twice that from the combined total from shrapnel and $\mathrm{x}$ rays.

\section{References}

1. Anderson, A. and A. Burnham, "X-ray response of fused silica," Lawrence Livermore National Laboratory, Document TAT 96-009.2 (March 22, 1996).

2. Tokheim, R.E., D.R. Curran, and L. Seaman, "Damage and Hardening Assessments for the National Ignition Facility Target Chamber Design," SRI International Report, SRI Project PYD1953 (August 1997).

3. Gerassimenko, M., A. Anderson, and A. Burnham, "Studies of First Wall Deposit Removal by Exposure to X rays," Lawrence Livermore National Laboratory, Document QDV-97-0005 (June 9, 1997).

4. Scott, J.M., "Variability of material response to NOVA x-ray emissions," Lawrence Livermore National Laboratory, Document TAT 98-05.2 (Feb. 19, 1998).

5. Burnham, A., personal communication (Jan. 1998). 
Table 1. Summary of shot data for the six-week exposure period.

\begin{tabular}{|c|c|c|c|c|c|c|c|}
\hline Date & $\begin{array}{l}\text { NOVA } \\
\text { shot \# }\end{array}$ & \begin{tabular}{|c|} 
Energy \\
into \\
target $(\mathrm{kJ})$
\end{tabular} & shot name & Date & $\begin{array}{l}\text { NOVA } \\
\text { shot \# }\end{array}$ & \begin{tabular}{|c|} 
Energy \\
into \\
target $(\mathrm{kJ})$
\end{tabular} & shot name \\
\hline $10 / 14 / 97$ & 27101406 & 20.443 & CAB_WISC_08 & $11 / 20 / 97$ & 27112009 & 21.767 & LML_BMIX_69 \\
\hline $10 / 14 / 97$ & 27101410 & 1.242 & CAB_SARAN_01 & $11 / 20 / 97$ & 27112012 & unknown & BDC_3WCALIB_231 \\
\hline $10 / 14 / 97$ & 27101414 & 21.453 & CAB_WISC_07 & $11 / 20 / 97$ & 27112018 & 15.817 & CWB_CYLGAP_85 \\
\hline $10 / 14 / 97$ & 27101418 & 1.126 & CAB_WISCCL_02 & $11 / 21 / 97$ & 27112105 & 15.079 & CWB_CYLGAP_84 \\
\hline $10 / 15 / 97$ & 27101504 & 22.063 & CAB_WISC_01 & $11 / 21 / 97$ & 27112111 & 26.010 & CWB_CYLIMP_83 \\
\hline $10 / 15 / 97$ & 27101508 & 22.393 & CAB_WISC_03 & $11 / 21 / 97$ & 27112114 & 24.274 & CWB_CYLIMP_81 \\
\hline $10 / 15 / 97$ & 27101510 & 20.952 & CAB_WISC_05 & $11 / 21 / 97$ & 27112117 & 23.045 & CWB_CYLIMP_80 \\
\hline $10 / 15 / 97$ & 27101513 & 19.108 & CAB_WISC_09 & $12 / 3 / 97$ & 27120303 & 11.670 & BDC_3WCALIB_232 \\
\hline $10 / 15 / 97$ & 27101515 & 24.624 & CAB_WISC_11 & $12 / 3 / 97$ & 27120307 & 0.532 & DRH_AUDISK_09 \\
\hline $10 / 15 / 97$ & 27101517 & 24.807 & CAB_WISC_10 & $12 / 4 / 97$ & 27120404 & 8.792 & RKK_GASBAG4_36 \\
\hline $10 / 16 / 97$ & 27101602 & 2.043 & CAB_WISCAU_01 & $12 / 4 / 97$ & 27120406 & 17.025 & RKK_GASBAG4_37 \\
\hline $10 / 16 / 97$ & 27101609 & 17.882 & SGG_SNRT_47 & $12 / 4 / 97$ & 27120411 & 11.704 & JDM_GASBAG4_38 \\
\hline $10 / 16 / 97$ & 27101612 & 14.876 & SGG_SNRT_45 & $12 / 4 / 97$ & 27120415 & 24.130 & MDW_LGHOH192 \\
\hline $10 / 16 / 97$ & 27101617 & 11.424 & SGG_SNRT_50 & $12 / 4 / 97$ & 27120417 & 24.031 & MDW_LGHOH204 \\
\hline $10 / 20 / 97$ & 27102003 & 10.830 & BDC_3WCALIB_225 & $12 / 4 / 97$ & 27120420 & 18.528 & MDW_LGHOH203 \\
\hline $10 / 21 / 97$ & 27102107 & 2.746 & DRH_AUDISK_06 & $12 / 4 / 97$ & 27120423 & 19.074 & MDW_LGHOH194 \\
\hline $10 / 21 / 97$ & 27102111 & 15.951 & $\mathrm{JDM} \_\mathrm{G} \Lambda \mathrm{SB} \Lambda \mathrm{G} 4 \_28$ & $12 / 5 / 97$ & 0504 & 18.927 & SGG_CONVRT_18 \\
\hline $10 / 21 / 97$ & 27102116 & 21.010 & JDM_GASBAG4_29 & $12 / 5 / 97$ & 27120506 & 21.203 & SGG_CONVRT_19 \\
\hline $10 / 21 / 97$ & 27102123 & 15.838 & JDM_GASBAG4_30 & $12 / 5 / 97$ & 27120510 & 16.963 & SGG_SNRT_46 \\
\hline $10 / 22 / 97$ & 27102204 & 19.849 & JDM_GASBAG4_31 & $12 / 5 / 97$ & 27120513 & 17.945 & SGG_SNRING_08 \\
\hline $10 / 22 / 97$ & 27102207 & 19.736 & RKK_GASBAG4_32 & $12 / 10 / 97$ & 27121003 & 2.223 & SHG_4WPROBE \\
\hline $10 / 22 / 97$ & 27102210 & 11.385 & RKK_GASBAG4_33 & $12 / 11 / 97$ & 27121105 & 11.660 & BDC_3WCALIB_233 \\
\hline $10 / 22 / 97$ & 27102213 & 17.485 & RKK_GASBAG4_34 & $12 / 11 / 97$ & 27121109 & 21.001 & JPJ_BEABCHAR_01 \\
\hline $10 / 22 / 97$ & 27102216 & 26.837 & DSM_SCL1_01 & $12 / 11 / 97$ & 27121111 & 19.522 & JPJ_BEABCHAR_02 \\
\hline $10 / 22 / 97$ & 27102224 & 20.932 & DSM_LGHOH_186 & $12 / 12 / 97$ & 27121206 & 19.621 & JPJ_BEABCHAR_03 \\
\hline $10 / 23 / 97$ & 27102309 & 22.180 & DSM_LGHOH_193 & $12 / 13 / 97$ & 27121305 & 21.719 & DRF_BMIX_70 \\
\hline $10 / 23 / 97$ & 27102313 & 20.074 & DSM_LGHOH_194 & $12 / 13 / 97$ & 27121313 & 20.830 & DRF_BMIX_71 \\
\hline $10 / 23 / 97$ & 27102315 & 22.046 & DSM_LGHOH_196 & $12 / 13 / 97$ & 27121315 & 21.412 & DRF_BMIX_72 \\
\hline $10 / 23 / 97$ & 27102318 & 20.385 & DSM_LGHOH_200 & $12 / 13 / 97$ & 27121317 & 18.859 & LML_BMIX_73 \\
\hline $11 / 17 / 97$ & 27111703 & 1.125 & RLS_ALIGN_26_U & $12 / 16 / 97$ & 27121605 & 2.105 & RLS_KPPALIGN_32U \\
\hline $11 / 18 / 97$ & 27111805 & 10.374 & BDC_3WCALIB_230 & $12 / 16 / 97$ & 27121608 & 27.384 & NCD_REDSCL_11 \\
\hline $11 / 18 / 97$ & 27111808 & 0.031 & GTS_FEDISK_01_U & $12 / 16 / 97$ & 27121610 & 31.608 & NCD_REDSCL_12 \\
\hline $11 / 18 / 97$ & 27111811 & 0.028 & GTS_FEDISK_04 & $12 / 16 / 97$ & 27121612 & 29.56 & NCD_REDSCL_13 \\
\hline $11 / 19 / 97$ & 27111907 & 22.587 & GTS_PLANARRT_34 & $12 / 17 / 97$ & 27121704 & 28.882 & NCD_REDSCL_14 \\
\hline $11 / 19 / 97$ & 27111910 & 24.189 & GTS_PI_ANARRT_35 & $12 / 17 / 97$ & 27121709 & 11.209 & SGG_DRDR_04 \\
\hline
\end{tabular}




\begin{tabular}{|c|c|r|c|r|r|r|c|}
\hline $11 / 19 / 97$ & 27111916 & 24.023 & GTS_PLANARRT_36 & $12 / 17 / 97$ & 27121711 & 10.433 & SGG_DRDR_05 \\
\hline $11 / 19 / 97$ & 27111918 & 23.801 & GTS_PLANARRT_37 & $12 / 17 / 97$ & 27121715 & 2.332 & KLW_CUOPAC_03 \\
\hline $11 / 19 / 97$ & 27111922 & 23.079 & DRF_BMIX_65 & $12 / 17 / 97$ & 27121718 & 5.941 & KLW_AUOPAC_15 \\
\hline $11 / 19 / 97$ & 27111926 & 21.715 & DRF_BMIX_66 & $12 / 18 / 97$ & 27121805 & 10.033 & DHK_SIDIFF_10 \\
\hline $11 / 20 / 97$ & 27112004 & 20.633 & DRF_BMIX_67 & $12 / 18 / 97$ & 27121810 & 26.911 & REC_ZNBKLT_12 \\
\hline $11 / 20 / 97$ & 27112006 & 21.779 & LML_BMIX_68 & $12 / 18 / 97$ & 27121813 & 25.097 & REC_ZNBKLT_11_X \\
\hline & & & & $12 / 18 / 97$ & 27121815 & 23.339 & REC_ZNBKLT_13_X \\
\hline
\end{tabular}

Table 2. Summary of weight loss measurements.

\begin{tabular}{|c|c|c|c|c|c|c|c|c|}
\hline & $\begin{array}{c}\text { Initial } \\
\text { weight }(\mathrm{g})\end{array}$ & $\begin{array}{l}\text { After } 1 \mathrm{wk} \\
\text { exposure }\end{array}$ & $\begin{array}{l}\text { After } 2 \mathrm{wk} \\
\text { exposure }\end{array}$ & $\begin{array}{l}\text { After } 6 \text { wk } \\
\text { exposure }\end{array}$ & $\begin{array}{c}\text { total } \\
\text { loss }(\mathrm{g})\end{array}$ & $\begin{array}{c}\text { Profilometer } \\
\text { depth }(\mu \mathrm{m})\end{array}$ & $\begin{array}{l}\text { Loss from } \\
x \text { rays }(g)\end{array}$ & $\begin{array}{l}\text { Loss from } \\
\text { shrapnel (g) }\end{array}$ \\
\hline GE \#1 & 17.9731 & 17.9731 & 17.9725 & 17.9073 & 0.066 & 0.50 & 0.0014 & \\
\hline GE \#2 & 18.0237 & 18.0238 & 18.0231 & 18.0157 & 0.008 & 0.48 & 0.0013 & 0.007 \\
\hline Corning \#1 & 17.4606 & 17.4605 & 17.4580 & 17.3199 & 0.141 & 0.45 & 0.0013 & \\
\hline Corning \#2 & 17.5407 & 17.5400 & 17.5395 & 17.4845 & 0.056 & & & \\
\hline Pyrex \#1 & $19 . \overline{657}$ & $19 . \overline{3646}$ & 19.3413 & 18.6525 & 0.713 & 0.76 & 0.0024 & \\
\hline Pyrex \#2 & 17.2669 & 17.2661 & 17.2657 & 17.1074 & 0.160 & 0.50 & 0.0016 & \\
\hline Tempax \#1 & 19.8057 & 19.8059 & 19.8053 & 19.7819 & 0.024 & 0.60 & 0.0019 & 0.022 \\
\hline Tempax \#2 & 17.7355 & 17.7354 & 17.7274 & 17.6941 & 0.041 & 0.70 & 0.0023 & 0.039 \\
\hline
\end{tabular}




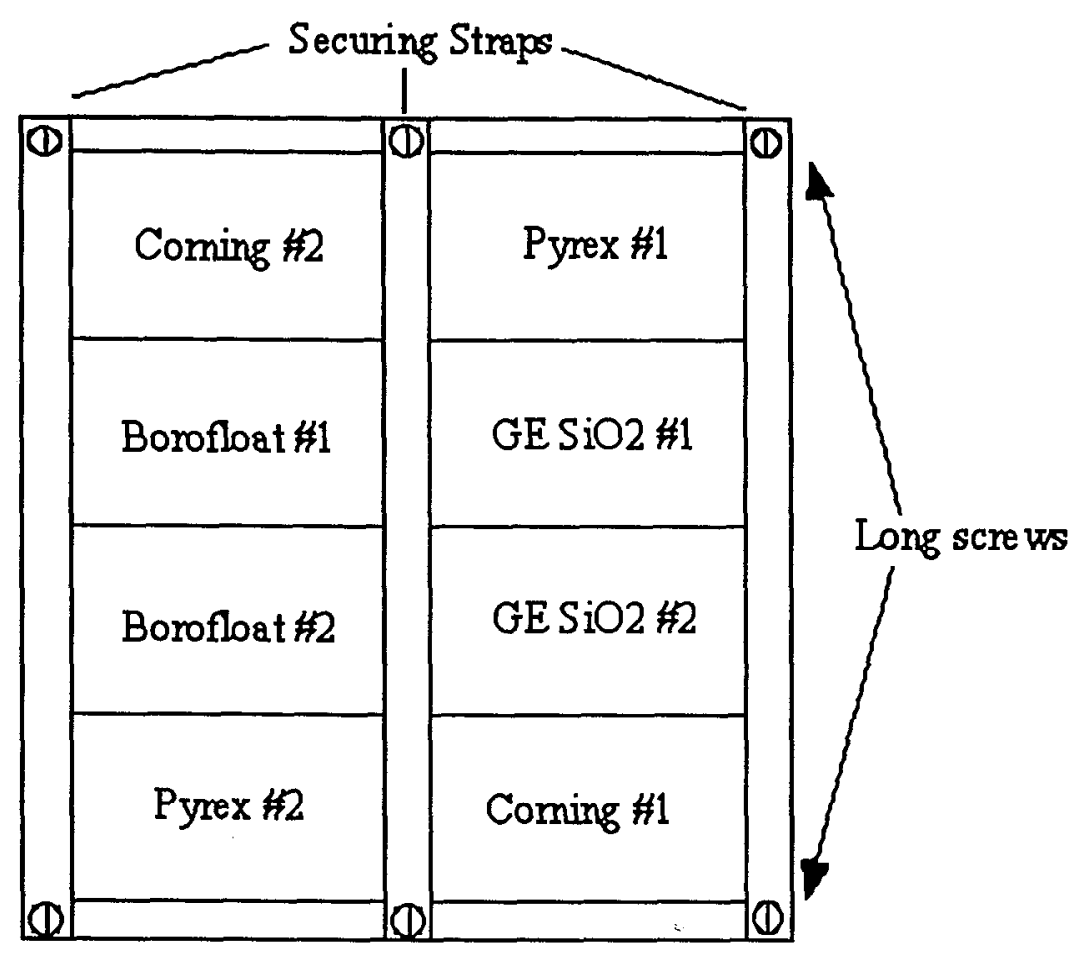

Figure 1. Apparatus used for long-term exposure of samples in NOVA.

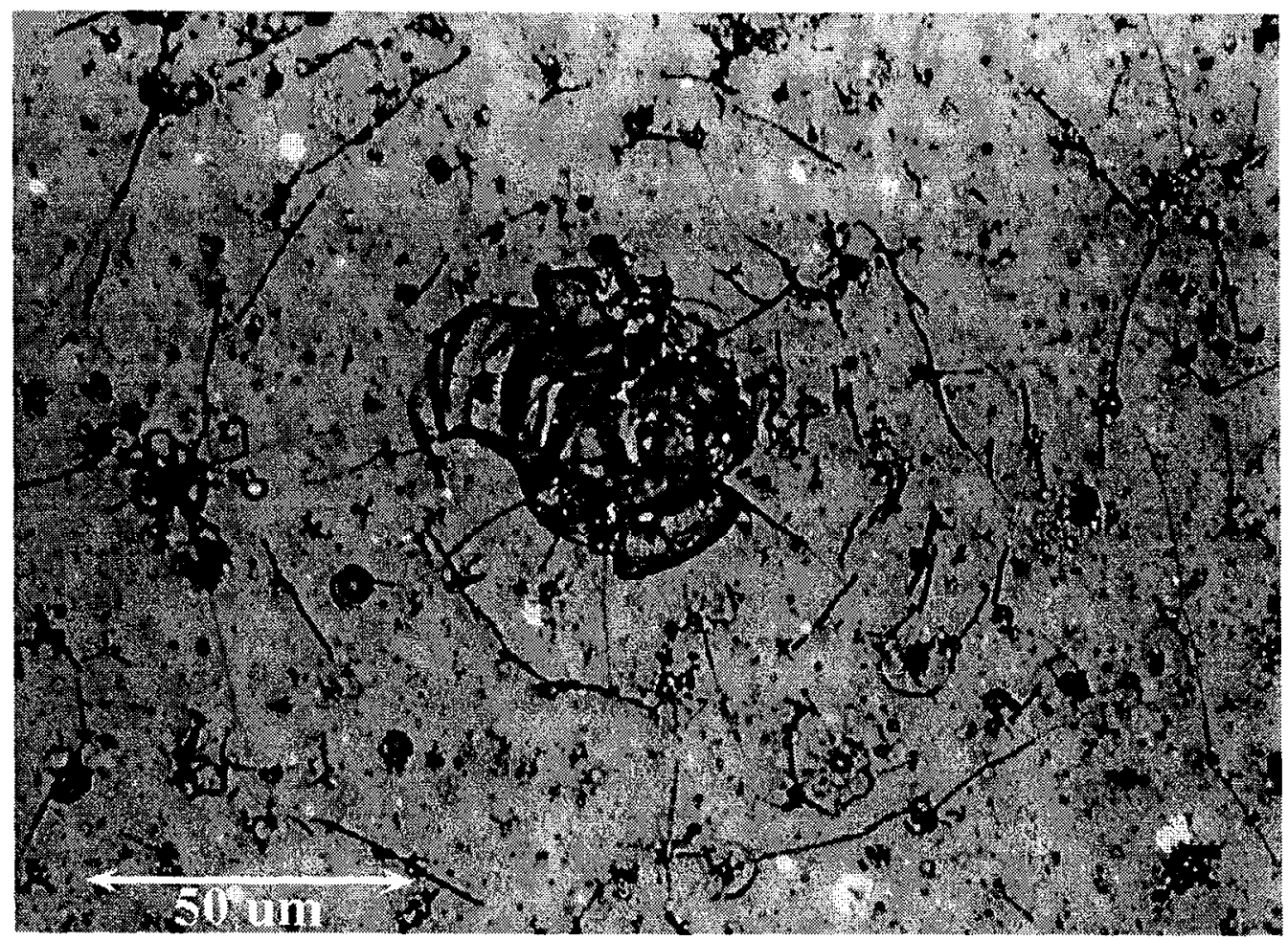

Figure 2. Damage site from micro-shrapnel impact on a sample. 


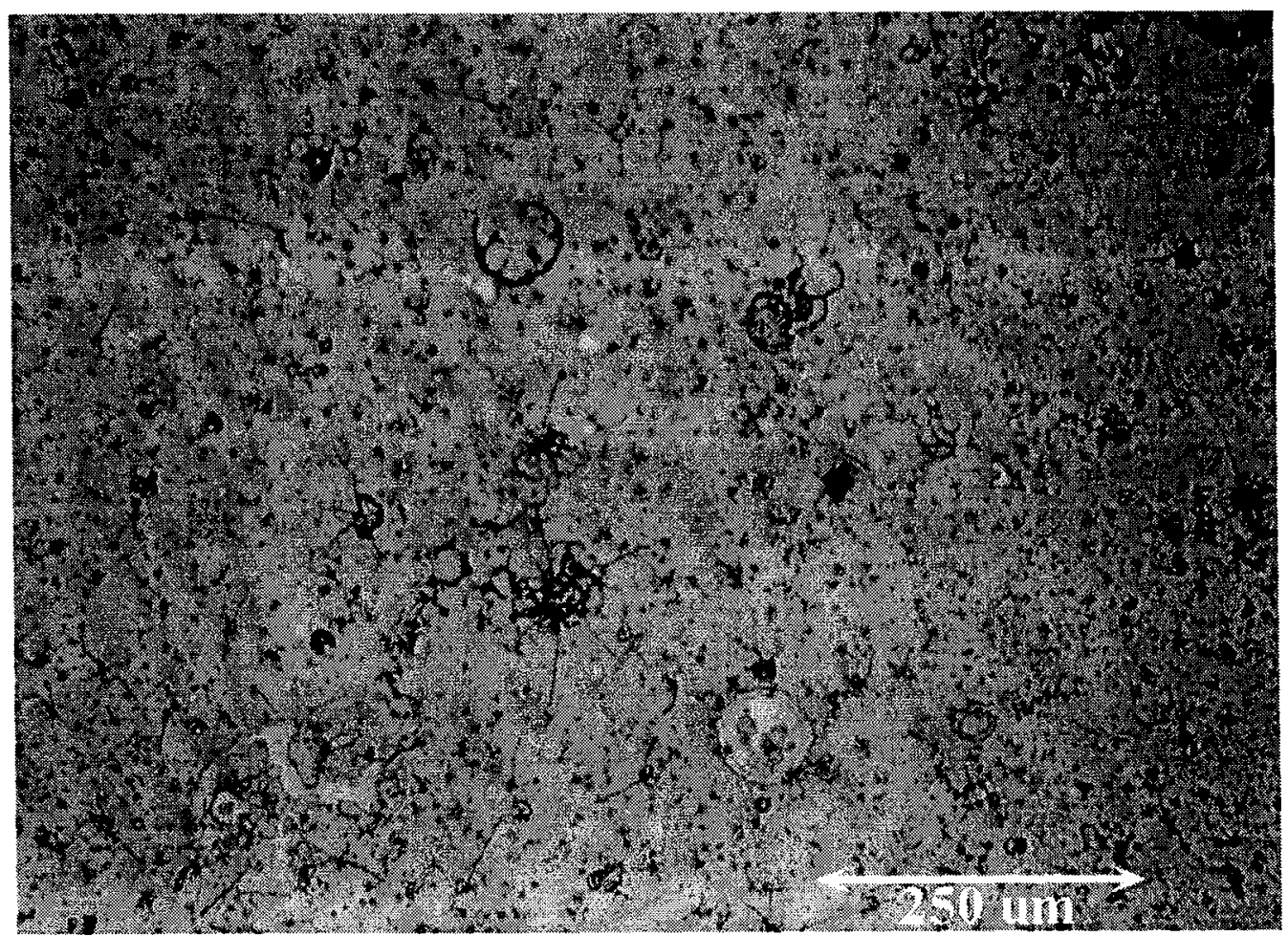

Figure 3. Typical view of the polished portion of a sample.

\section{3 exposures}

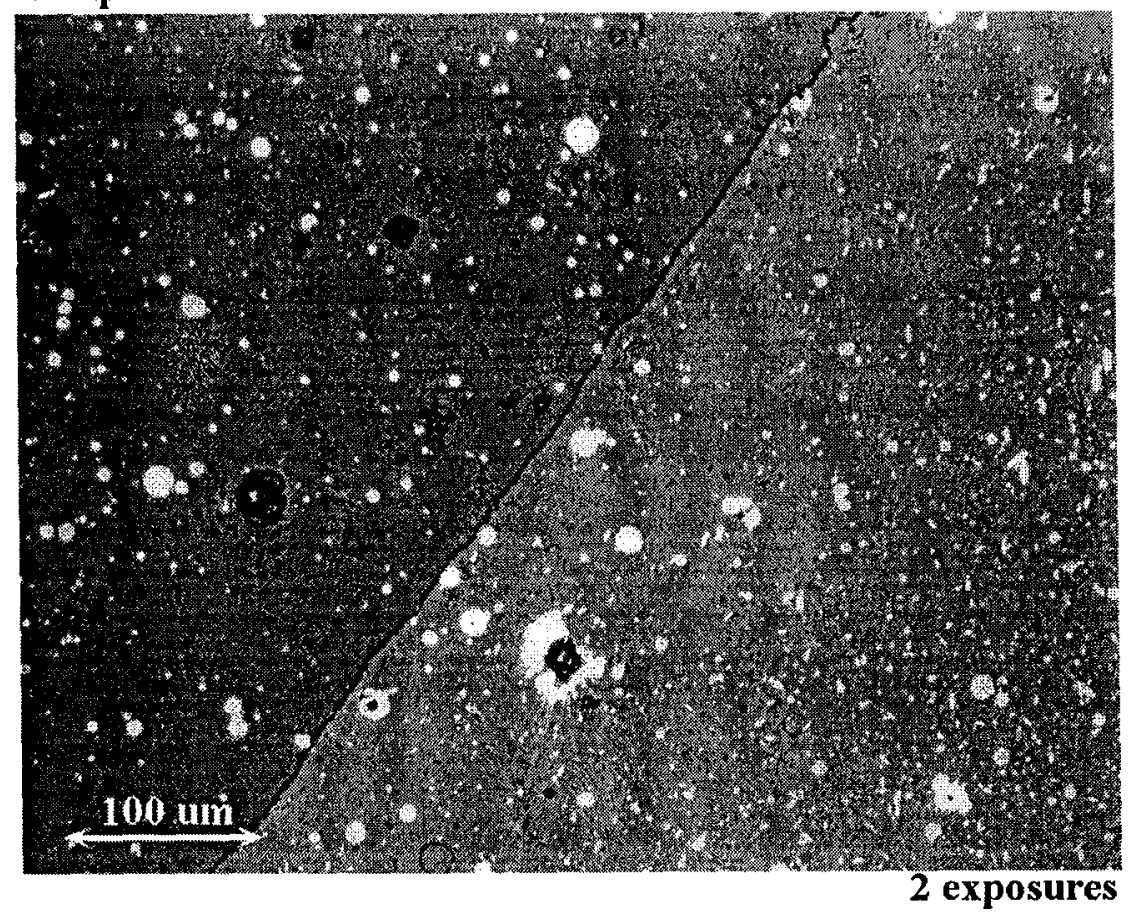

Figure 4. Two-exposure and three-exposure surfaces of fused silica. 


\subsection{Long-term exposure of $\mathrm{B}_{4} \mathrm{C}$ to the Nova target chamber environment}

The predictable response of the NIF first wall to target emissions is required to calculate the contamination threat to the final optics debris shields from vaporized first wall material. In short-term exposure tests, a few Nova shots, that measured the removal of material vs. $x$-ray fluence, $\mathrm{B}_{4} \mathrm{C}$ performed the best compared to all first wall candidate materials. In those shortterm exposures the amount of material removal from the $\mathrm{B}_{4} \mathrm{C}$ at low $\mathrm{x}$-ray fluences, $\sim 1 \mathrm{~J} / \mathrm{cm}^{2}$ was difficult to measure due to roughening of the samples upon exposure. In an attempt to better characterize the removal of the material at these low fluences and to view the performance of $\mathrm{B}_{4} \mathrm{C}$ in a NIF-like target chamber environment, 8 samples of $\mathrm{B}_{4} \mathrm{C}$ were exposed in a set of two longterm experiments in the Nova chamber.

\section{Experiment}

Eight $\mathrm{B}_{4} \mathrm{C}$ samples, 1" $\times 2$ ", were mounted in a fixture, sketched in Fig. 1, approximately $4.5^{\prime \prime} \times 4.5^{\prime \prime}$ in size. In fig.1, the position of each sample is labeled as they remained the same through both exposure periods. Two stainless straps attach to fixture and secure the samples in position. Once the samples are placed into the fixture, it is mounted to copper activation tube no. 1 inside the Nova target chamber. This position is chosen because of its proximity to the target and its location $25^{\circ}$ off the hohlraum axis. Experiments measuring material removal by $\mathrm{x}$ rays were located on SIM5, also $25^{\circ}$ off the hohlraum axis. The experiment mounts to the face of the copper activation tube, leaving the samples' front surfaces approximately $42 \mathrm{~cm}$ from target chamber center. At this distance, the samples receive a nominal x-ray fluence of $0.9 \mathrm{~J} / \mathrm{cm}^{2}$ from scale-1 hohlraums driven by a 1-ns pulse. Determination of this fluence is discussed in a previous memo.'

The samples were exposed in two different periods, six weeks and eleven weeks, respectively. Before the first exposure the samples were beadblasted, weighed, characterized by $\mathrm{x}$-ray induced $\mathrm{x}$-ray fluorescence (XXRF) in order to measure the amount of contaminants that were added to the samples during the exposure period. This process was repeated for the second exposure period. After each exposure period the samples were weighed and analyzed by XXRF again. Then, in order to measure the ability of beadblasting to remove surface contaminants, the samples were beadblasted, weighed and analyzed by XXRF. The XXRF analysis measures the quantities of $\mathrm{Cu}, \mathrm{Au}$, and $\mathrm{Fe}$ on the samples. These materials are common target chamber metals. Copper is used for shine shields, gold for hohlraums, and the iron comes from diagnostic snouts that near the vicinity of the target when it is shot.

\section{Results}

The first exposure period ranged from Aug. 15, 1997, to Oct. 2, 1997 for a total of 85 shots. The second exposure period ranged from Jan. 12, 1998, to April 3, 1998 for a total of 176 shots. The eight samples consisted of $\mathrm{B}_{4} \mathrm{C}$ samples from various manufacturing process, 
including hot press, plasma spray, and cermet. The mass changes for both exposure periods are shown in table 1. In both exposures, nearly all the samples gained some mass as indicated by the positive weight changes in the first column of each section. The positive weight change is due to the accumulation of contaminants on the surface. Before exposure, the sample surfaces are black but after exposure the surface of each sample has a metallic appearance from the deposited contaminants.

The XXRF measurements for both exposure periods indicate that each sample gained 1-2 mg of contaminant mass. For the first exposure period data, if the measured mass of contaminants is subtracted from the after exposure the mass change is generally within in a fraction of a milligram either as a gain or loss in weight. Though the table lists the weight changes as tenths of a milligram, the detection limit of these measurements has been set at $1 \mathrm{mg}$, because of the scale used to measure the samples. These indefinitive results from the first exposure prompted a second exposure of the samples for a significantly greater period of time. With a longer exposure period, the removal of $\mathrm{B}_{4} \mathrm{C}$ should be greater and easier to characterize. Furthermore, any initial exposure effects due to surface layers formed during manufacturing would be reduced.

The results from the second exposure period show a larger amount of contamination on each sample as would be expected. The amount of contaminant added to each sample was between 1 and $2 \mathrm{mg}$. The measurement of the net mass change is significantly more consistent than in the first exposure period. Most of the samples experienced no mass change and the remaining two only had a positive mass change of $0.1 \mathrm{mg}$.

\section{Discussion}

For both exposure periods, there was a mass change in each sample that gave acceptable performance. Though the results from the first exposure period were not very conclusive, the second exposure period gave more definitive results. Over an 11 week period, the weight variation in the samples was a couple of milligrams due to the added weight of the metal contaminants. By measuring the amount of contaminants with XXRF and subtracting this mass from the after exposure mass of the samples, the net mass change is below the $1 \mathrm{mg}$ detectable limit. Assuming that each samples loses $1 \mathrm{mg}$ during the second exposure period and that shot energies over $10 \mathrm{~kJ}$ produce significant ablation this is equivalent to $3 \mathrm{~nm} / \mathrm{shot}$ removed. This figure sets an upper bound for removal of $\mathrm{B}_{4} \mathrm{C}$ for this experiment. The current limit ${ }^{2}$ set for material removal from the target chamber is $\sim 1 \mu \mathrm{g} / \mathrm{cm}^{2} /$ shot. For $\mathrm{B}_{4} \mathrm{C}$, this corresponds to 4 $\mathrm{nm} / \mathrm{shot}$, well above the removal rates in this experiment. It should be emphasized that the fluence level in this experiment was $0.9 \mathrm{~J} / \mathrm{cm}^{2}$ and in the initial operating phase of the NIF, the expected $\mathrm{x}$-ray fluence level at the wall is $\sim 1 \mathrm{~J} / \mathrm{cm}^{2}$. The removal of contaminants by $\mathrm{x}$ rays is not measured in this experiment but their importance as a threat to the final optics debris shields was identified by Gerrassimenko and Burnham ${ }^{3}$. 
When ignition shots begin the $\mathrm{x}$-ray fluence will be reach up to $2 \mathrm{~J} / \mathrm{cm}^{2}$ at the wall, but the $\mathrm{x}$-ray spectrum will be different from these Nova experiments. For ignition shots, the blackbody spectrum from the target is expected to be $\sim 350 \mathrm{eV}$, while for Nova the typical spectrum is $\sim 200$ $\mathrm{eV}$. Since different wavelength photons have different absorption coefficients in materials this will affect the response of $\mathrm{B}_{4} \mathrm{C}$ in some fashion. Additionally, experiments measuring the remobilization of contaminants from first wall materials show that the threat from reablated contaminants becomes significant as the level of contaminants build up on the sample. ${ }^{3}$ Therefore, it is difficult to predict the performance of a contaminated $\mathrm{B}_{4} \mathrm{C}$ first wall to the first yield shots from these results.

A long-term exposure also measures a material's resistance to the shrapnel threat posed by $\mathrm{Cu}$ shine shields and other near target materials. In the long-term exposure of fused silica and borosilicate glasses, shrapnel is a significant threat due to the brittle nature of glass ${ }^{4}$. For $\mathrm{B}_{4} \mathrm{C}$, in both exposures there was no damage from shrapnel that could be witnessed from looking at the surface of the sample. On a couple of samples, there were large pieces of shrapnel that stuck to the surface when it collided with the sample. This was also seen in another experiment that exposed a sample of $\mathrm{B}_{4} \mathrm{C}$ for a six week period ${ }^{3}$. Removal of these shrapnel pieces did not reveal detectable damage to the surface by the naked eye. For fused silica, interaction with a large piece of shrapnel would likely result in a surface 'ding' similar to that of a BB hitting a car windshield. The mass change results support the contention that $\mathrm{B}_{4} \mathrm{C}$ is resistant to shrapnel damage. If damage to the surface by shrapnel resulted in the removal of some $\mathrm{B}_{4} \mathrm{C}$ this would have had an impact on the net change in mass. The results from both exposure periods would indicate that shrapnel damage had little or no impact on the samples.

As mentioned earlier, after each exposure the samples were beadblasted to measure the effectiveness of this cleaning process. Previously, in situ $\mathrm{CO}_{2}$ cleaning was proposed as a means to clean first wall $\mathrm{B}_{4} \mathrm{C}$ panels, but the limited effectiveness and high cost ruled out this method ${ }^{2}$. Beadblasting was suggested as an alternative because it was simpler and cheaper. Unfortunately, beadblasting requires the first wall panels be removed from the chamber for cleaning. This lengthens the amount of time it takes to clean the first wall to at least two months.

When the samples were beadblasted, the criteria for determining when the samples were clean was by visual inspection. Essentially, once the metallic coating was no longer visible the sample were considered clean. Table 1 shows the mass loss from beadblasting and table 2 shows the cleaning results for both exposure periods. All the samples performed well in terms of weight loss. The greatest removal rates, $\sim .01 \mathrm{~mm}$, were from the plasma sprayed samples. Yet, this rate is not significant enough to affect the lifetime of the $\mathrm{B}_{4} \mathrm{C}$ layer. Four cleanings per year for five years would remove only $0.2 \mathrm{~mm}$, and the minimum thickness considered is $1.5 \mathrm{~mm}$ for hotpressed $\mathrm{B}_{4} \mathrm{C}$. In terms of resilience to the beadblasting as measured by mass loss, the best performer was the hot pressed material performed followed by the cermet and then by the plasma sprayed samples. From table 2, bcadblasting removed at lcast $90 \%$ of the contaminants from the surface in both exposure periods. This result combined with the mass loss figures from 
beadblasting show that beadblasting is a viable method of cleaning a first wall composed of $\mathrm{B}_{4} \mathrm{C}$ panels with the constraint that the panels must be removed from the chamber.

\section{Conclusions}

Eight samples of $\mathrm{B}_{4} \mathrm{C}$ were exposed to the Nova target chamber in a series of two longterm exposure experiments. Thesc exposure were at conditions similar to those expected for the NIF in the years before ignition shots. The first experiment was for six weeks and the second for eleven weeks. The results from the first exposure were not very conclusive in measuring the removal of material due to $\mathrm{x}$ rays but it did show that $\mathrm{B}_{4} \mathrm{C}$ has resistance to shrapnel damage. The second exposure showed that the average removal of $\mathrm{B}_{4} \mathrm{C}$ for this experiment was within the established rate of removal of material from the first wall. As in the first exposure, $\mathrm{B}_{4} \mathrm{C}$ showed no detectable damage from shrapnel during the second exposure. Beadblasting of the samples after each exposure showed that this is an effective means to remove metal contaminants from the surface without adversely affecting the lifetime of $\mathrm{B}_{4} \mathrm{C}$ components.

\section{References}

1. Gerassimenko, M., Anderson A., Burnham A., "Studies of First Wall Deposit Removal by Exposure to X Rays", Document QDV-97-0005, June 9, 1997.

2. Burnham, A. et al, "Constraints on Target Chamber First Wall and Target Designs That Will Enable NIF Debris Shields to Survive", SSLA-ICF 1998 Conference, Monterey, CA, June 7-11, 1998.

3. Gerassimenko, M., Burnham, A., "Studies of First Wall Contamination and Mobilization of Contaminants", Document QDV-97-0020, Dec. 1, 1997.

4. Scott, J. M., "Long-term exposure of fused silica and borosilicate glass on Nova", NIF0006362 , Feb. 19, 1998. 
Table 1--Mass change of $\mathrm{B}_{4} \mathrm{C}$ samples during six week and eleven week exposures.

\begin{tabular}{|c|c|c|c|c|c|c|c|c|}
\hline \multirow[b]{2}{*}{ Sample } & \multicolumn{4}{|c|}{6 week exposure } & \multicolumn{4}{|c|}{11 week exposure } \\
\hline & $\begin{array}{c}\text { mass } \\
\text { change } \\
(\mathrm{mg}) \\
\end{array}$ & $\begin{array}{c}\text { mass of } \\
\mathrm{Cu} \& \\
\mathrm{Au}\end{array}$ & $\begin{array}{c}\text { net mass } \\
\text { change } \\
(\mathrm{mg})\end{array}$ & $\begin{array}{c}\text { mass } \\
\text { change bead } \\
\text { blasting }\end{array}$ & $\begin{array}{l}\text { mass } \\
\text { change } \\
(\mathrm{mg})\end{array}$ & $\begin{array}{c}\text { mass of } \\
\mathrm{Cu} \& \\
\mathrm{Au} \\
\end{array}$ & $\begin{array}{c}\text { net mass } \\
\text { change } \\
(\mathrm{mg})\end{array}$ & $\begin{array}{c}\text { mass } \\
\text { change bead } \\
\text { blasting }\end{array}$ \\
\hline $\mathrm{APS} 027^{\mathrm{a}}$ & 0.8 & 0.8 & 0.0 & 45.0 & 2.1 & 2.1 & 0.0 & 56.5 \\
\hline APS795 ${ }^{b}$ & 0.2 & 0.8 & -0.6 & 49.6 & 1.6 & 1.6 & 0.0 & 36.5 \\
\hline PR012 & 1.2 & 0.8 & 0.4 & 17.6 & 1.4 & 1.4 & 0.0 & $\mathrm{n} / \mathrm{m}$ \\
\hline $\mathrm{CE} 022^{\mathrm{d}}$ & 1.2 & 0.8 & 0.4 & 3.1 & 1.9 & 1.9 & 0.0 & 6.2 \\
\hline $\mathrm{CEDM}^{\mathrm{e}}$ & 0.8 & 0.7 & 0.1 & 2.6 & 1.9 & 1.9 & 0.0 & 3.0 \\
\hline NOR999 & -1.1 & 1.4 & -2.5 & 6.9 & 1.4 & 1.4 & 0.1 & 6.4 \\
\hline CER666 ${ }^{\mathrm{g}}$ & 1.5 & 0.6 & 0.9 & 6.4 & 1.6 & 1.6 & 0.1 & 7.9 \\
\hline CER777 ${ }^{\mathrm{h}}$ & 0.9 & 0.9 & 0.0 & 11.9 & 1.1 & 1.1 & 0.0 & 27.3 \\
\hline
\end{tabular}

a. APS plasma-sprayed $\mathrm{B}_{4} \mathrm{C}$

b. Plastic-filled APS plasma-sprayed $\mathrm{B}_{4} \mathrm{C}$

c. ProTec plasma-sprayed $\mathrm{B}_{4} \mathrm{C}$

d. Ceradyne 1/4" hot-pressed $\mathrm{B}_{4} \mathrm{C}$

e. Modified Ceradyne hot-pressed $\mathrm{B}_{4} \mathrm{C}$

f. Norton $1 / 8$ " hot-pressed $\mathrm{B}_{4} \mathrm{C}$

g. Cercom 1/16" hot-pressed $\mathrm{B}_{4} \mathrm{C}$

h. Greenleaf heat-treated $\mathrm{B}_{4} \mathrm{C}$-Al cermet

Table 2--Beadblasting effectiveness at removing metal contaminants.

\begin{tabular}{l|rrr|rrr}
\hline \multirow{2}{*}{ Sample } & \multicolumn{3}{|c|}{6 week exposure } & \multicolumn{3}{c}{11 week exposure } \\
\cline { 2 - 7 } & $\begin{array}{c}\text { contaminant } \\
\text { before } \\
\text { beadblast } \\
\text { (mg) }\end{array}$ & $\begin{array}{c}\text { contaminant } \\
\text { after } \\
\text { beadblast } \\
(\mathrm{mg})\end{array}$ & $\begin{array}{c}\% \\
\text { removed }\end{array}$ & $\begin{array}{c}\text { contaminant } \\
\text { before } \\
\text { beadblast } \\
\text { (mg) }\end{array}$ & $\begin{array}{c}\text { contaminant } \\
\text { after } \\
\text { beadblast } \\
(\mathrm{mg})\end{array}$ & $\begin{array}{c}\% \\
\text { removed }\end{array}$ \\
\hline APS027 & 0.96 & 0.01 & $95 \%$ & 2.38 & 0.01 & $100 \%$ \\
APS795 & 0.93 & 0.00 & $100 \%$ & 1.81 & 0.00 & $100 \%$ \\
PR012 & 0.95 & 0.08 & $91 \%$ & 1.62 & $\mathrm{n} / \mathrm{m}$ & $\mathrm{n} / \mathrm{m}$ \\
CE022 & 0.92 & 0.06 & $93 \%$ & 2.13 & 0.06 & $97 \%$ \\
CEDM8 & 0.76 & 0.01 & $99 \%$ & 2.13 & 0.08 & $96 \%$ \\
NOR999 & 1.59 & 0.03 & $98 \%$ & 1.58 & 0.10 & $94 \%$ \\
CER666 & 0.74 & 0.08 & $89 \%$ & 1.84 & 0.08 & $96 \%$ \\
CER777 & 1.01 & 0.05 & $95 \%$ & 1.31 & 0.06 & $96 \%$
\end{tabular}




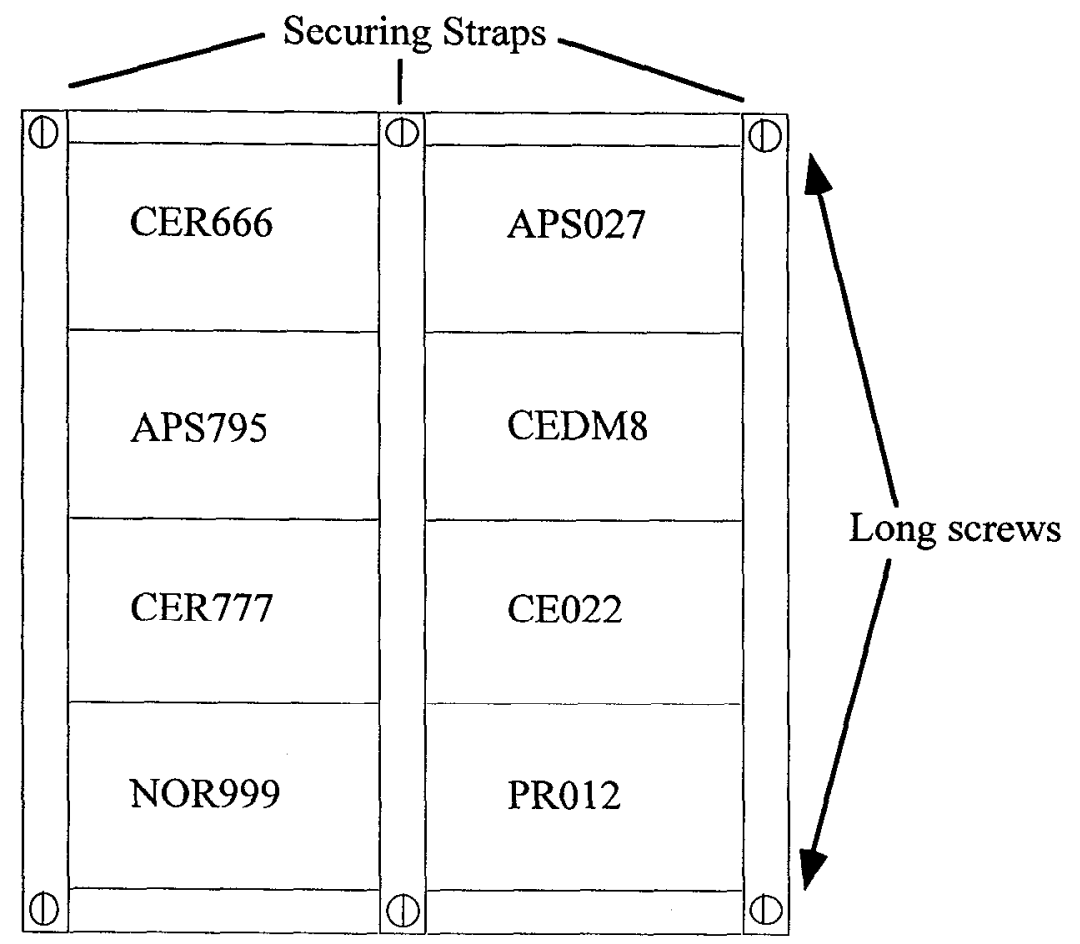

Figure 1--Schematic of sample layout on long-term exposure apparatus 


\subsection{X-ray response of stainless steel}

Four samples of stainless steel 409, a candidate first-wall material for NIF, were exposed to NOVA target $\mathrm{x}$-ray emissions. The exposures took place over a series of four shots, with the first occurring on December 5, 1997, and the last three occurring on December 13, 1997. After the exposure, optical microscopy and profilometry were performed to determine the amount and nature of the material removal.

\section{Experiment}

The experimental setup for the series of exposures is the same as used in previous experiments assessing material response to $\mathrm{x}$-ray exposure. A set of four samples are placed various distances from target chamber center to achieve varying fluences from to 1 to $3.5 \mathrm{~J} / \mathrm{cm}^{2}$. The stainless steel samples were obtained by Leonard Summers of C\&MS from Specialty Steel and Forge (Fairfield, NJ). The samples were cut into $1-\mathrm{cm}$ squares and polished by Robert Kershaw of C\&MS to a $0.1-\mu \mathrm{m}$ finish, to facilitate profilometry measurements after exposure. Additionally, four samples of stainless steel 316 and one sample of stainless steel 304 were tested. The results from these samples were not significantly different from SS409, and, consequently, the discussion of this memo focuses on the results from SS409 samples.

For this few-exposure experiment, areas with one, two, and four exposures were obtained by using tantalum masks and covering portions of the samples after the first and second shots. The NOVA targets for this particular set of samples were scale-1 hohlraums as in previous experiments measuring material removal. For each shot, eight beams were pointed into the hohlraums for a total energy of approximately $20 \mathrm{~kJ}$. Table 1 summarizes the shot conditions for the stainless steel exposures.

\section{Observations}

After the exposure, optical microscopy, atomic force microscopy (AFM), and profilometry were used to characterize the removal mechanism characteristic of stainless steel x-ray ablation. Examination under the microscope showed no cracking on the surface of the samples, but the surfaces appeared wavy. Figure 1 is a view of the surface of the highest fluence sample. What is evident is that the waviness of the sample increases with more exposures to $\mathrm{x}$ rays. Figures 2 and 3 are views of the four exposure surfaces of the lowest and highest fluence samples. The first distinguishing feature is that the surface of the highest fluence sample is considerably rougher. It seems that the roughness of the sample increases both with the fluence and with the number of exposures. On each of these samples, numerous craters can be seen. These craters are the result of shrapnel impacting the surface when the surface has not completely resolidified. Many of the impact craters have a raised rim and a raised central spot, indicating some splash when the shrapnel encounters the sample. Like stainless steel, previous experiments with aluminum show these craters as well. Additionally, scanning electron 
microscope analysis of fused silica shows evidence of these impact craters ${ }^{1}$ when the sample is viewed at $2500 \mathrm{X}$ magnification. The distinctly different feature from the stainless steel as compared to fused silica is the absence of 'splats' of metal target debris on the surface of the samples. Figure 4 is a photograph of the one-exposure surface of the highest fluence sample, showing evidence of splash from the edge of the exposed surface of the sample.

Profilometer measurements were made with a Tencor alpha-step 200. Due to the aforementioned waviness and splash from the edge of the samples, it was difficult to measure an ablation step. A typical profilometer scan is pictured in Fig. 5. Though the profilometer data did not provide information regarding the amount of material removed, it did provide information regarding how samples roughened with repeated exposure and different fluences. The highest fluence sample achieved $130 \mathrm{~nm}$ of roughness after one exposure. This changed to $220 \mathrm{~nm}$ after the second exposure and $395 \mathrm{~nm}$ after the fourth exposure. The second highest fluence sample obtained $110 \mathrm{~nm}, 190 \mathrm{~nm}$, and $350 \mathrm{~nm}$ of roughness after the first, second, and fourth exposures, respectively. The third and fourth samples reached $195 \mathrm{~nm}$ and $95 \mathrm{~nm}$ of roughness after four exposures.

Since it was difficult to measure an ablation step by profilometry, AFM was used as an alternative to try to measure the difference in height between the unexposed and exposed regions of the sample. Typical AFM plots are shown in Figs. 6 and 7. As can be seen in Fig. 6, there is some splash from the exposed area to the unexposed area. In Fig. 6, there appear to be deposits on the surface of the sample from target debris. These are not seen by optical microscopy. The splashing over the edge combined with the roughness of the sample interferes with the profilometer measurement by the Tencor machine. Figure 7 demonstrates the roughness of the lowest fluence sample as well as more examples of the cratering due to shrapnel impact. Unfortunately, the AFM analysis did not aid in determining the amount of material removal.

Interferometry was chosen as the next analysis tool to determination the removal of stainless steel. A Wyko 2000 was used to analyze the samples. The Wyko provides a 3-D surface profile of the surface just as the AFM plots, but the Wyko software package provides a histogram plot of the surface data. Shown in Fig. 8 is a histogram plot from the four-exposure surface of the lowest fluence sample. This plot displays the number of points at a given height vs the height of the surface. For a perfectly flat sample, we would expect this plot to show a delta function at 0 height. For a sinusoidal or other surface with a variation occurring periodically, we would expect to see a rectangle centered about 0 height. If our sample ablated in easy-to-measure steps, we would expect a spike at the removal depth. Since our sample has a wavy surface with some material removal, what we see is a Gaussian-looking distribution with the peak occurring at the average depth of removal. In this manner, the amount of material removed was determined for each of the samples. The interferometry analysis gave the $\mu \mathrm{m}$ removed vs X-ray fluence data shown in Fig. 9. 


\section{Discussion and Implications for NIF}

The primary removal mechanism for stainless steel seems to be liquid ejection, just as it is for aluminum; the rough wavy surface is indicative of this. Essentially the heating of the material combined with the thermal expansion coefficient can drive forces necessary to eject liquid from the melted surface. The waviness would be a result of some of the liquid drops being retained at the surface, because they were unable to overcome the surface tension forces holding the liquid layer together. The liquid splash viewed at the edge of the samples would also support the assertion that liquid ejection is the mechanism for removal of the steel.

Shown in Fig. 10 is the result of a calculation with Andy Anderson's ABLATOR model. Plotted on the figure are the melt depth, the vaporization depth, and the experimental data. Comparisons with the calculation suggest that some of the liquid layer is removed along with the vaporized material.

Other removal mechanisms that have been identified in studying other materials are thermal cracking/spall and vaporization. There was no evidence of cracking from any of the optical microscopy performed on the stainless steel samples. Though vaporization plays some role in some of the removal, comparison with calculation and the waviness of the exposed surface suggest liquid motion and splash.

Stainless steel is a candidate material for both the first wall and beam dumps on NIF. The functional form of the first wall and beam dumps will probably be a louver design due to the louvers' ability to passively capture the escaping plume of material from one louver onto the back side of the adjacent louver. Given that both the first wall and beam dumps are composed of stainless steel, and taking the $1-\mathrm{J} / \mathrm{cm}^{2}$ removal value as the average removal on a per shot basis for $\mathrm{NIF}$, a fairly good estimate for varying conditions expected on $\mathrm{NIF}^{2}$ we would expect $1.2 \mu \mathrm{g} / \mathrm{cm}^{2}$ of stainless steel contamination homogeneously spread over the target chamber first-wall area. This figure includes a $90 \%$ capture ratio from the louvered geometry. Current estimates allow for $1 \mu \mathrm{g} / \mathrm{cm}^{2}$ of contamination per shot, including that directly from targets, assuming a maximum acceptable total contamination rate on the debris shields of $1 \mathrm{~nm}$ per shot. Given the uncertainty in the figures, such as the waviness of the samples and the varying x-ray fluence with the polar position in the chamber, and the transport efficiency to the recessed debris shields, this calculation shows that a clean SS409 first wall is near, but slightly above, the allowable contamination limit. What this calculation does not include and cannot account for is remobilization of deposited material from previous shots. That issue was investigated in a recent set of experiments ${ }^{3}$ and is currently being studied in a second set of experiments of a similar nature. Materials deposited on the first wall material from target debris and ablated first wall material will affect the x-ray response of the first wall. Once the deposited film of material reaches a thickness on the order of a mean free path length of the target $x$ rays, we can expect the first wall to behave more like the deposited material. 


\section{Conclusions}

Four coupons of stainless steel 409, a candidate NIF first-wall material, were exposed to $x$-ray emissions from a scale-1 NOVA hohlraum driven by a 1-ns pulse. The samples received a total of four exposures and were placed at various distances from the target corresponding to fluences from 1 to $3.5 \mathrm{~J} / \mathrm{cm}^{2}$. The exposed samples displayed waviness characteristic of liquid melt layer ejection. Profilometry showed that the samples roughened, both with number exposures and the fluence received. Interferometry determined the thickness of the material removed from the surface of the samples.

\section{References}

1. Anderson, A and A. Burnham, "X-ray response of fused silica," Lawrence Livermore National Laboratory, Document TAT 96-009.2 (March 22, 1996).

2. Anderson, A., X-Ray Ablation Measurements and Modeling for ICF Applcations, Lawrence Livermore National Laboratory, UCRL-LR-125352 (September 1996).

3. Gerassimenko, M. and A. Burnham, "Studies of First Wall Contamination and Mobilization of Contaminants," ," Lawrence Livermore National Laboratory, Document QDV-97-0020

(December 1, 1997). 
Table 1. Summary of shot data for stainless steel 409 exposures.

Date NOVA shot \# Energy into pulse length shot name target (kJ)

$\begin{array}{lllll}12-05-97 & 27120513 & 17.945 & 1 \mathrm{~ns} \mathrm{sq} & \text { SGG_SNRING_08 } \\ 12-13-97 & 27121305 & 20.719 & 1 \mathrm{~ns} \mathrm{sq} & \text { DRF_BMIX_70 } \\ 12-13-97 & 27121313 & 20.830 & 1 \mathrm{~ns} \mathrm{sq} & \text { DRF_BMIX_71 } \\ 12-13-97 & 27121315 & 21.412 & 1 \mathrm{~ns} \mathrm{sq} & \text { DRF_BMIX_72 }\end{array}$

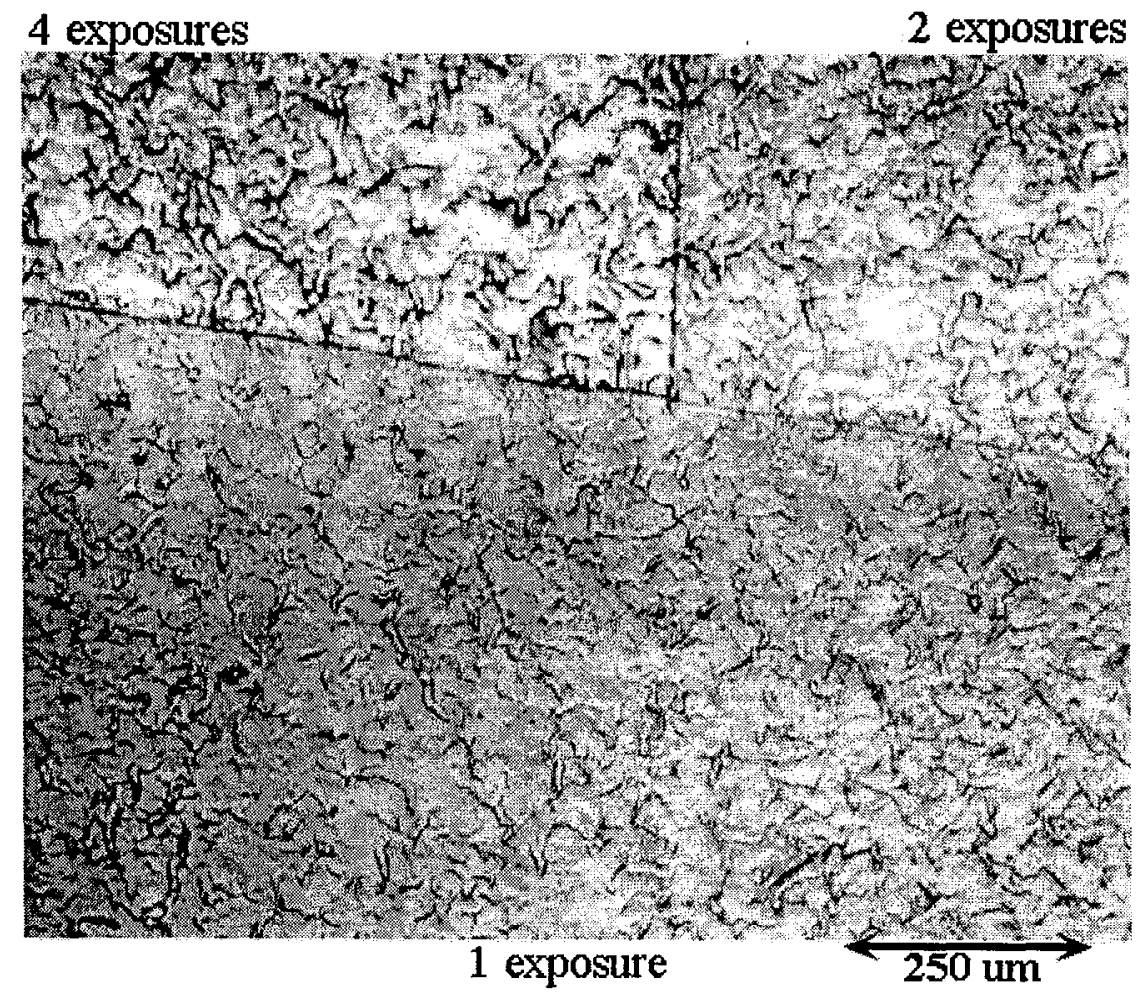

Figure 1. Photograph of highest fluence sample showing 1-exposure, 2-exposure, and 4-exposure regions. 


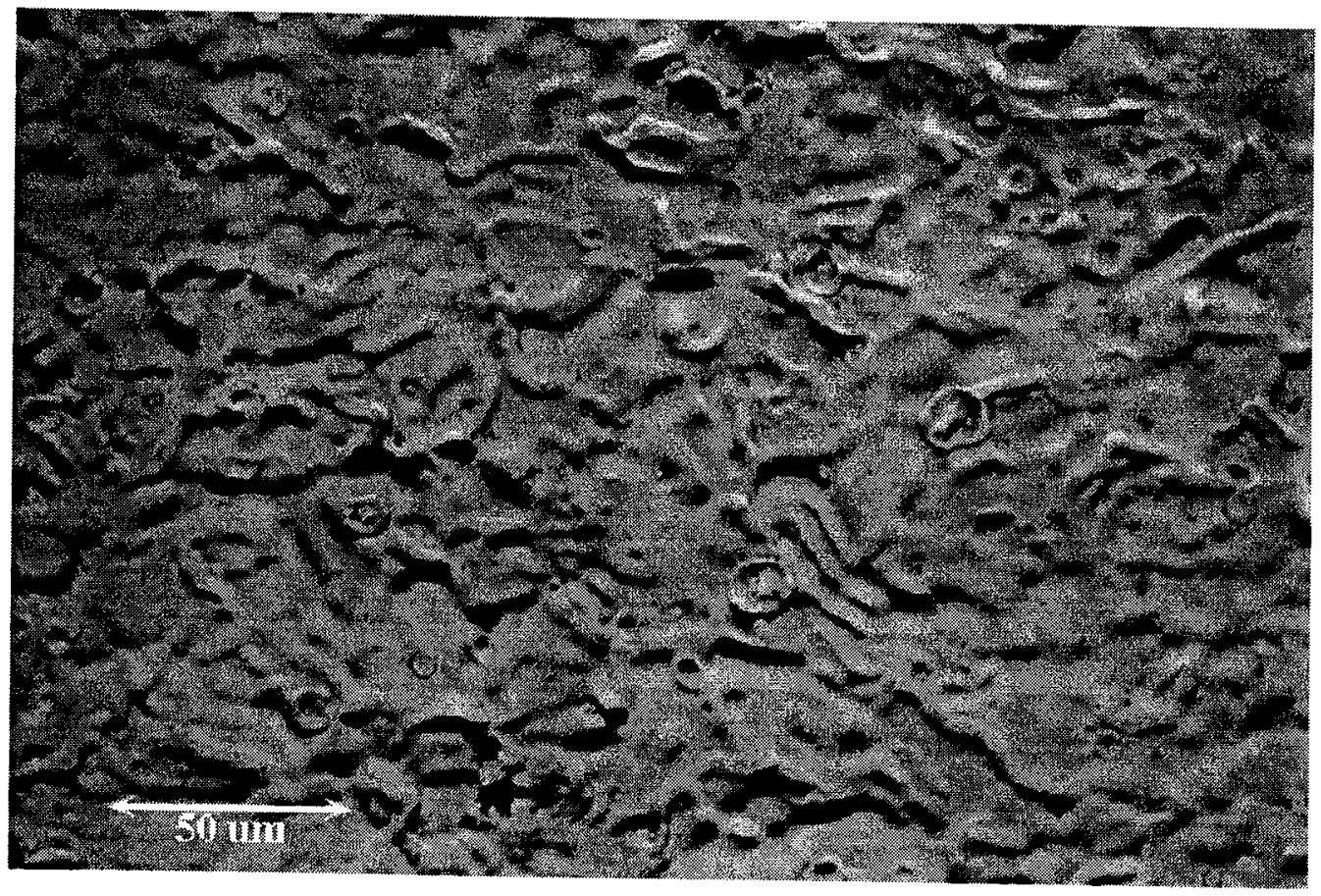

Figure 2. Photograph of the 4-exposure surface of the lowest fluence sample.

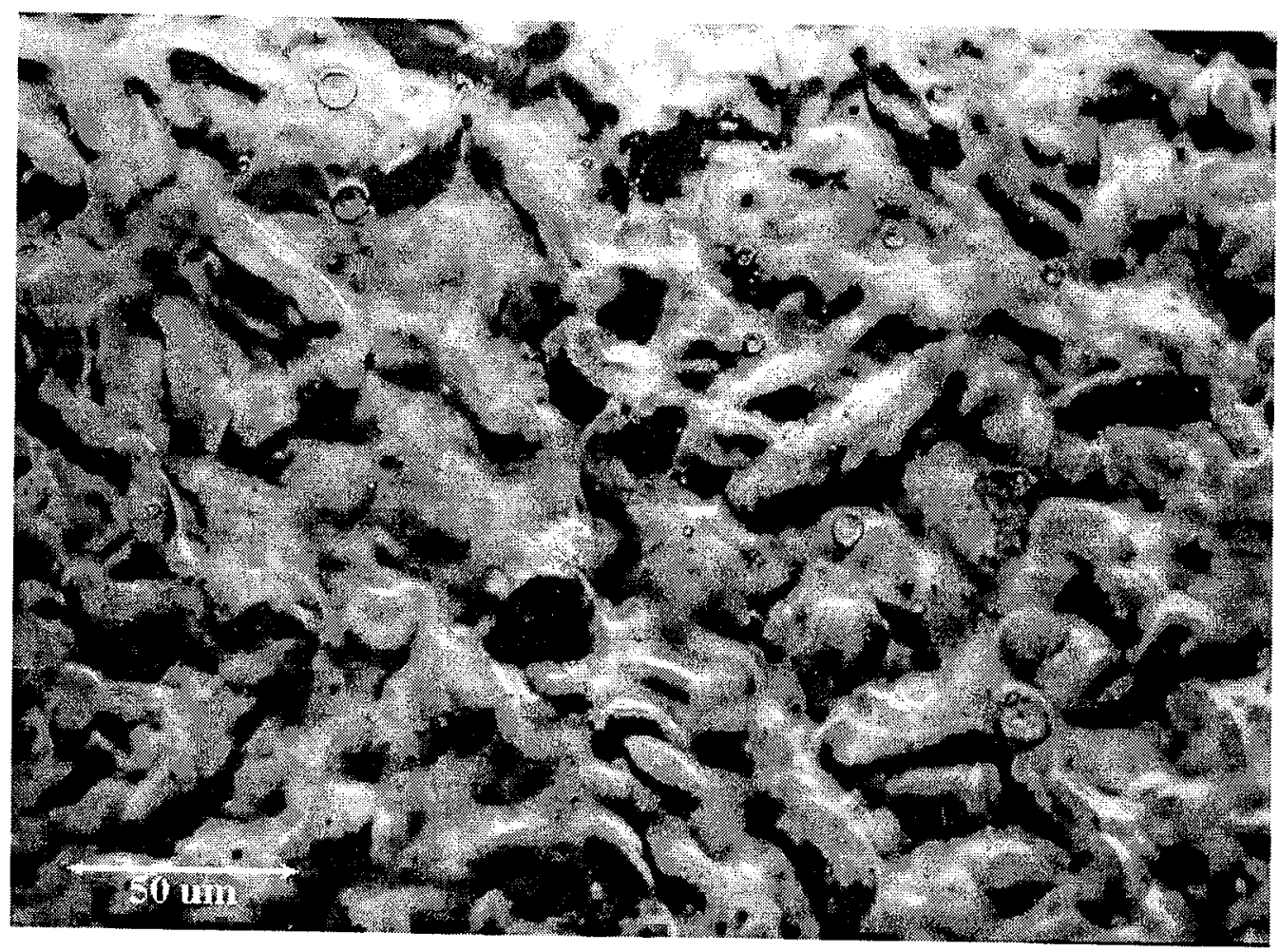

Figure 3. Photograph of the 4-exposure surface of the highest fluence sample. 


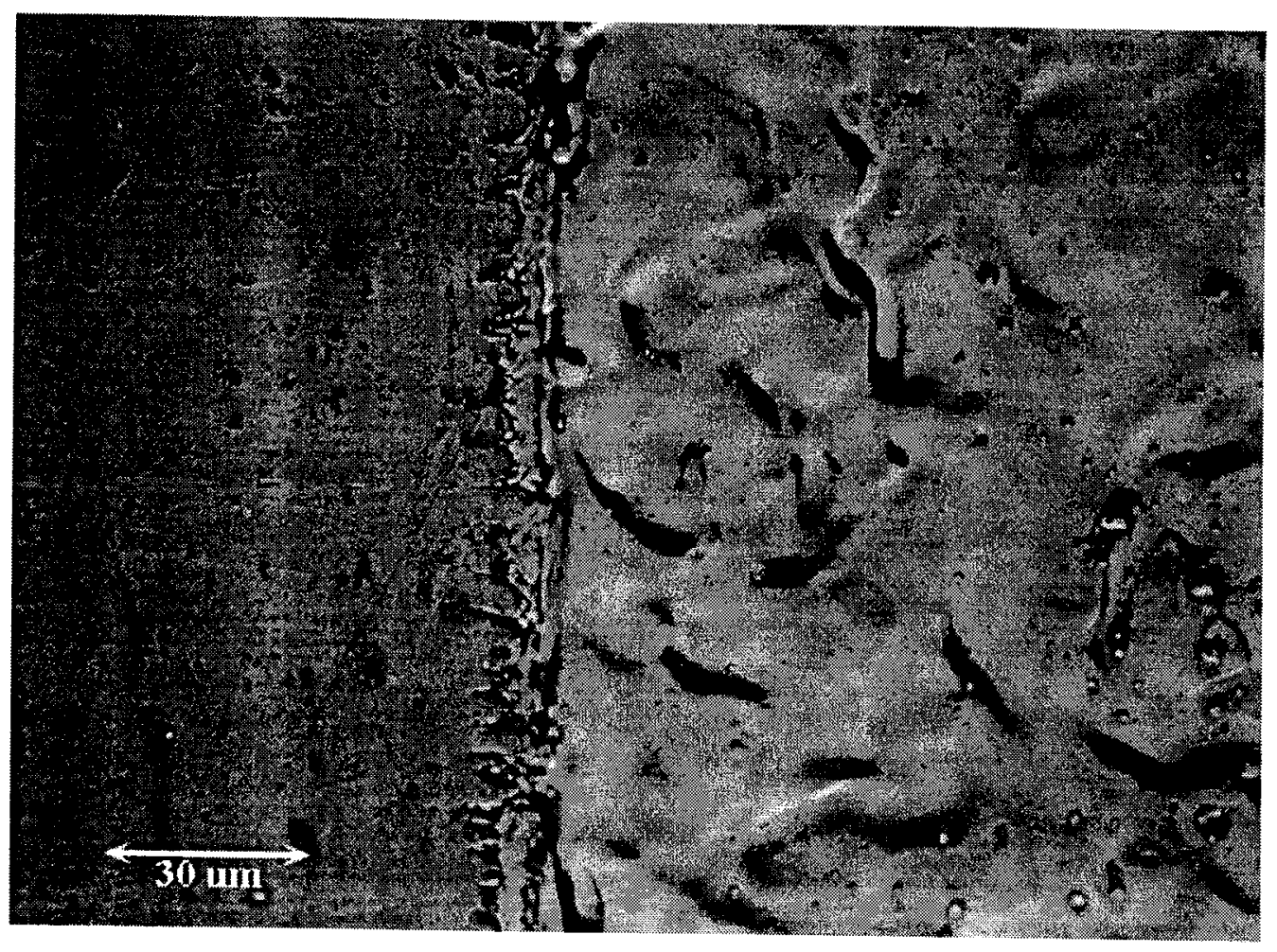

Figure 4. Photograph showing splash from exposed to unexposed region.

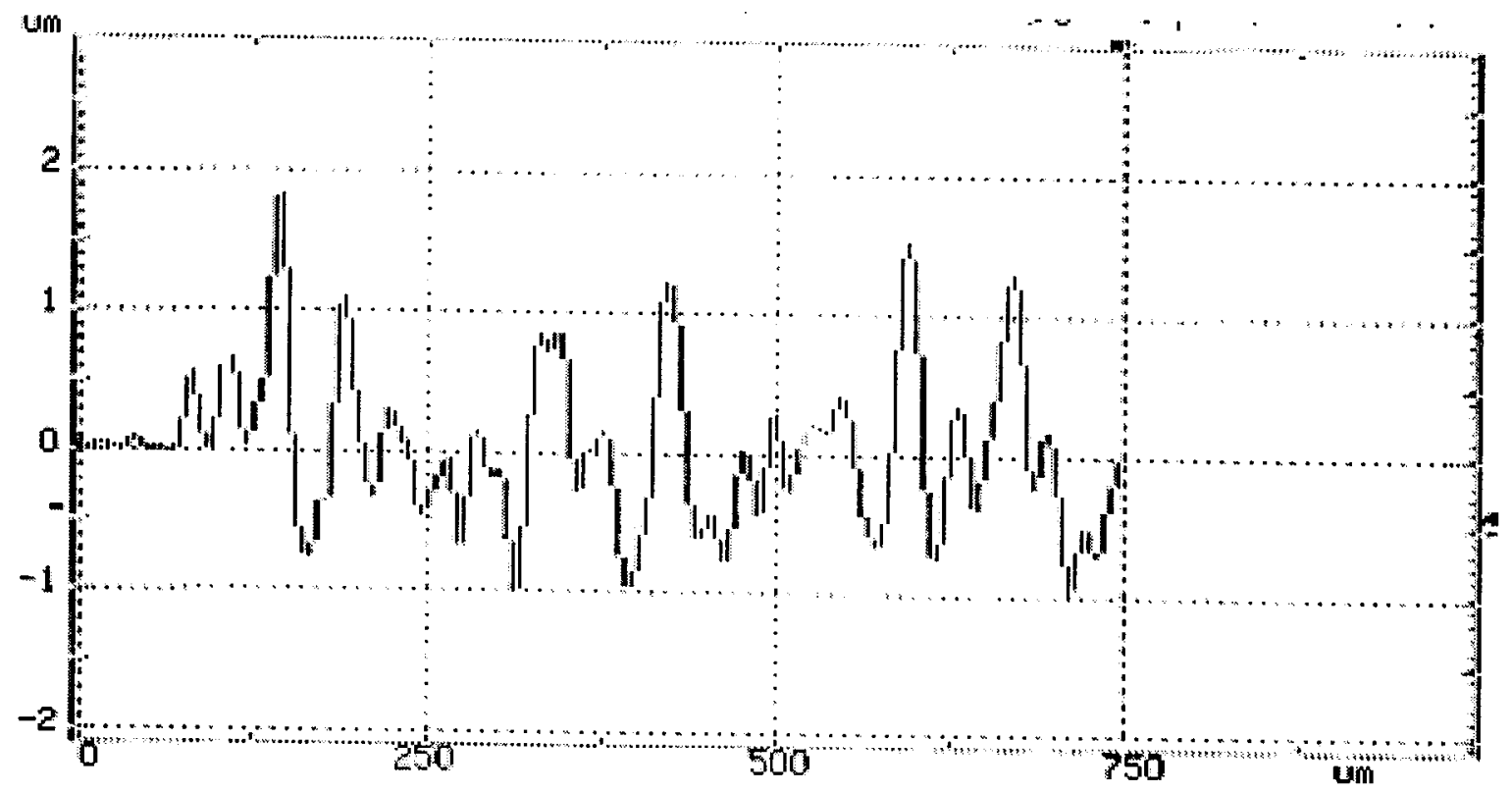

Figure 5. Profilometer scan of exposed surface. 


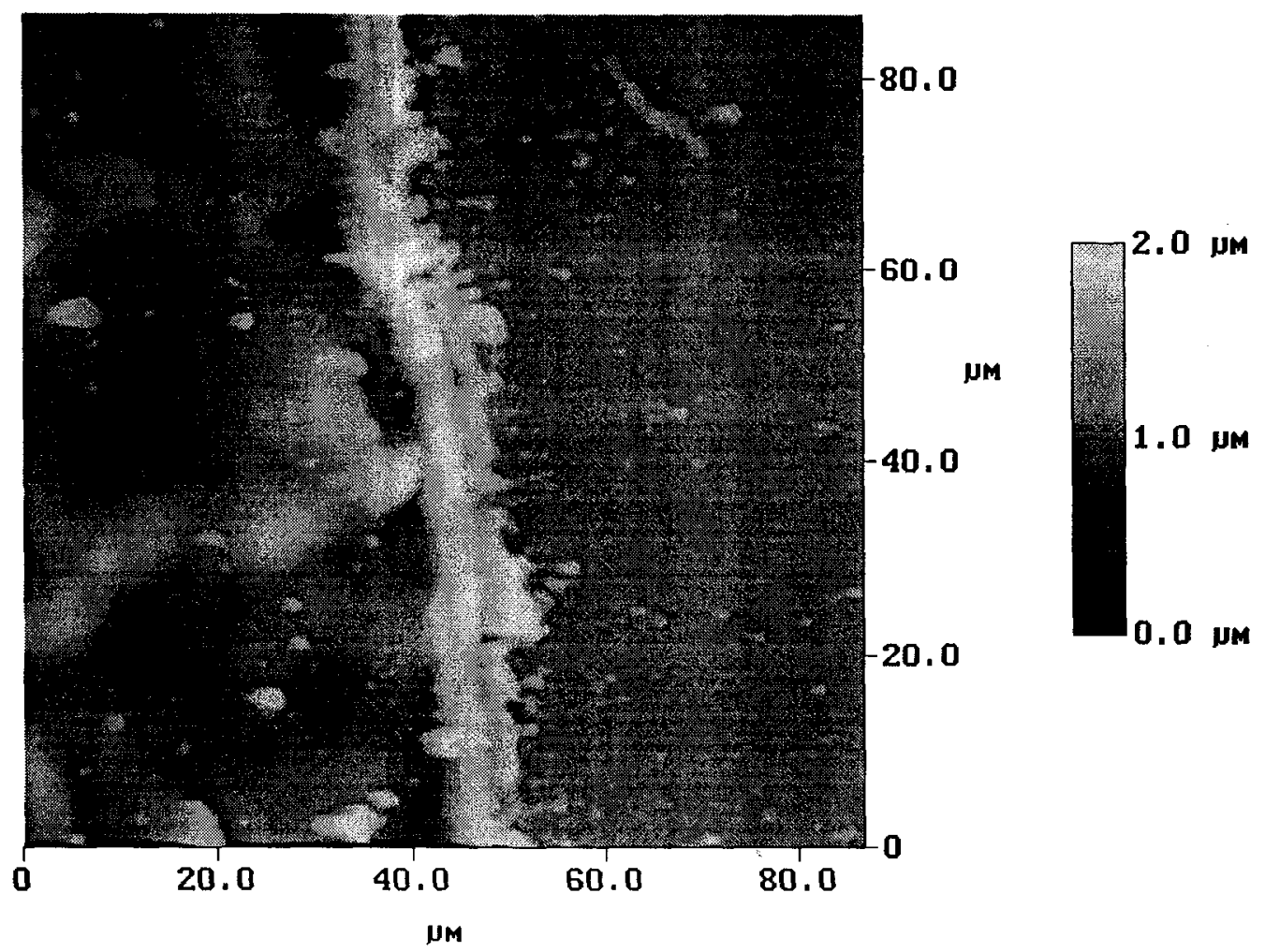

Figure 6. Typical AFM scan of edge of exposure region. Note the formation of a lip at the edge of exposed region.

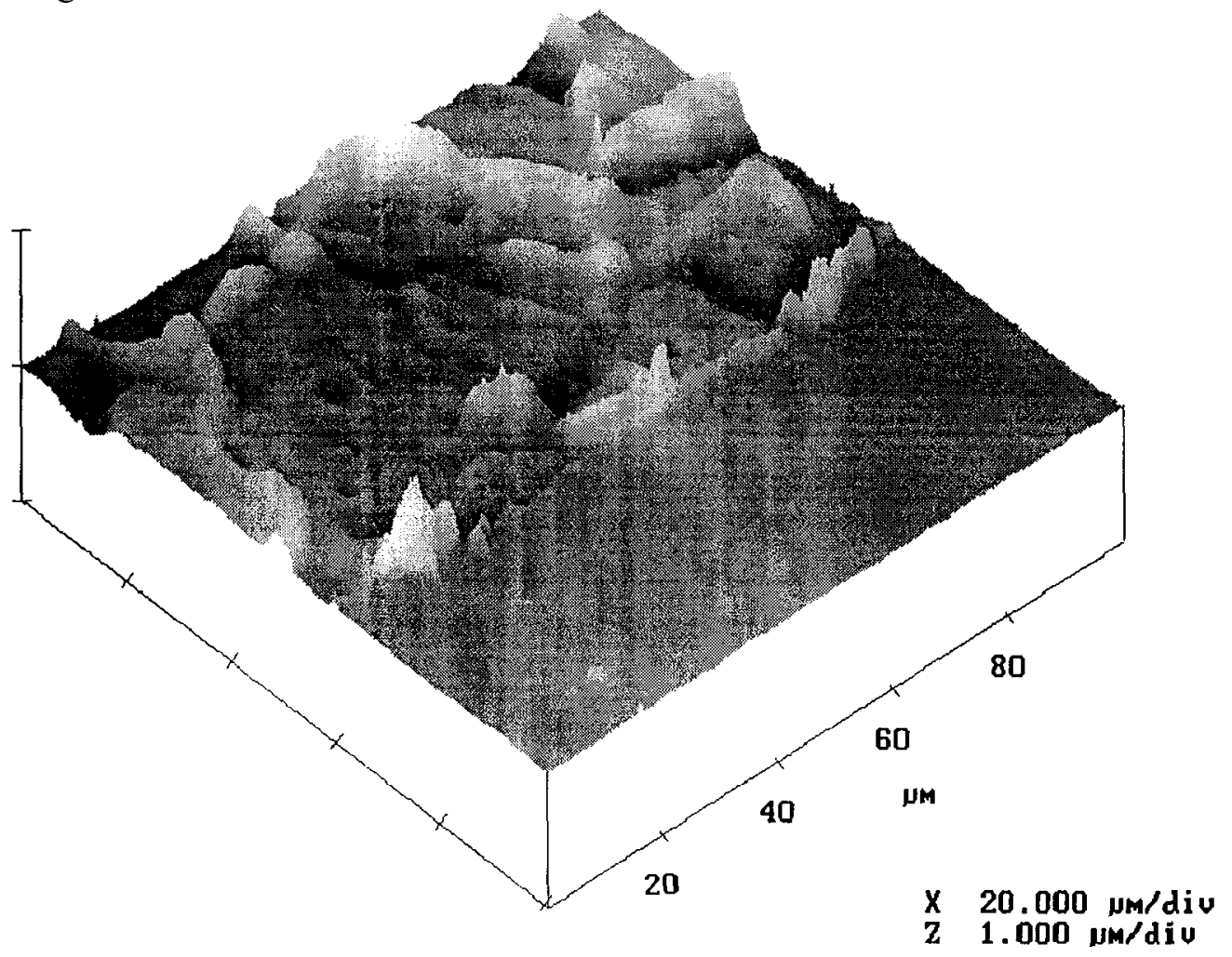

Figure 7. AFM scan of exposed surface showing impact craters with raised centers. 


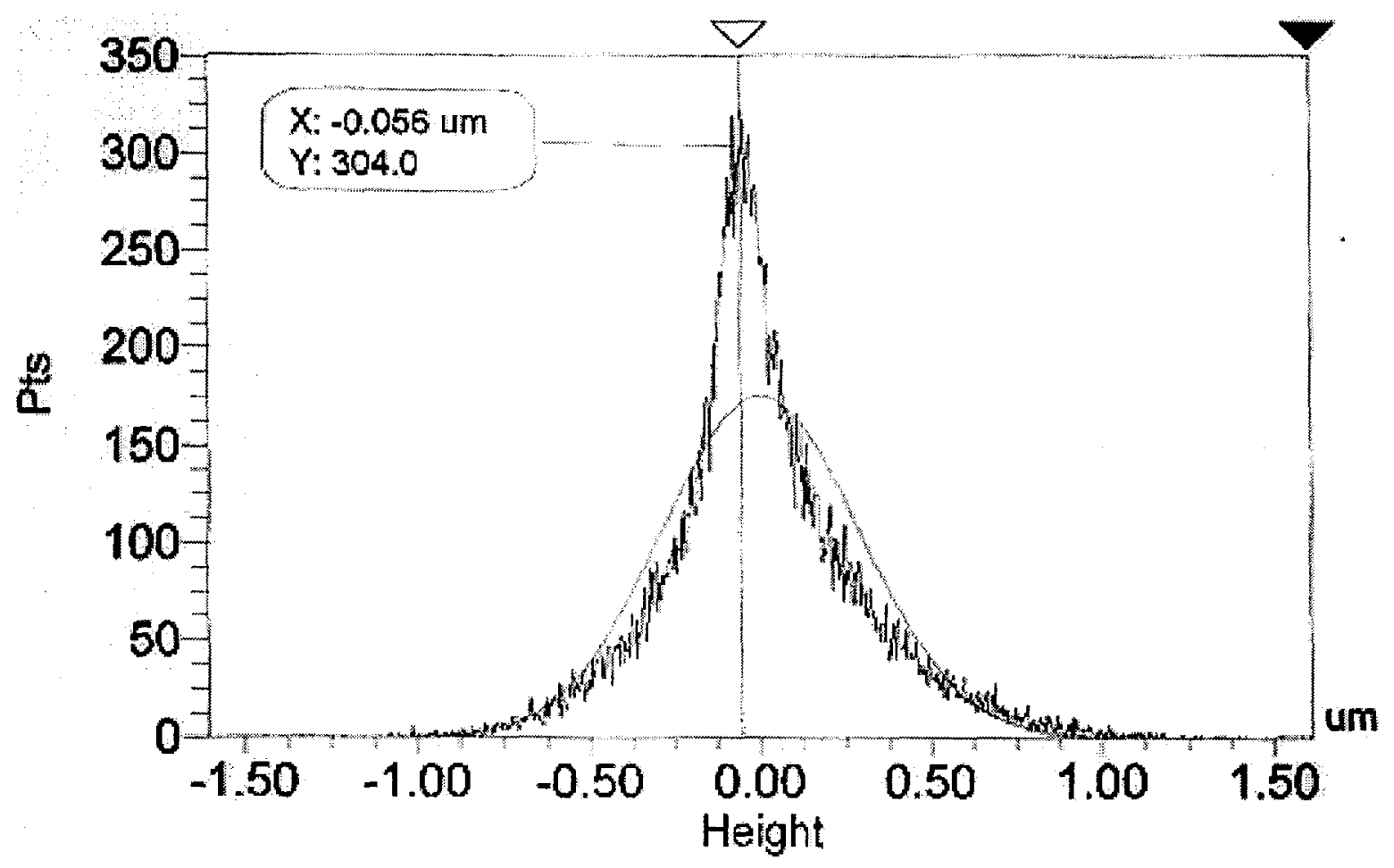

Figure 8. Histogram plot giving information regarding surface profile of sample.

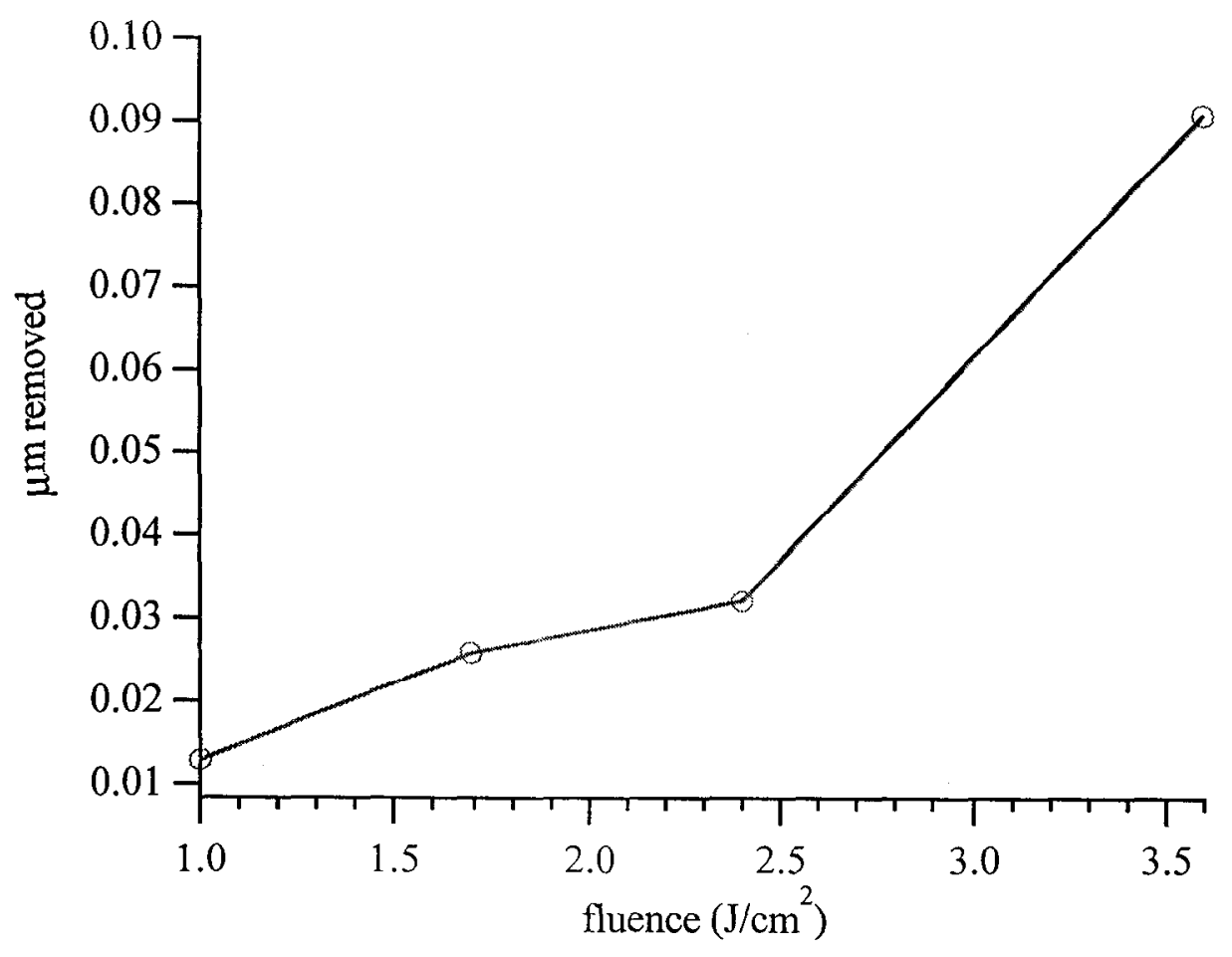

Figure 9. Microns removed vs x-ray fluence for stainless steel 409. 


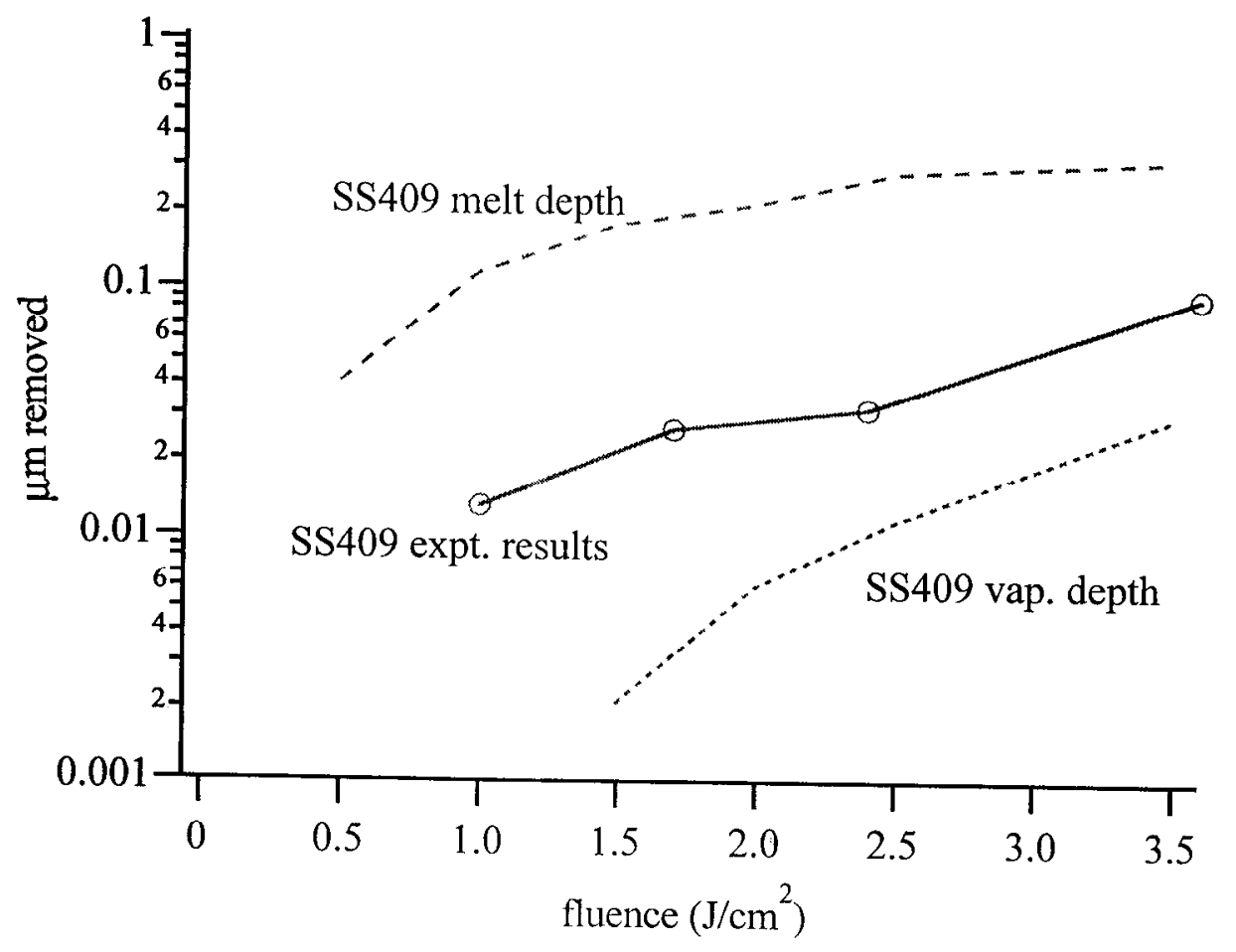

Figure 10. Comparison of ABLATOR calculation with experiment results. 


\subsection{Louvered geometry experiments with NIF first wall materials}

The NIF first wall will likely be a source of contamination for the final optics debris shields. Unlike Nova, where $\mathrm{x}$-ray fluence from targets is $\sim .05 \mathrm{~J} / \mathrm{cm}^{2}$, the expected $\mathrm{x}$-ray fluence on NIF can be as high as $2 \mathrm{~J} / \mathrm{cm}^{2}$ for $20 \mathrm{MJ}$ target yields. With respect to the $\mathrm{x}$-ray fluence level, the Nova first wall is a sink for material that deposits on its surface. On NIF, the x-ray fluence will be great enough to mobilize first wall material and contaminants that have been deposited on the first wall. Since $90 \%$ of the aluminum target chamber surface area will consist of first wall panels, it is critical to choose a material that is not easily mobilized by target x-ray emissions. Additionally, it would be advantageous to have a first wall design that provides a sink for mobilized material in the target chamber. The combination of an appropriate x-ray resistant material with a geometry that effectively retards material transport should keep final optics debris shield contamination below a minimum level for an appropriate amount of time commensurate with the established cleaning schedule for the target chamber. With these issues at hand, a louver design has been proposed as the configuration of the NIF first wall. An experiment simulating the proposed louver geometry was fielded on Nova at $\mathrm{x}$-ray fluence levels comparable to those expected on NIF. This memo discusses the results of that experiment and how they can be applied in understanding NIF contamination issues.

\section{Experiment}

Shown in fig. 1 is a head on view and an overhead view of the experimental apparatus used for this experiment. Sketched in fig. 2 is a schematic view of the experimental setup showing the configuration of the samples and collecting foils. The purpose of this experiment is to expose a sample of stainless steel 409 (SS409) and boron carbide, both NIF first wall candidates, to target debris and $\mathrm{x}$-ray emissions. The ejected plume of material leaving the surface of the two samples is captured by titanium collecting foils facing the samples. The head on view of the setup shows that the $\mathrm{SS} 409$ and $\mathrm{B}_{4} \mathrm{C}$ samples are tilted at a 45 degree angle to the target. The experiment is mounted in the Nova target chamber on top of copper activation tube \#1. The view of the target from this point in the chamber is $25^{\circ}$ from the hohlraum axis. Other experiments conducted for studying issues related to the NIF first wall have used the SIM5 diagnostic tube also $25^{\circ}$ from the hohlraum axis. Once in position, the center of the face of the samples are approximately $40 \mathrm{~cm}$ from target chamber center. The expected $\mathrm{x}$-ray fluence over the sample area at this distance is $\sim 0.7 \mathrm{~J} / \mathrm{cm}^{2}$ (Normally, at $40 \mathrm{~cm}$ from target chamber center the $\mathrm{x}$-ray fluence is $\sim 1 \mathrm{~J} / \mathrm{cm}^{2}$ but the sample is tilted at a $45^{\circ}$ degree angle reducing the fluence by a factor of $\sqrt{2}$. However, the penetration depth is also reduced by a factor of $\sqrt{2}$, so the surface tcmpcrature nominally reaches the same value). Calculation of this fluence level is discussed in a previous report ${ }^{1}$.

Six separate one-week exposure periods were conducted from Dec. 1997, to April 1998. The samples witness approximately 15-20 Nova shots during the course of a week exposure. At the end of this exposure period the Ti foils are taken from the expcriment setup and analyzed by $\mathrm{x}$-ray induced $\mathrm{x}$-ray fluorescence to measure material distribution on the foils. Tables 1-4 list the 
relevant shot data for the last four exposure periods. The data from two of the exposure periods are less reliable because of circumstances that affected the results in an unknown fashion. The first week was affected by stray light from the rear, and the second week appeared to be installed at the wrong angle. Fresh louvers were used to start the third week.

\section{Observations}

The deposits on the Ti foils are typically brown in color. This was true of both the louver foils and the dogleg foils. For purposes of nomenclature, 'louver foils' refer to the Ti collectors directly adjaccnt the samples and 'dogleg foils' refer to the Ti collectors on the dogleg extensions of the apparatus. The darker parts of the $\mathrm{Ti}$ samples are where the most deposition of material occurred and the lighter parts are where less material was deposited.

During the first week of exposure, the experiment did not have the dogleg extensions nor the backing plate that are labeled in fig. 2. They were both added after the first week of exposure finished. The backing plate was added because observation of the louver foils suggested that laser light was mobilizing material that had been deposited. As a result the data from the first week is not included here. There were clear and distinct clean areas of the foils that should have had material deposited on them as well as the expected deposited contamination. In fact, from looking at the apparatus from a particular angle one could determine the direction of the source of laser light. In order to correct for this unforeseen problem, the backing plate was added in order to shield the louver foils from being exposed to scattered light. Though the exact fluence of the laser light was unknown, this happenstance highlights scattered laser light as another threat for mobilizing material deposited on the first wall of NIF. The dogleg extensions were added because the louver design on NIF evolved to having a dogleg bend. This dogleg portion is nominally parallel to the line of sight of the target exposing its surface to a minimal x-ray fluence. The thickness of the louvers should be kept to a minimum because material will be vaporized from the edge that is facing the target.

Optical microscopy and scanning electron microscopy (SEM) were used to determine the nature of the deposit on the louver foils opposite an initially clcan SS409 sample. A previous memo ${ }^{2}$ discusses the nature of the deposits opposite the $\mathrm{B}_{4} \mathrm{C}$ sample. Fig. 3 is a pair of darkfield micrographs of two Ti foils. The foil on the left has not been exposed to a sample ablation plume and the Ti foil on the right was opposite the SS409 sample during the exposure period from $1 / 26 / 98$ to $1 / 30 / 98$. On the exposed sample, we can see a distribution of particles on the surface not present on the unexposed foil. SEM photographs of the exposed sample are shown in fig. 4 . The lower magnification photo on the left shows particles distributed over the surface. The higher magnification photo on the right shows particles ranging in size from tenths of a micron to a few microns in diameter. Fluorescence spectra from a virgin piece of $\mathrm{Ti}$ and one of the particles is shown in fig. 5 and fig. 6, respectively. The spectrum from the particle indicates the presence of $\mathrm{Fe}, \mathrm{Cr}, \mathrm{Si}$, and $\mathrm{Al}$. The presence of $\mathrm{Fe}$ and $\mathrm{Cr}$ is due to the Ti foil being opposite the SS409. $\mathrm{Ni}$ is not present because SS409 is a no-nickel stainless steel. A likely reason for the presence of $\mathrm{Si}$ is that the sample was bead blasted before its exposure. Aluminum was used in some of the 
targets that were shot during the exposure period. Unexpectedly, $\mathrm{Cu}$ is not present in the particles that were scanned even though $\mathrm{Cu}$ is a common target chamber contaminant. Though from $\mathrm{x}$-ray induced $\mathrm{x}$-ray fluorescence (XXRF) measurements there is a small amount of $\mathrm{Cu}$ on the Ti foil in amount that is a factor of 20 less than the amount of Fe. From these observations, it appears that the ablation plume from an initially clean SS409 sample deposits in the form of film in combination with particles. This is consistent with the observation that SS409 removal by $\mathrm{x}$ rays occurs with some liquid melt ejcction ${ }^{3}$.

\section{Performance of $\mathrm{B}_{4} \mathrm{C}$ and SS409 substrates}

At the end of each one week exposure period the XXRF measurements were performed to determine the areal density of $\mathrm{Cu}, \mathrm{Au}$ and $\mathrm{Fe}$ on each of the Ti foils. A purpose of these measurements was to assess the difference in contaminant remobilization from a $\mathrm{B}_{4} \mathrm{C}$ substrate as compared to a $\mathrm{SS} 409$ substrate. A previous experiment characterized the remobilization from a $\mathrm{B}_{4} \mathrm{C}$ sample receiving approximately $1 \mathrm{~J} / \mathrm{cm}^{2}$ of $\mathrm{x}$-ray fluence ${ }^{2}$. Compared to this experiment we would expect that the calculated remobilization fractions of contaminants from the $\mathrm{B}_{4} \mathrm{C}$ sample would be lower than the previously attained values because of the lower fluence. For comparing the two substrates, the simplest hypothesis would be that the material providing the better overall heat sink should have less remobilization of material from the surface. Determination of the better heat sink would rely on several factors including the nature of the contamination (thin film or particles), how the contaminant is bonded to the substrate, the amount of the contaminant, and the x-ray responses of the substrate and contaminant. The combination of these factors will directly affect the amount of contamination removed from the substrate surface. Since we do not currently have the capability for modeling this process, this experiment provided a direct comparison between the two candidate materials. Additionally, the effect of contaminants on the first wall response can be studied. It has been proposed that the addition of contaminants to the first wall surface will reduce the removal of the first wall material. Essentially, the contaminants may become the first wall material if the deposited layer is sufficiently thick. Gerassimenko and Burnham identified this as a reason to provide a sink for mobilized material in the chamber ${ }^{2}$.

Table 5 summarizes the deposition of $\mathrm{Cu}, \mathrm{Au}$, and $\mathrm{Fe}$ onto the $\mathrm{Ti}$ louver foils for the last four exposure periods. The rates are calculated based on the number of shots that were over 10 $\mathrm{kJ}$ in energy. It is assumed that shots less than $10 \mathrm{~kJ}$ do not contribute to remobilization of material because the $\mathrm{x}$-ray fluence would not be sufficient to remove a significant amount of material ${ }^{4}$. Given that the $\mathrm{B}_{4} \mathrm{C}$ and $\mathrm{SS} 409$ samples have contaminants deposited at the same rates then the total figures from this table would indicate that $\mathrm{B}_{4} \mathrm{C}$ has less remobilization of $\mathrm{Cu}$ and Au than SS409.

There are several features of this data that need to be highlighted. The first exposure period began with clean SS409 and $\mathrm{B}_{4} \mathrm{C}$ samples and the shot schedule had the higher energy shots early in the week. This would explain why the deposition of Fe was so high on the SS409 
louver foil. With subsequent exposure periods the net amount of $\mathrm{Fe}$ deposition dropped precipitously, implying that with contaminant buildup the removal of the substrate drops.

There is other evidence suggesting that contaminants affect first wall material removal. During exposure period 2, the deposition of contaminants on the foils was the lowest of all exposure periods because there were a total of 17 shots with only 3 above $10 \mathrm{~kJ}$. Some buildup of contaminants on the $\mathrm{B}_{4} \mathrm{C}$ and SS409 samples would occur due to the low energy shot schedule. In exposure 3, the net amount of Fe remobilized from the SS409 sample was zero. The net amount of Fe deposition would be calculated as the deposition on the SS409 louver foil less that from the $\mathrm{B}_{4} \mathrm{C}$ foil. This calculation is necessary to subtract out background sources of Fe in the chamber and from the experimental apparatus. The total amount of $\mathrm{Cu}$ and $\mathrm{Au}$ remobilized was the greatest of the four exposure periods during exposure period 3. This phenomenon highlights how the variability of the shot schedule will affect the contamination loading in the chamber. During weeks where the x-ray fluence on the wall will be low target and near-target ablated materials will buildup on the first wall and contaminant remobilization will be low. These deposits will be mobilized when higher energy shots follow. From this experiment, we can expect the contaminant remobilization to be the greatest during a week with higher energy shots that followed a week with low energy shots. It is important to note here, that the remobilization numbers from exposure period 3 show nearly equal amounts of $\mathrm{Cu}, \mathrm{Au}$ and $\mathrm{Fe}$ from both the $\mathrm{B}_{4} \mathrm{C}$ and SS409. This would indicate that during periods of heavier contamination, the contamination could effectively act as the first wall. Since the NIF will start with low energies and gradually increase over a few years, it is likely that the lirst wall will be largely covered by target debris by the time the $\mathrm{x}$-ray fluences reach mobilizing levels.

Using the same technique as in a previous experiment ${ }^{2}$ the total remobilization fractions for $\mathrm{Au}$ and $\mathrm{Cu}$ were calculated for both first wall materials. The remobilization fraction is defined as the fraction of contaminant deposited on the substrate that has been removed by subsequent exposure. For the total remobilization calculation, a geometric factor that accounts for the amount of material captured on the louver must be determined. The geometric factor for the previous experiment was based on previous data showing a lorentzian spatial distribution of the plume. For this experiment a geometric factor of 0.5 was used. This figure is based on a calculation from the U. C. Berkeley hydrodynamics code, TSUNAMI. Calculations based on a geometric factor based on the same lorentzian distribution as the previous experiment give values that differ by a few percent. The calculation results for a geometric factor of 0.5 are given in the following table:

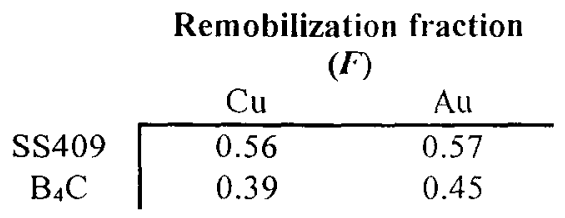

The results for $\mathrm{B}_{4} \mathrm{C}$ from the previous experiment give remobilization fractions of 0.5 and 0.67 for $\mathrm{Cu}$ and $\mathrm{Au}$, respectively. The values calculated for the current experiment were $\sim 20 \%$ lower than the previous values. However, we must discern whether the lower fluence or the lower total 
number of shots from this experiment is responsible for this difference. If we were to take the calculated remobilization parameters from this experiment and calculate the total remobilization fraction for the same number of shots as the previous experiment we get values of 0.58 and 0.64 for $\mathrm{Cu}$ and $\mathrm{Au}$. Both these values are comparable to the values from the previous experiment. This would suggest that the lesser number of shots is responsible for the different remobilization values from the $\mathrm{B}_{4} \mathrm{C}$ sample and that the lower average fluence did not have a strong effect.

As mentioned before, these values show that $\mathrm{B}_{4} \mathrm{C}$ allows for less remobilization than SS409. There could be several factors that contribute to this. If the $\mathrm{B}_{4} \mathrm{C}$ substrate is remains cooler than the SS409 substrate during the x-ray energy deposition it would serve as a more efficent heat sink providing a means for the deposited material to cool by thermal conduction. If the contaminant level is low and the samples receive a fluence that would normally ablate a clean sample then it is likely that the contaminant will be removed with the sample material. This is most likely the case for the first exposure in table 5 for the SS409 sample. Since $\mathrm{B}_{4} \mathrm{C}$ has a higher threshold for ablation than SS409 this could contribute to a greater remobilization rate from the SS409. As mentioned earlier, in the case of a thick contamination layer, it seems that the contaminants can act as the first wall.

The results for the remobilization fractions presented above are calculated based on the material that is captured on the louver foils. The data from the dogleg foils was not used in the calculation because there was deposition of material onto those foils directly from the target. Fig. 7 shows a dogleg foil with several $\mathrm{Cu}$ splats deposited at a steep incidence angle. These splats artificially raise the $\mathrm{Cu}$ amount on the foil. Though the apparatus was aligned before each exposure period to prevent direct contamination of the dogleg foils, debris sources such as shine shields could be large enough to provide line of sight contact with the dogleg foils.

Burnham developed an analytical model describing contaminant remobilization ${ }^{5}$ based on the assumption that contaminant remobilization is dependent on the amount present on the first wall. With a constant deposition rate, the total remobilization can be expressed as:

$$
F=1-\frac{1-e^{-b c t}}{b c t}
$$

where $F$ is the fraction of the total amount of deposited contaminant that has been remobilized, $b$ is the fraction mobilized each shot, $c$ is the fraction that is mobilized that goes to a sink, and $t$ is the number of shots. For this experiment the value of $c$ is fixed at one since all the remobilized material exits from the system. For this experiment given the $F$ values of 0.4 to 0.6 from above , the value of $b$ ranges from 0.03 to 0.06 . Given these $b$ values, and the amount of material present on the SS409 and $\mathrm{B}_{4} \mathrm{C}$ samples we can estimate the amount of remobilization per shot at the end of the experiment. XXRF measurement show $\sim 7$ and $\sim 11 \mu \mathrm{g} / \mathrm{cm}^{2}$ of metal on the SS409 and $\mathrm{B}_{4} \mathrm{C}$, respectively. Multiplying $b$ times the areal density gives $\sim 0.4$ and $\sim 0.3 \mu \mathrm{g} / \mathrm{cm}^{2} / \mathrm{shot}$ remobilization for SS409 and $\mathrm{B}_{4} \mathrm{C}$. . This number is near the limit of the allowed remobilization from the first wall, $0.5 \mu \mathrm{g} / \mathrm{cm}^{2} / \mathrm{shot}$, if it were not captured by the louvers. Also, the amount of 
remobilization is nearly independent of the substrate. Using the model mentioned previously it can be demonstrated how this occurs. The amount of contaminant on the sample is described by:

$$
N=\frac{R}{b c}\left(1-e^{-b c t}\right)
$$

where $N$ is the amount of contaminant and $R$ is the rate (assumed constant) at which the contaminant is deposited. The rate at which contaminants are remobilized is given by the product of $b$ and $N$. Therefore, the amount of remobilization, $f$, from the sample at a particular time $t$ is:

$$
f=\frac{R}{c}\left(1-e^{-b c t}\right)
$$

For the experiment, the contaminants from both the $\mathrm{B}_{4} \mathrm{C}$ and the SS409 go to a sink i.e. $c=1$. Given that the samples were side by side and $40 \mathrm{~cm}$ from the target, the rate of contamination for each was nearly equal. With these simplifications the ratio of $f_{\mathrm{B} 4 \mathrm{C}}$ and $f_{\mathrm{SS}}$ is:

$$
\alpha=\frac{1-e^{-b_{B} 4 C^{t}}}{1-e^{-b_{S S} t}}
$$

During the last exposure period we would expect that the average value of $\alpha$ is 0.8 given the calculated total remobilization fraction values from the measured contaminant amounts on the Ti foils and first wall samples. Our experiment gives an average $\alpha$ value of $\sim 2 / 3$ over the last exposure period. This is relatively good agreement with the assumptions that the remobilization is dependent on the amount of material present and the variability of the shot to shot conditions. It is important to note, that if the constant contamination remobilization fraction assumption is true then as $t$ approaches infinity, $\alpha$ goes to 1 . This is true for any value of $R$ or $c$ because these values will be identical given the same target chamber design and shot schedule. Consequently, the long-term behavior of contaminant remobilization will be the same for either first wall material. With the $b$ values from this experiment and a $c$ value of 0.67 (a sink fraction achievable by a louvered first wall), it would take $\sim 90$ shots for $\alpha=0.9$. In other words, after 5 weeks of NIF opcration, the contaminant remobilization from a $\mathrm{B}_{4} \mathrm{C}$ or SS409 first wall would be nearly equal.

It should be emphasized that the amount remobilized per shot will depend on the x-ray fluence and the substrate as the results of this experiment and the previous experiment indicate. Additionally, the x-ray spectrum probably has some effect on this value as well. These calculations do not include the amount of first wall material that is removed but only the remobilization of contaminants. The threat of the removal of first wall material still remains. The data in table 5 shows that in addition to the contaminants some removal of the SS409 occurred.

\section{Conclusions}

A louvered geometry experiment was exposed on a long-term basis to Nova target chamber conditions. Two potential first wall materials, SS409 and $\mathrm{B}_{4} \mathrm{C}$, were exposed to target $\mathrm{x}$ - 
rays and target debris. The ablation plumes from both samples were captured on Ti foils and the foils were analyzed to measure the concentration of common target chamber contaminants. Exposure occurred in one week periods for a total of six weeks. The results from the first two weeks were ignored due to experimental complications. Analysis of a Ti foil opposite an initially clean SS409 sample show the presence of particles containing $\mathrm{Fe}$ and $\mathrm{Cr}$, the primary components of SS409. XXRF measurements from the Ti foil indicate the presence of $\mathrm{Au}$ and $\mathrm{Cu}$ on the sample as well. The presence of the sub-micron to micron size particles support the notion that SS409 ablates with some ejection of a melt layer. A previous experiment analyzed deposits from $\mathrm{a} \mathrm{B}_{4} \mathrm{C}$ sample and hence that analysis was not completed here ${ }^{2}$.

The relative performance of potential first wall materials, $\mathrm{B}_{4} \mathrm{C}$ and SS409, was compared with regards to contaminant remobilization. The results show that $\mathrm{B}_{4} \mathrm{C}$ has less contaminant remobilization than SS409. Further analysis of the experimental data shows that approximately $6 \%$ and $3 \%$ of the contaminants are remobilized per shot from the SS409 and $\mathrm{B}_{4} \mathrm{C}$, respectively. This led to total remobilization fractions ranging of $\sim 60 \%$ for $\mathrm{SS} 409$ and $\sim 40 \%$ for $\mathrm{B}_{4} \mathrm{C}$. Comparison of these results for $\mathrm{B}_{4} \mathrm{C}$ to a previous experiment show that the lesser number of shots in this experiment led to lower total remobilization fractions for both $\mathrm{Cu}$ and $\mathrm{Au}$. With parameters calculated from the experimental data, it was demonstrated that the long-term remobilization behavior of $\mathrm{B}_{4} \mathrm{C}$ and SS409 would become equal. This result is based on the assumption that contaminant remobilization fraction is constant. At the end of this experiment, the remobilization from each sample was calculated as $\sim 0.4$ and $\sim 0.3 \mu \mathrm{g} / \mathrm{cm}^{2} / \mathrm{shot}$ for SS409 and $\mathrm{B}_{4} \mathrm{C}$. This values approach the allowed limit of $0.5 \mu \mathrm{g} / \mathrm{cm}^{2} / \mathrm{shot}$. Since the calculated values are nearly at the limit it is important to note that remobilization is dependent on the fluence level and the $\mathrm{x}$-ray spectrum that the samples experience. This experiment has examined the effect of an average lower fluence on the $\mathrm{B}_{4} \mathrm{C}$ sample but the effect of a different $\mathrm{x}$-ray spectrum warrants further study.

\section{Acknowledgments}

The experimental apparatus was assembled and modified with the help of John Mihoevich. We would like to thank Jim Hughes who performed the XXRF measurements, Derek Coker for the SEM analysis, and Don Gemmell for coordinating the experiment on Nova.

\section{References}

1. Gerassimenko, M., Anderson A., Burnham A., "Studies of First Wall Deposit Removal by Exposure to X Rays", Document QDV-97-0005, June 9, 1997

2. Gerassimenko, M., Burnham, A., "Studies of First Wall Contamination and Mobilization of Contaminants", Document QDV-97-0020, December 1, 1997

3. Scott, J., "X-ray Response of Stainless Steel", NIF-0006363, Feb. 19, 1998 
4. Scott, J., "Variability of material response to NOVA x-ray emissions", NIF-0005818, Feb. 19, 1998.

5. Burnham, A., "Effects of a Sink for Reablated Metal on Target Chamber Cleaning Requirements," NIF-0000327, July 23, 1996. 
Table 1--Exposure period 3, 1/26/98-1/30/98

\begin{tabular}{|c|c|c|c|}
\hline Date & Nova Shot No. & $\begin{array}{c}\text { Energy into } \\
\text { target }(\mathrm{kJ})\end{array}$ & Shot name \\
\hline $1 / 27 / 98$ & 28012703 & 0.004 & TSP_AUDISK \\
$1 / 27 / 98$ & 28012705 & 16.494 & TSP_RIKSPH_37 \\
$1 / 27 / 98$ & 28012708 & 21.311 & TSP_RIKSPH_38 \\
$1 / 27 / 98$ & 28012717 & 16.583 & DHK_LOWTRT_77 \\
$1 / 27 / 98$ & 28012720 & 17.520 & DHK_LOWTRT_76 \\
$1 / 27 / 98$ & 28012723 & 11.018 & BDC_2WCALIB_56 \\
$1 / 28 / 98$ & 28012802 & 17.600 & KSB_2SHOCK_06 \\
$1 / 28 / 98$ & 28012806 & 18.321 & DRF_BMIX_76 \\
$1 / 28 / 98$ & 28012808 & 19.004 & DRF_BMIX_77 \\
$1 / 28 / 98$ & 28012810 & 20.186 & LML_BMIX_74 \\
$1 / 28 / 98$ & 28012812 & 20.432 & LML_BMIX_75 \\
$1 / 29 / 98$ & 28012903 & 16.479 & DHK_LOWTRT_78 \\
$1 / 29 / 98$ & 28012907 & 0.495 & DHK_AUDISK_53 \\
$1 / 29 / 98$ & 28012913 & 3.929 & DHK_LOWTDIFF_19 \\
$1 / 29 / 98$ & 28012915 & 0.002 & SHG_4WPROBE_24 \\
$1 / 29 / 98$ & 28012918 & 1.398 & RLS_ALIGN_33_U \\
$1 / 29 / 98$ & 28012920 & 1.916 & MDW_ALIGN_01_U \\
$1 / 29 / 98$ & 28012922 & 13.801 & BDC_3WCALIB_236
\end{tabular}

Table 2--Exposure period 4, 2/10/98-2/13/98

\begin{tabular}{|c|c|c|c|}
\hline Date & Nova Shot No. & $\begin{array}{c}\text { Energy into } \\
\text { target }(\mathrm{kJ})\end{array}$ & Shot name \\
\hline $2 / 10 / 98$ & 28021006 & 2.025 & DRH_SIAUDISK_14 \\
$2 / 10 / 98$ & 28021009 & 1.093 & RLS_AL_IGN_35_U \\
$2 / 10 / 98$ & 28021011 & 11.525 & BDC_3WCALIB_237 \\
$2 / 10 / 98$ & 28021018 & 0.371 & DHK_SIDIFF12 \\
$2 / 11 / 98$ & 28021104 & 0.149 & DHK_SIAUDISK_02 \\
$2 / 11 / 98$ & 28021105 & 1.519 & RLS_ALIGN_35_U \\
$2 / 11 / 98$ & 28021109 & 0.375 & DHK_LOWTRT_81 \\
$2 / 11 / 98$ & 28021113 & 0.619 & DHK_LOWTRT_80 \\
$2 / 11 / 98$ & 28021116 & 31.559 & CAB_NWETS_05 \\
$2 / 11 / 98$ & 28021118 & 34.954 & CAB_NWETS_04 \\
$2 / 12 / 98$ & 28021208 & 8.962 & KSB_PESBRK_23 \\
$2 / 12 / 98$ & 28021211 & 4.991 & KSB_PESBRK_24 \\
$2 / 12 / 98$ & 28021214 & 4.695 & KSB_PESBRK_25 \\
$2 / 12 / 98$ & 28021217 & 9.112 & KSB_2SHOCK_07 \\
$2 / 12 / 98$ & 28021220 & 9.012 & KSB_2SHOCK_08 \\
$2 / 12 / 98$ & 28021222 & 0.004 & SHG_4WPROBE_27 \\
$2 / 12 / 98$ & 28021224 & 2.456 & RET_PCDCAL_03
\end{tabular}


Table 3--Exposure period 5, 3/2/98-3/6/98

\begin{tabular}{|c|c|c|c|}
\hline Date & Nova Shot No. & $\begin{array}{c}\text { Energy into } \\
\text { target }(\mathrm{kJ})\end{array}$ & Shot name \\
\hline $3 / 2 / 98$ & 28030203 & 0.005 & BDC_IWCALIB_118 \\
$3 / 2 / 98$ & 28030206 & 10.451 & BDC_3WCALIB_240 \\
$3 / 3 / 98$ & 28030302 & 9.981 & BDC_2WCALIB_59 \\
$3 / 3 / 98$ & 28030304 & 2.825 & DRH_AUDISK_15 \\
$3 / 3 / 98$ & 28030309 & 2.928 & DRH_AUDISK_16 \\
$3 / 3 / 98$ & 28030312 & 17.464 & DHK_LOWTRT_83 \\
$3 / 3 / 98$ & 28030318 & 5.995 & DHK_LOWTDIF_20 \\
$3 / 4 / 98$ & 28030404 & 21.377 & TSP_RIKSPH_39 \\
$3 / 4 / 98$ & 28030407 & 20.053 & ISP_RIKSPH_40 \\
$3 / 4 / 98$ & 28030412 & 15.929 & SGG_SNRING_11 \\
$3 / 4 / 98$ & 28030415 & 16.474 & SGG_SNRING_12 \\
$3 / 5 / 98$ & 28030503 & 21.987 & JAC_BBUMP_01 \\
$3 / 5 / 98$ & 28030506 & 25.743 & JAC_BBUMP_02 \\
$3 / 5 / 98$ & 28030508 & 24.098 & JAC_BBUMP_04 \\
$3 / 5 / 98$ & 28030512 & 23.482 & JAC_BBUMP_03 \\
$3 / 5 / 98$ & 28030515 & 27.797 & JAC_BBUMP_07 \\
$3 / 5 / 98$ & 28030517 & 21.721 & JAC_BBUMP_05 \\
$3 / 5 / 98$ & 28030521 & & GTS_CAL_02 \\
$3 / 5 / 98$ & 28030523 & & GTS_CAL_03 \\
$3 / 6 / 98$ & 28030604 & 20.020 & TSP_RIKSPH_41 \\
$3 / 6 / 98$ & 28030607 & 21.869 & TSP_RIKSPH_42 \\
$3 / 6 / 98$ & 28030611 & & DRF_DMIX_01 \\
$3 / 6 / 98$ & 28030613 & 1.243 & DRF_DMIX_02 \\
& & &
\end{tabular}

Table 4--Exposure period 6, 4/20/98-4/24/98

\begin{tabular}{|c|c|c|c|}
\hline Date & Nova Shot No. & $\begin{array}{c}\text { Energy into } \\
\text { target }(\mathrm{kJ})\end{array}$ & Shot name \\
\hline $4 / 20 / 98$ & 28042003 & 11.990 & BDC_3WCALIB_250 \\
$4 / 20 / 98$ & 28042006 & 0.383 & BDC_1WCAL___124 \\
$4 / 21 / 98$ & 28042107 & 22.173 & REC_ZNBKLT_19X \\
$4 / 21 / 98$ & 28042110 & 23.153 & REC_ZNBKLT_21X \\
$4 / 21 / 98$ & 28042113 & 24.140 & REC_ZNBKLT_22X \\
$4 / 21 / 98$ & 28042117 & 25.488 & REC_ZNBKLT_23X \\
$4 / 22 / 98$ & 28042204 & 13.675 & TSP_MFAWE_12 \\
$4 / 22 / 98$ & 28042207 & 16.917 & TSP_MFAWE_13 \\
$4 / 22 / 98$ & 28042210 & 18.570 & TSP_MFAWE_15 \\
$4 / 22 / 98$ & 28042214 & 21.714 & TSP_MFAWE_10 \\
$4 / 22 / 98$ & 28042217 & 21.489 & TSP_MFAWE_11 \\
$4 / 22 / 98$ & 28042220 & 19.822 & TSP_MFAWE_14 \\
$4 / 23 / 98$ & 28042303 & 8.733 & KSB_2SHOCK_09 \\
$4 / 23 / 98$ & 28042308 & 8.508 & KSB_2SHOCK_10 \\
$4 / 23 / 98$ & 28042314 & 3.424 & DMG_EEOS_04 \\
$4 / 23 / 98$ & 28042317 & 0.384 & DMG_EEOS 07 \\
$4 / 23 / 98$ & 28042320 & 1.041 & DMG_EEOS_08 \\
$4 / 23 / 98$ & 28042323 & 2.683 & DMG_EEOS 05X \\
& & &
\end{tabular}


Table 5--Summary of deposition of contaminants onto Ti foils.

\begin{tabular}{|c|c|c|c|c|c|c|c|}
\hline & \multirow[b]{2}{*}{ shots } & \multicolumn{3}{|c|}{$\begin{array}{l}\text { deposition rates on Ti foil opposite } \mathrm{B}_{4} \mathrm{C} \\
\left(\mu \mathrm{g} / \mathrm{cm}^{2} / \mathrm{shot}\right)\end{array}$} & \multicolumn{3}{|c|}{$\begin{array}{l}\text { leposition rates on Ti foil opposite SS409 } \\
\left(\mu \mathrm{g} / \mathrm{cm}^{2} / \mathrm{shot}\right)\end{array}$} \\
\hline & & $\mathrm{Cu}$ & $\mathrm{Au}$ & $\mathrm{Fe}$ & $\mathrm{Cu}$ & $\mathrm{Au}$ & $\mathrm{Fe}$ \\
\hline Exposure 1 & 12 & 0.037 & 0.023 & 0.022 & 0.046 & 0.029 & 0.769 \\
\hline Exposure 2 & 3 & 0.084 & 0.027 & 0.034 & 0.134 & 0.052 & 0.087 \\
\hline Exposure 3 & 14 & 0.095 & 0.029 & 0.047 & 0.089 & 0.030 & 0.045 \\
\hline \multirow{4}{*}{$\begin{array}{c}\text { Exposure } 4 \\
\text { average }\end{array}$} & 11 & 0.054 & 0.029 & 0.009 & 0.080 & 0.043 & 0.015 \\
\hline & & 0.066 & 0.027 & 0.028 & 0.077 & 0.035 & 0.257 \\
\hline & & \multicolumn{3}{|c|}{ Total Deposition $\mathrm{B}_{4} \mathrm{C}\left(\mu \mathrm{g} / \mathrm{cm}^{2}\right)$} & \multicolumn{3}{|c|}{ Total Deposition SS409 $\left(\mu \mathrm{g} / \mathrm{cm}^{2}\right)$} \\
\hline & & $\mathrm{Cu}$ & $\mathrm{Au}$ & $\mathrm{Fe}$ & $\mathrm{Cu}$ & $\mathrm{Au}$ & $\mathrm{Fe}$ \\
\hline \multicolumn{2}{|c|}{ Exposure 1} & $\overline{0.45}$ & 0.27 & 0.26 & 0.55 & 0.35 & 9.23 \\
\hline \multicolumn{2}{|c|}{ Exposure 2} & 0.25 & 0.082 & 0.10 & 0.40 & 0.16 & 0.26 \\
\hline \multicolumn{2}{|c|}{ Exposure 3} & 1.34 & 0.41 & 0.66 & 1.24 & 0.43 & 0.63 \\
\hline \multirow{2}{*}{\multicolumn{2}{|c|}{$\begin{array}{c}\text { Exposure } 4 \\
\text { Total }\end{array}$}} & 0.59 & 0.32 & 0.098 & 0.88 & 0.47 & 0.17 \\
\hline & & 2.63 & 1.08 & 1.12 & 3.08 & 1.40 & 10.28 \\
\hline
\end{tabular}




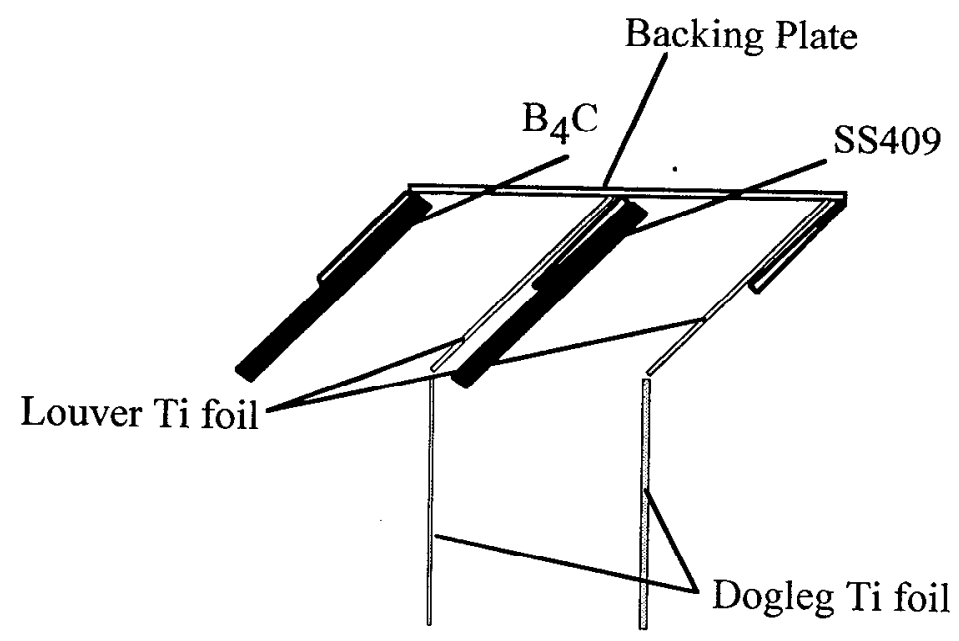

Fig. 2--Schematic drawing of experimental apparatus.
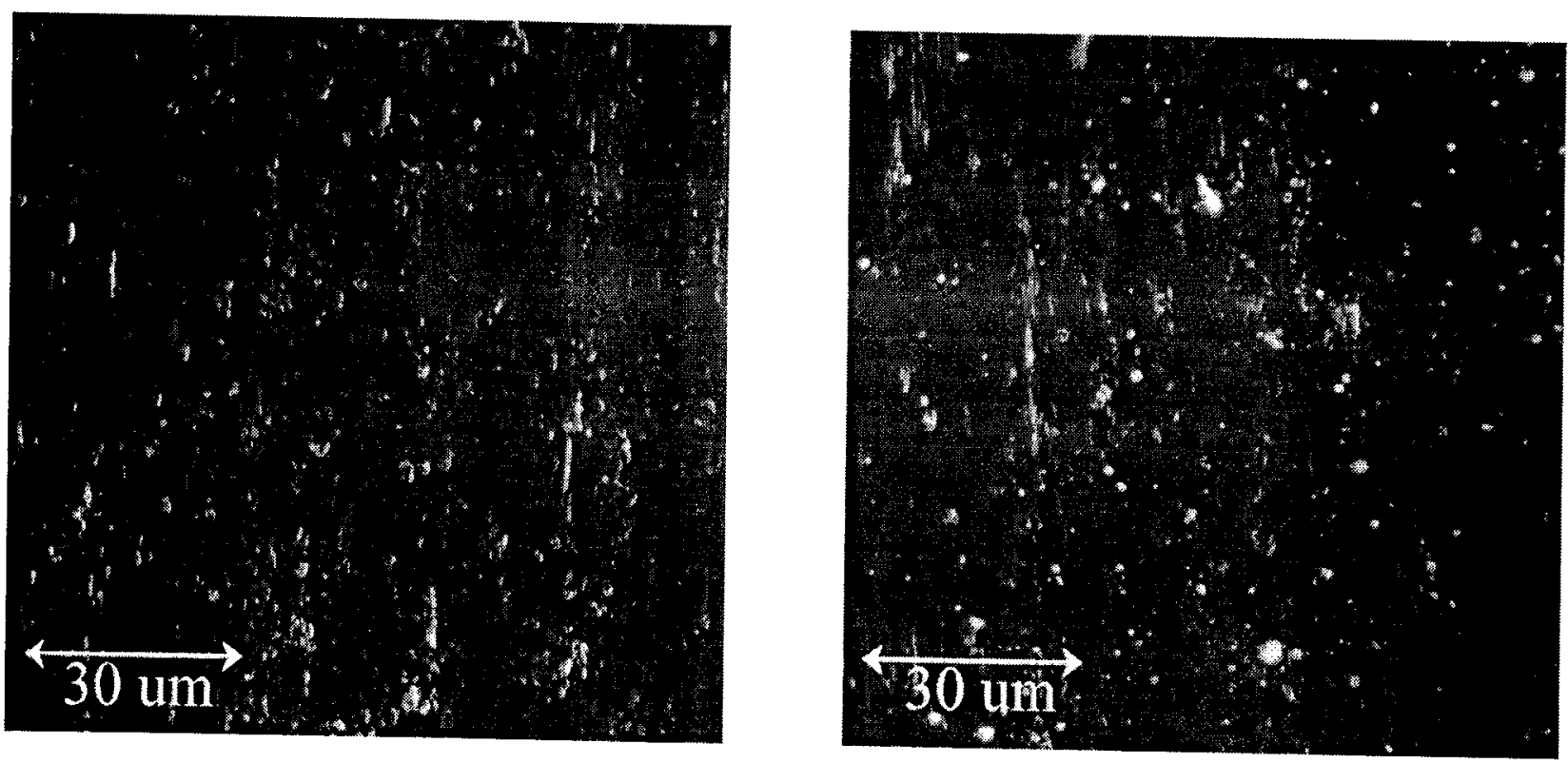

Fig. 3--Darkficld micrographs of an unexposed Ti foil (left) and a Ti foil (right) that was opposite SS409. Note the particles on the exposed sample. 

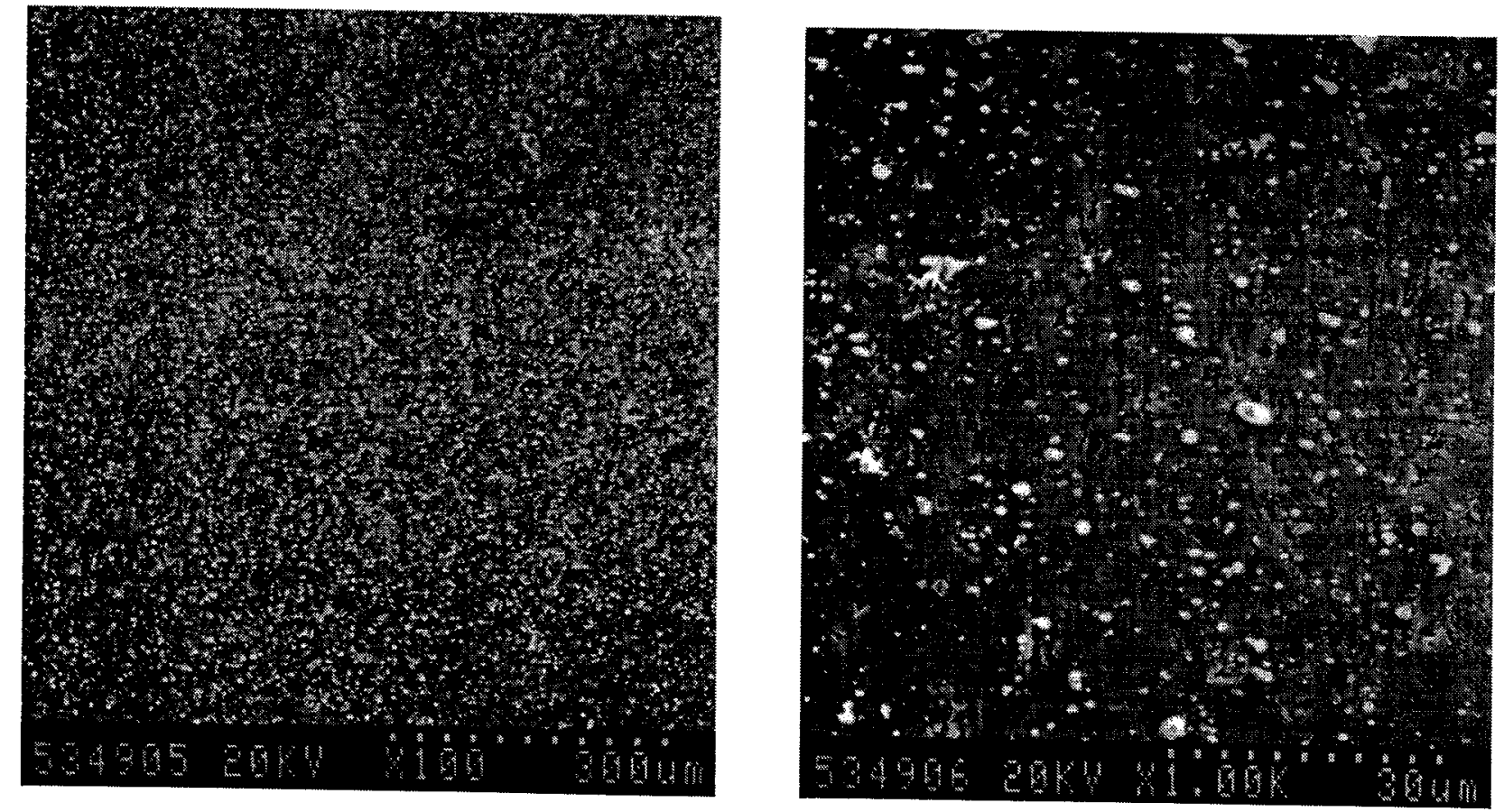

Fig. 4--SEM photographs of Ti foil opposite an intially clean SS409 sample.

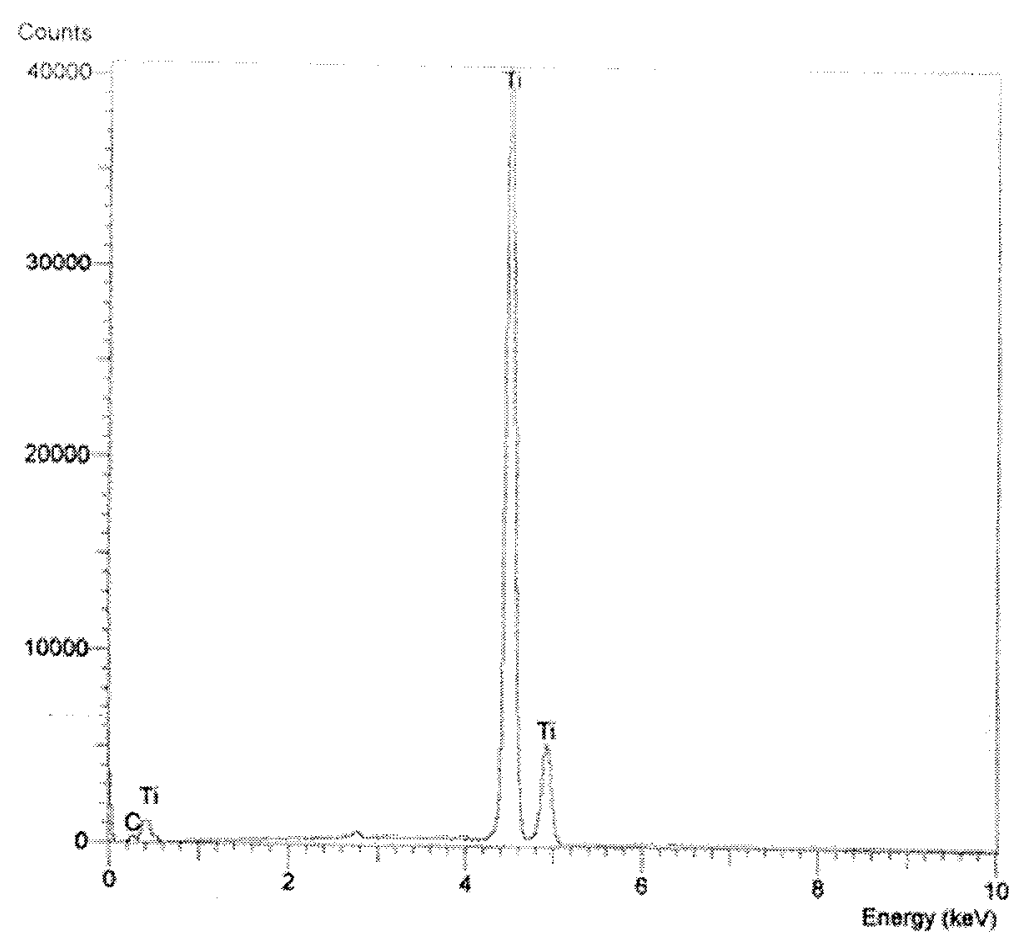

Fig. 5--Fluorescence spectrum from an unexposed Ti foil. 


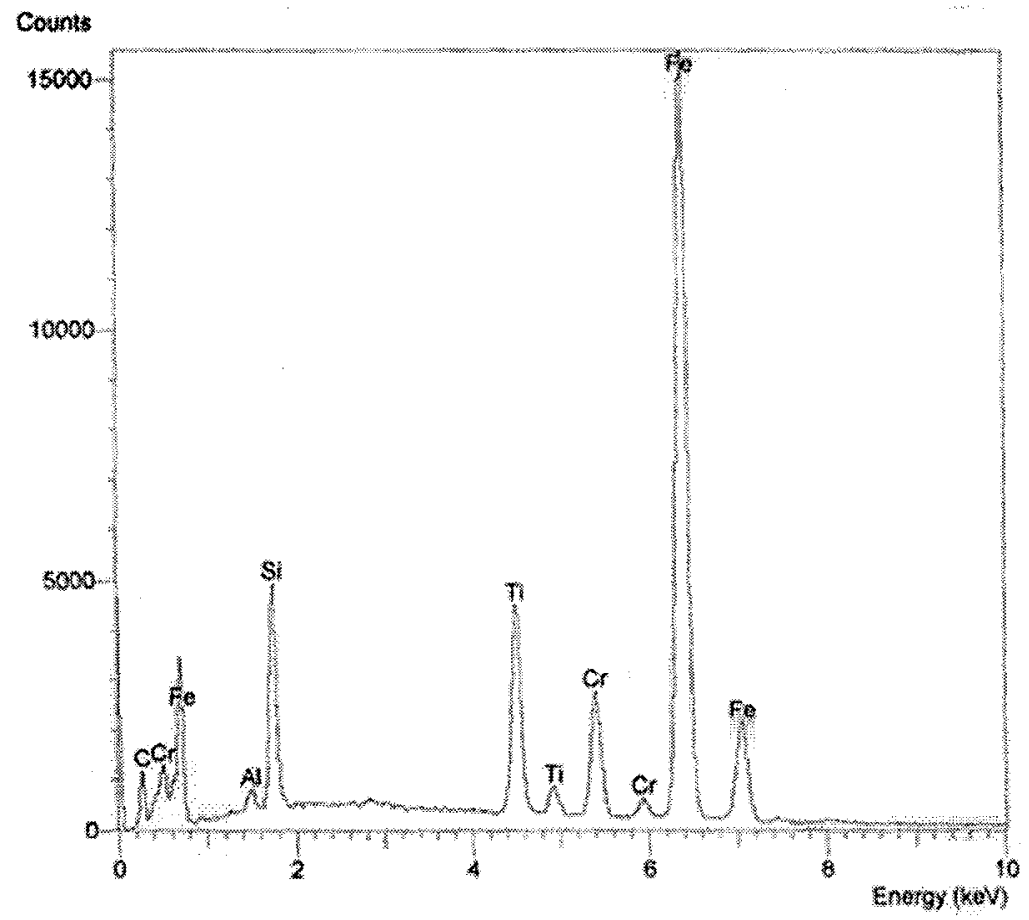

Fig. 6--Fluorescence spectrum from Ti foil opposite an initially clean SS409 sample.

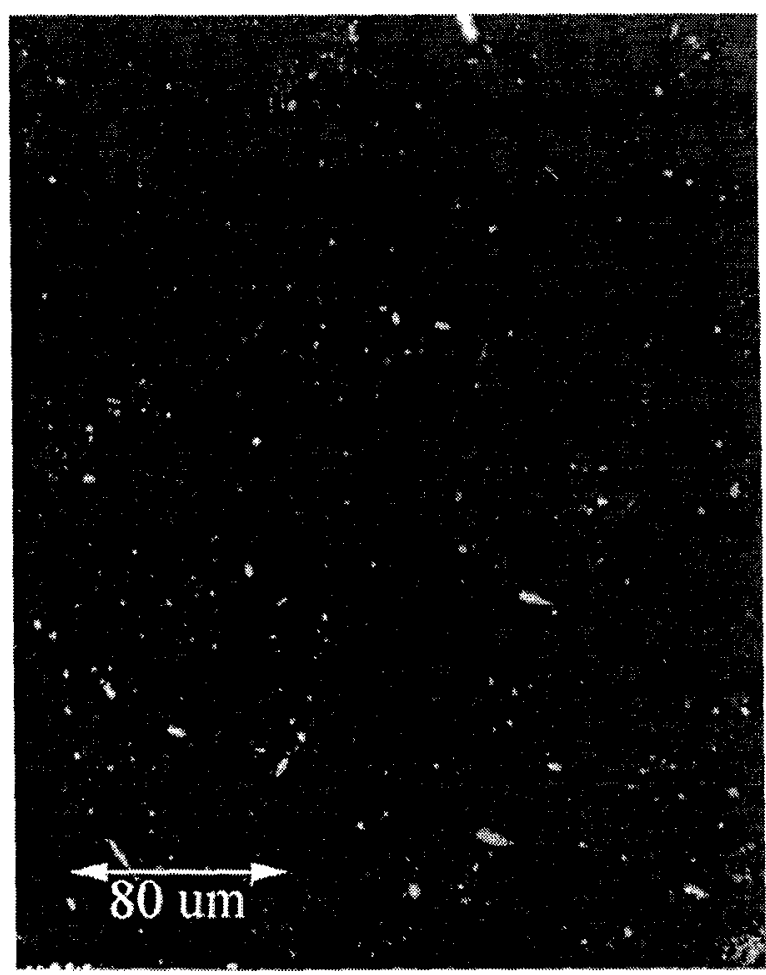

Fig. 7--Splats of copper deposited at a steep angle to the dogleg foil. 


\subsection{Capture fraction calculations for the NIF first wall}

With expected fluences up to $2 \mathrm{~J} / \mathrm{cm}^{2}$, the NIF first wall will be a source of contamination for the final optics debris shields. The first wall has been designed to provide a sink for material that will be mobilized by exposure to target x-rays. The louvered geometry will help to minimize accumulation of contaminants on the final optics debris shields by providing a surface for mobilized debris to deposit in a place out of the target's line of sight view. An adequate sink must be provided to keep the debris shield contamination rate at a level appropriate for the planned cleaning schedule of the first wall. The louvered panels are expected to capture some fraction of the material released from the first wall on each shot. An experiment simulating the proposed louver geometry was fielded on Nova at x-ray fluence levels comparable to those expected on NIF. In this memo, the results of the experiment will be compared to calculations from the U. C. Berkeley hydrodynamics code, TSUNAMI. Additionally, the discussion will include calculations of the capture fraction for the design of the first wall.

\section{Experiment}

Shown in fig. 1 is a head on view and an overhead view of the experimental apparatus used for this experiment. Sketched in fig. 2 is a schematic view of the experimental setup showing the configuration of the samples and collecting foils. The ejected plume of material leaving the surface of the two samples is captured by titanium collecting foils facing the samples. The head on view of the setup shows that the SS409 and $\mathrm{B}_{4} \mathrm{C}$ samples are tilted at a 45 degree angle to the target. The experiment is mounted in the Nova target chamber on top of copper activation tube \#1. The view of the target from this point in the chamber is $25^{\circ}$ from the hohlraum axis. Other expcriments conducted for studying issues related to the NIF first wall have used the SIM5 diagnostic tube also $25^{\circ}$ from the hohlraum axis. Once in position, the center of the face of the samples are approximately $40 \mathrm{~cm}$ from target chamber center. The expected x-ray fluence over the sample area at this distance is $\sim 0.7 \mathrm{~J} / \mathrm{cm}^{2}$ (Normally, at $40 \mathrm{~cm}$ from target chamber center the $\mathrm{x}$-ray fluence is $\sim 1 \mathrm{~J} / \mathrm{cm}^{2}$ but the sample is tilted at a $45^{\circ}$ degree angle reducing the fluence by a factor of $\sqrt{2}$. However, the penetration depth is also reduced by a factor of $\sqrt{2}$, so the surface temperature nominally reaches the same value). Calculation of this fluence level is discussed in a previous report ${ }^{1}$.

For modeling purposes, the focus of this memo will be the results for material removal from the SS409 sample during the third exposure period. For this period, the experimental setup had a clean sample of SS409. The data from that exposure period is listed in table 1. The third exposure is the most appropriate period to model because the sample response to $\mathrm{x}$ rays will be the most similar to the response of a sample that is always free from contamination. This is important because we do not currently have the capability to model the effect of contaminants on the ablation of the underlying substrate. 


\section{Experiment results and calculation}

At the end of the one week exposure period x-ray induced $\mathrm{x}$-ray fluorescence (XXRF) measurements were performed to determine the areal density of $\mathrm{Cu}, \mathrm{Au}$ and $\mathrm{Fe}$ on each of the $\mathrm{Ti}$ foils. A more detailed discussion on the nature of the deposits from the SS409 and the $\mathrm{B}_{4} \mathrm{C}$ can be found in two previous memos. ${ }^{1,2}$ The distribution of the Fe plume that was collected on the Ti louver foil adjacent to the SS409 sample is shown in fig. 3. The difficulty in correctly predicting the fraction of ablated vapor that is captured is two-fold. We would like to be able to predict both the amount of material deposited and the shape of the distribution on the collecting foil.

The amount of material that is removed from the sample on each shot varies given the shot conditions. Since this experiment did not have dedicated shots it was subject to widely varying conditions. The method by which the fluence at the sample surface is predicted is based on certain shot conditions that are not repeated with each shot. Therefore, the exact fluence experienced by the sample is not known with great certainty. This makes it difficult to predict the amount of material that was removed from the surface of the sample. As discussed in a previous memo ${ }^{2}$ regarding this same experiment, the buildup of contaminants on the surface appears to hinder the removal of the underlying substrate. The combination of these two factors will lead to removal depths of the SS409 that will be overpredicted by current models.

The spatial distribution of the plume may be somewhat independent of the amount of material removed from the surface, but it can be affected by other phenomena in the chamber. From fig. 3, we would expect the peak of the distribution to be at the end of the foil that was closest to target chamber center. Yet, we see a peak displaced from the edge of the foil by several $\mathrm{mm}$. A possible explanation of this may be the interaction of the ablation plume with expanding target debris. The velocity of the target debris has been assessed ${ }^{3}$ to be on the order of 1.5-2.0 $\mathrm{cm} / \mu \mathrm{s}$. It takes approximately $20-25 \mu \mathrm{s}$ to travel the $40 \mathrm{~cm}$ to the samples. Calculations indicate that the ablation plume deposits on the foil over a time span of $50 \mu \mathrm{s}$. Therefore it may be likely that the ablation plume is affected by target debris. This phenomenon was also observed in an experiment measuring the distribution of an $\mathrm{Al}$ ablation plume. ${ }^{4}$ Unlike the Nova experiments, target debris will be unable to interfere because it must traverse a distance of $5 \mathrm{~m}$, while the ablation plume from the wall will have to travel a few $\mathrm{cm}$.

Fig. 3 also shows a comparison of a TSUNAMI calculation with the experiment data. The peak value of the measured distribution and the calculations differ by $10 \%$, but the shapes of the distributions differ significantly. As mentioned previously the displaced distribution from the experiment suggests interaction of the plume with oncoming target debris. If the data from the TSUNAMI calculation is shifted to match the experimental data peak to peak then the shapes of the two distributions are qualitatively the same but the amount of material present is overpredicted by the calculation. There may be less material present because as the week of exposure progressed the removal of the SS409 was hindered by deposited contamination or because of the variation of the fluence received by the sample. This is good agreement, 
considering the fairly uncontrolled conditions for this experiment. Future calculations should try to predict the effect of the interaction of the plume with the oncoming target debris to help resolve the discrepancies.

\section{Predictions of NIF first wall capture performance}

A total of four TSUNAMI calculations were performed to predict the collection efficiency of the proposed louver geometry for NIF pictured in fig. 4. As shown in the figure, an ablation plume is generated on the lower portion of the louver by $\mathrm{x}$ rays emanating from target chamber center. It is assumed that an ablation plume is not generated on the upper portion of the louver because it is nearly perpendicular to the target. There is likely to be ablation from the louver edge facing the target, but that effect is not modeled here. Keeping the louver thickness small should minimize the amount of ablated mass from the edge.

In these calculations, it is assumed that all the intercepted mass from the ablation plume condenses on the back surface of the louver. This assumption is likely to be valid for a metal condensing onto the surface given that the temperature rise imparted to the surface by the depositing mass is not too great. For each simulation the parameters $x, y, z$ were varied to get an idea of how changing the dimensions of the louvers would affect the collection efficiency. The amount of mass collected was measured on both louver 1 and louver 2 as shown in fig. 3. This differentiation is made in order to measure the effectiveness of adding the extension (labeled as louver 2) to the original proposed concept for the louver design. The following table lists the dimensions $x, y, z$ for each simulation and the collection results.

$\begin{array}{clccclcl}\begin{array}{l}\text { Simulation } \\ \#\end{array} & \begin{array}{l}\text { Energy } \\ \text { deposited }\end{array} & \text { length of } x & \text { length of } y & \text { length of } z & \begin{array}{l}\text { louver 1 } \\ \text { collection }\end{array} & \begin{array}{l}\text { louver } 2 \\ \text { collection }\end{array} & \begin{array}{l}\text { amount } \\ \text { lost }\end{array} \\ 1 & 2 \mathrm{~J} / \mathrm{cm}^{2} & 1 & 1 & 1 & 51 \% & 40 \% & 9 \% \\ 2 & 4 \mathrm{~J} / \mathrm{cm}^{2} & 1 & 1 & 1 & 49 \% & 35 \% & 16 \% \\ 3 & 2 \mathrm{~J} / \mathrm{cm}^{2} & 1 & 1 & .5 & 77 \% & 17 \% & 6 \% \\ 4 & 2 \mathrm{~J} / \mathrm{cm}^{2} & 1 & 2 & 1 & 51 \% & 42 \% & 7 \%\end{array}$

Changing the $x, y, z$ parameters of the louvers does not affect the total collection efficiency of the louvers greatly. Depositing more energy into the ablating surface increased the amount of mass that was missed by the louvers. Generally speaking, the mass deposits onto the louver over the course of $40 \mu \mathrm{s}$ for the runs where $z=1$. For the simulation where $z=.5$ the condensing mass deposits over the course of $15 \mu \mathrm{s}$. This time is less than half the time for the case where $z=1$ because as the material expands from the surface the plume spreads out in space.

The results of the TSUNAMI calculations show that approximately $90 \%$ of the vapor plume can be captured by the louvered geometry pictured in fig. 4. Additionally, once captured, this material will be unavailable for remobilization on subsequent shots. A view factor calculation for this geometry gives an estimated capture fraction of $75 \%$. The actual capture fraction may lie between these two values. It has been suggested that a sink capture ratio of $67 \%$ will be sufficient to help mitigate the remobilization threat from the first wall ${ }^{1}$. 
A concern for this calculation is the amount of heat added to the condensing surface by the deposited mass. The amount of material arriving at the surface minus the amount of material leaving the surface is the net condensation flux to the surface. To a first approximation, the temperature of the wall $T_{\text {wall }}$ will be a measure of the ability of the surface to handle the incoming flux of material. If this temperature becomes high and approaches saturation conditions then the condensing surface will not be able to accommodate the incoming flux. As an estimate for the surface temperature rise on the louver we use the solution for a constant heat flux on a semiinfinite medium:

$$
\mathrm{T}=\mathrm{T}_{\mathrm{o}}+\frac{2 \mathrm{q}_{\mathrm{o}}}{\mathrm{k}} \sqrt{\frac{\alpha \mathrm{t}}{\pi}}
$$

where

$$
\begin{aligned}
& T=\text { surface temperature } \\
& T_{o}=\text { initial surface temperature } \\
& q_{o}=\text { heat flux } \\
& k=\text { thermal conductivity } \\
& \alpha=\text { thermal diffusivity } \\
& t=\text { time }
\end{aligned}
$$

The semi-infinite medium approximation is valid because the thermal penetration length in SS409 for a deposition time of $50 \mu \mathrm{s}$ is $\sim 20 \mu \mathrm{m}$. The louvers are likely to be at least $250 \mu \mathrm{m}$ in thickness. Assuming that all the energy from the $\mathrm{x}$ rays is in the vapor plume and the entire plume deposits its energy into the louver, a fairly conservative estimate, the temperature rise from each run is given in the table to the left. The greatest rise is $700 \mathrm{~K}$. If the initial temperature were $300 \mathrm{~K}$ then the surface could reach a temperature of $1000 \mathrm{~K}$, a temperature that is still cool in comparison to the melting temperature of SS409 of $\sim 1830 \mathrm{~K}$. Given this result and the conservatism of the estimate it is likely that the assumption that all the ablated vapor is fully accommodated by the surface is a good assumption. In other words, the sticking coefficient should be close to 1 . Michel Gerrasimenko came to this conclusion in a previous report'.

\section{Conclusions}

An experiment studying the louvered geometry concept for the NIF first wall was conducted on Nova at fluence levels comparable to expected fluence levels for the NIF first wall. $\mathrm{Ti}$ collecting foils were employed to measure the distribution of the ablation plume that leaves the exposed first wall sample. Comparisons of the measured distributions to calculations from the U.C. Berkeley code TSUNAMI give good results considering the uncontrolled nature of the experimental conditions. Predicitons of the capture performance of the louvered design of the first wall show that up to $90 \%$ of the ablation plume from the first wall can be intercepted. This

\begin{tabular}{|cc|}
\hline Simulation & $\begin{array}{c}\text { Temperature } \\
\text { rise }\end{array}$ \\
1 & 350 \\
2 & 700 \\
3 & 570 \\
4 & 350 \\
\hline
\end{tabular}
can siginificantly reduce the threat to the final optics debris shields from remobilized material and first wall material. A louvered wall will provide a source of passive cleaning for the target chamber and reduce the rate of debris accumulation on the debris shields by limiting the 
amount of mobilized material per shot.

\section{References}

1. Gerassimenko, M., Burnham, A., "Studies of First Wall Contamination and Mobilization of Contaminants", Document QDV-97-0020, December 1, 1997

2. Scott, J., "Louvered geometry experiments with NIF first wall materials",

3. Gerassimenko, M., Serduke, F., "Impulse Measurements on NOVA",

4. Gerassimenko, M., Burnham A., "Studies of Gold and Aluminum Mobilized by Exposure to X rays", Document QDV-97-0016, August 8, 1997. 
Table 1--Exposure period 3, 1/26/98-1/30/98

\begin{tabular}{|r|r|r|c|}
\hline Date & Nova Shot No. & $\begin{array}{r}\text { Energy into } \\
\text { target }(\mathrm{kJ})\end{array}$ & Shot name \\
\hline $1 / 27 / 98$ & 28012703 & 0.004 & TSP_AUDISK \\
$1 / 27 / 98$ & 28012705 & 16.494 & TSP_RIKSPH_37 \\
$1 / 27 / 98$ & 28012708 & 21.311 & TSP_RIKSPH_38 \\
$1 / 27 / 98$ & 28012717 & 16.583 & DHK_LOWTRT_77 \\
$1 / 27 / 98$ & 28012720 & 17.520 & DHK_LOWTRT_76 \\
$1 / 27 / 98$ & 28012723 & 11.018 & BDC_2WCALIB_56 \\
$1 / 28 / 98$ & 28012802 & 17.600 & KSB_2SHOCK_06 \\
$1 / 28 / 98$ & 28012806 & 18.321 & DRF_BMIX_76 \\
$1 / 28 / 98$ & 28012808 & 19.004 & DRF_BMIX_77 \\
$1 / 28 / 98$ & 28012810 & 20.186 & LML_BMIX_74 \\
$1 / 28 / 98$ & 28012812 & 20.432 & LML_BMIX_75 \\
$1 / 29 / 98$ & 28012903 & 16.479 & DHK_LOWTRT_78 \\
$1 / 29 / 98$ & 28012907 & 0.495 & DHK_AUDISK_53 \\
$1 / 29 / 98$ & 28012913 & 3.929 & DHK_LOWTDIFF_19 \\
$1 / 29 / 98$ & 28012915 & 0.002 & SHG_4WPROBE_24 \\
$1 / 29 / 98$ & 28012918 & 1.398 & RLS_ALIGN_33_U \\
$1 / 29 / 98$ & 28012920 & 1.916 & MDW_ALIGN_01_U \\
$1 / 29 / 98$ & 28012922 & 13.801 & BDC_3WCALIB_236 \\
& & &
\end{tabular}




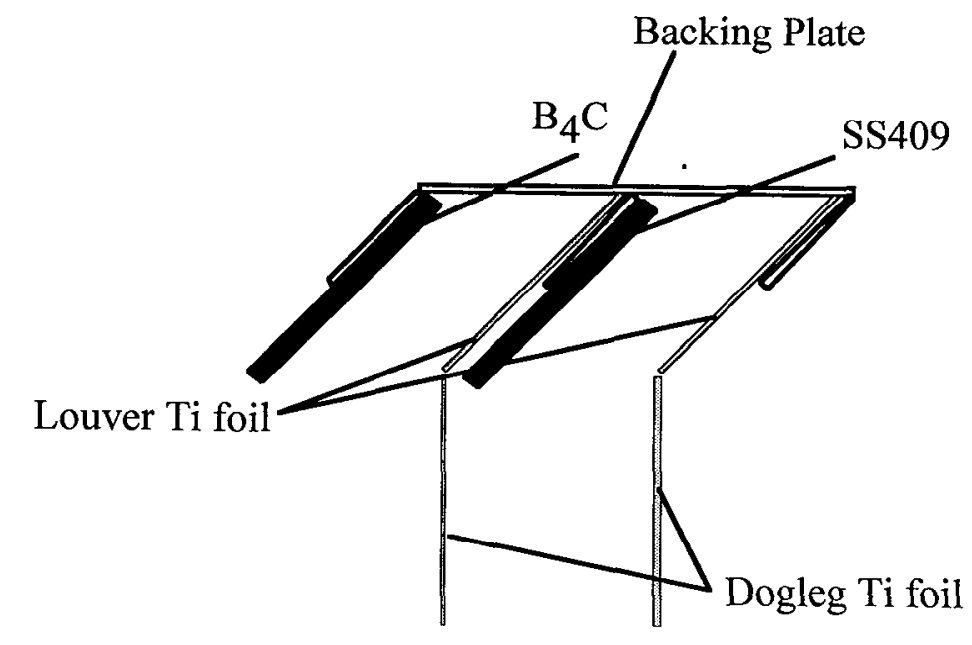

Fig. 2--Schematic drawing of cxperimental apparatus.

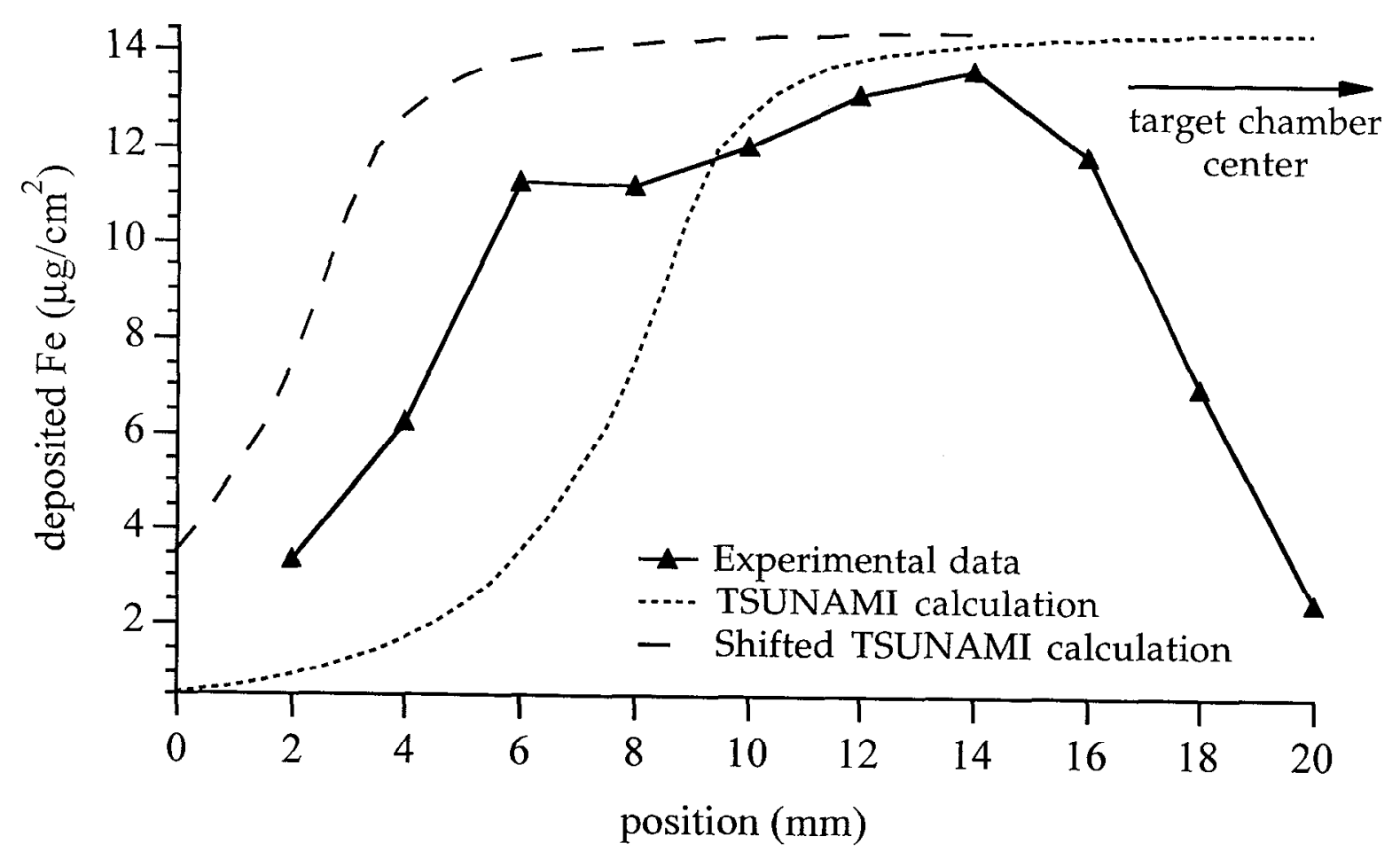

Fig. 3--Comparison of TSUNAMI calculation with experimental data. 


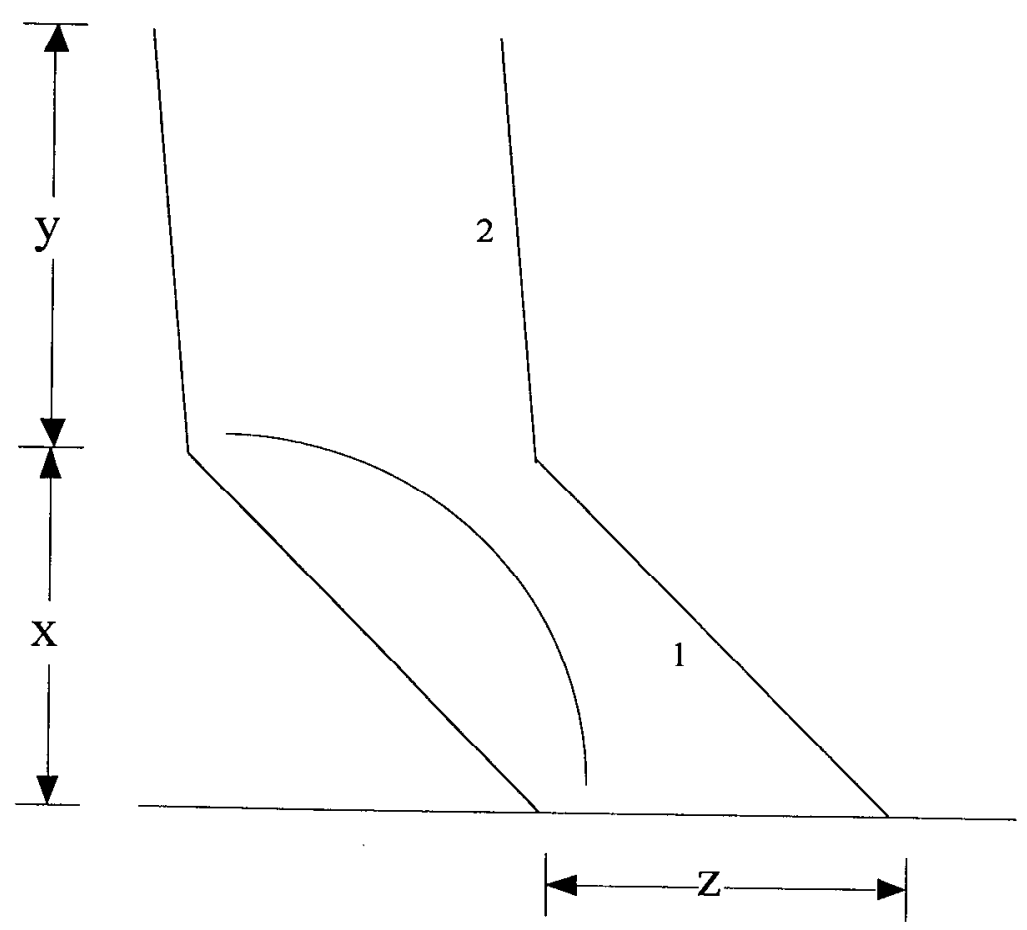

Fig. 4--NIF Louver geometry 


\subsection{Variability of material response to NOVA $x$-ray emissions}

The prediction of material response to $\mathrm{x}$ rays is necessary in order to assess the threat to the NIF final optics debris shields from vaporized target chamber and beam dump material. As part of the asscssment, cxpcriments simulating the x-ray environment under which the materials would operate in the NIF were conducted on the NOVA facility. A primary subset of these experiments has been the measurement of material removal as a function of the $\mathrm{x}$-ray fluence the samples experienced. This memo discusses the variability of the results in the experimental data and offers explanations for the variability. Data from similar experiments performed by CEA and AWE are compared to the data produced at LLNL.

\section{Experiment Observations}

For the NOVA experiments, samples of a particular material are exposed to $\mathrm{x}$ rays in series of shots. The samples are placed at various distances from target chamber center corresponding to nominal x-ray fluences of 1 to $3.5 \mathrm{~J} / \mathrm{cm}^{2}$. Determination of the distance/x-ray fluence conversion factor is described in a previous document. ${ }^{1}$ For many of the experiments, a fused silica sample was used as a control to determine the x-ray fluence seen by the exposed samples of NIF target chamber candidate materials. As a result, a large suite of data exists for fused silica. It has been noted that the results from recent measurements differ largely from previous measurements of fused silica. Consequently, recently exposed samples and the earliest exposed samples were reexposed and tested side by side in an attempt to resolve the discrepancy observed in the data. Shown in Table 1 is the history of measurements gathered for fused silica, and Fig. 1 is a graph of the data with a linear fit to the data.

In order to maintain uniform conditions for each exposure, the data shown here are from experiments where samples were exposed to scale-1 hohlraums with 1-ns-square laser pulses. All the experiments with the exception of the longterm exposure were conducted on the SIM5 diagnostic located on the west side of the target chamber, $25^{\circ}$ from the hohlraum axis. The longterm exposure experiment took place on copper activation tube \#1, also $25^{\circ}$ from the hohlraum axis. After exposure, the removal of material is measured easily by profilometry, since fused silica ablates in 1-D steps with little surface roughness.

\section{Discussion}

At a given fluence, the experimental measurements vary by up to a factor of five. Unfortunately, this kind of uncertainty makes it difficult to determine whether some materials meet the stringent contamination requirements set for the NIF final optics debris shields. Though such things as location in the chamber and types of targets were kept constant throughout the series of experiments, some elements of the experiment were not constant, and these elements can be used to help resolve the discrepancies seen in the results. 
The primary varying element through these experiments is the total laser energy into the hohlraum. From Table 1, the laser energy varies up to a factor of two. Figure 2 is a graph showing the variation of ablation depth with laser energy for the samples exposed at a distance corresponding to nominal fluence of $2.4 \mathrm{~J} / \mathrm{cm}^{2}$. At lower laser energies, the ablation depth is reduced by a factor of two. Since less energy is being put into the hohlraum, it reaches a lower equivalent blackbody temperature. Generally, a softer spectrum of $\mathrm{x}$ rays is a greater threat to materials because of their shorter path length in materials compared to higher energy x rays. Although that is the case here, there is also less energy available to the $\mathrm{x}$ rays at lower laser energies. If the proportion of laser energy converted to $\mathrm{x}$ rays is constant, then the lowest energy shots have only $\sim 75 \%$ as much energy in $\mathrm{x}$ rays as the higher energy shots. Combining these effects at a given distance from a target would result in a lower fluence than the nominal fluence and a colder spectrum of $x$ rays.

Additionally, the hohlraums that reach a higher temperature will be able to emit $\mathrm{x}$ rays for a longer period of time, because they take longer to cool to temperatures where $\mathrm{x}$-ray emission is no longer significant. For the low laser energy shots, the temperature the interior of the hohlraum reaches is cooler to begin with, and so it cools to an insignificant temperature quickly compared to the higher energy shot. Therefore, the samples experiencing the high energy shots receive a longer pulse of $x$ rays effective at heating and vaporizing the surface layers. The results from recent experiments would suggest this as a plausible argument. Unfortunately, the earliest data does not follow this reasoning. The earliest tested samples experienced the highest laser energies over the entire data set, but they experienced the lowest amount of material removal. The data taken since those samples have been consistent with the above explanation. It is likely that there was a condition distinctly different in the first exposures that we are unaware of currently.

A second varying parameter that may affect the results of the experiments is the position of the samples on the experimental apparatus. Figure 3 gives a head-on view and a side view of the apparatus. The samples are mounted on paddles that mount onto a stainless steel rod. Due to the geometry of a SIM tube, the paddles are limited for the most part to be mounted so that the samples are above or adjacent to the stainless steel rod. The view of the target from SIM5 allows for the samples to see some of the interior of the hohlraum. Since all the samples are mounted at different circumferential positions off the SIM5 axis, they do not have the same view of the target. Some see different portions of the interior of the hohlraum than others. The angular positions of samples would be important because the hohlraum is not illuminated in an axissymmetric manner. If all ten beams are pointed into the hohlraum, there are ten distinct hot spots inside the hohlraum. These hot spots are distributed as two rings of five near either end of the hohlraum. Since the view from SIM5 includes some portion of the interior of the hohlraum, the argument can be made that depending on the angular position of the samples around the axis of SIM5, some of the samples may view a hot spot on the hohlraum wall and others may not. If this is the case, then the x-ray spectrum seen by those samples is different, and it is likely that the removal depths would be different. This effect could be enhanced in some cases because we have never required a strict alignment of the diagnostic when we perform experiments. Therefore, the alignment for each exposure has not been strictly the same throughout the history of 
experiments. Michel Gerrassimenko has suggested carrying out an experiment where we put a set of samples the same distance from the target, but mount them at various angular positions. This would provide information about the variability of the results regarding the angular position of the samples.

\section{Comparison to AWE and CEA Data}

Similar experiments to those performed on NOVA have been performed on the Helen and Phebus facilities of the AWE and CEA, respectively. Figure 4 compares the data from AWE and CE $\Lambda$ to the results obtained on NOVA. Unfortunately, there is limited data available at low fluences from the CEA; the same is true for the AWE data at higher fluences. On first observation, the CEA data matches the fit to the NOVA data, but there is only one point from the CEA data that lies within the range of the NOVA data. The typical spectrum for AWE data is $200 \mathrm{eV}$, for CEA data $120 \mathrm{eV}$, and for NOVA $200 \mathrm{eV}$. Unfortunately, the spectrum of radiation was not measured for any of these experiments. From the experiment conditions, we would expect similar results for the NOVA and AWE experiments. The CEA data should be distinctly different from that of NOVA and AWE because of the different blackbody spectrum.

Taking the various spectra into account, we would expect the results to lie on the same line for both the AWE data and the NOVA data. The data shows something different. The AWE found greater material removal at lower fluences. Figure 5 is a chart of a calculation by Andy Anderson's ABLATOR model. Displayed in the chart is the expected response of fused silica to various blackbody spectra. The calculation shows that the softer spectra should gave a greater removal rate over the fluence range of interest. The limited data from the CEA and the scatter in the data from NOVA smear any difference in the removal rate between these two sets of data. Given the calculation results, the location of the AWE data implies that the spectrum from their experiments is softer than in the NOVA and CEA data.

Material removal from the samples is dependent on the blackbody spectrum of the target. The results of the calculation in Fig. 5 demonstrate that at some fluence, more material will be removed by a higher temperature blackbody then by a lower temperature blackbody. This is a direct result of the penetration distance of the $\mathrm{x}$ rays. Since the $\mathrm{x}$ rays of a colder blackbody have a shorter mean free path in the material, they tend to deposit closer to the surface; hence, their efficiency of removing material at lower fluences. At higher fluences, their shorter mean path limits their ability to heat the bulk of the material. Instead, the $x$ rays heat the material that has been vaporized, raising the temperature of the removed material. The $x$ rays from a higher temperature blackbody penetrate further into a material. At lower fluences, their energy is deposited over a larger mass of material than the energy from a colder blackbody, leading to less rcmoval. At high fluences, the larger mean free path allows for better heating of the material bulk. More efficient heating of the bulk at higher fluences leads to greater removal of material than from a colder blackbody. 


\section{Conclusion}

Material removal experiments on NOVA have shown variations in the results by up to a factor of five at a given fluence. Though a majority of the experiment parameters remained consistent throughout the experiments, the few uncontrolled parameters, such as laser energy and sample orientation on the experiment apparatus, contributed to the variation in the results. The motivation for this study was a result of the difference in results of current experiments compared to initial exposures of fused silica to NOVA target $x$ rays. The difference between the most recent experiments and the earliest experiments includes the entire range of the data. The parameters discussed above can account for the variability in the results in the data, except for the initial experiments. As discussed above, it is probable that there was a condition distinctly different in the first set of experiments from the remainder of the experiments.

Comparison of NOVA data to CEA and AWE data give unclear results. Though the estimated blackbody spectrum of the targets is the same, the comparison with AWE data indicates otherwise. From the data we would conclude that the effective blackbody temperature in the AWE experiments was lower than in the NOVA and CEA experiments. The CEA results are consistent with our experience on NOVA, even though the estimated blackbody temperature is lower. From the results gathered here, it is critical to know the spectrum of $\mathrm{x}$ rays for each sample exposure. The data are not consistent with the estimated values of the blackbody spectrum, and model calculations show that the amount of material removal depends on the temperature of the blackbody spectrum.

\section{References}

1. Gerassimenko, M., A. Anderson A. and A. Burnham, "Studies of First Wall Deposit Removal by Exposure to X Rays," Lawrence Livermore National Laboratory, Document QDV-97-0005 (June 9, 1997). 
Table 1. Summary of fused silica removal data.

\begin{tabular}{|c|c|c|c|c|}
\hline Date & $\begin{array}{l}\text { NOVA } \\
\text { shot no. }\end{array}$ & $\begin{array}{l}\text { Energy into } \\
\text { target }(\mathrm{kJ})\end{array}$ & $\begin{array}{l}\text { Fluence } \\
\left(\mathrm{J} / \mathrm{cm}^{2}\right)\end{array}$ & $\begin{array}{l}\text { Removal } \\
\text { depth }(\mu \mathrm{m})\end{array}$ \\
\hline $12 / 18 / 95$ & 25121815 & 25.945 & 3.2 & 0.20 \\
\hline $12 / 18 / 95$ & 25121819 & 27.892 & 2.3 & 0.08 \\
\hline $12 / 18 / 95$ & 25121824 & 28.099 & 1.7 & 0.03 \\
\hline $12 / 18 / 95$ & 25121828 & 26.969 & 1 & 0.005 \\
\hline \multicolumn{5}{|c|}{ Note: the above results were averaged over the 4 shots listed } \\
\hline $8 / 28 / 96$ & \multicolumn{2}{|c|}{ TSP RIKSPH03 } & 2.4 & 0.22 \\
\hline $8 / 28 / 96$ & \multicolumn{2}{|c|}{ TSP RIKSPH03 } & 1.2 & 0.05 \\
\hline $12 / 5 / 97$ & 27120513 & 17.945 & 2.4 & 0.14 \\
\hline $12 / 13 / 97$ & 27121305 & 20.719 & 2.4 & 0.22 \\
\hline $12 / 13 / 97$ & 27121313 & 20.83 & 2.4 & 0.26 \\
\hline $12 / 13 / 97$ & 27121315 & 21.412 & 2.4 & 0.26 \\
\hline $1 / 27 / 98$ & 28012705 & 16.494 & 1.1 & 0.01 \\
\hline $1 / 27 / 98$ & 28012705 & 16.494 & 1.7 & 0.05 \\
\hline $1 / 27 / 98$ & 28012705 & 16.494 & 1.7 & 0.04 \\
\hline $1 / 27 / 98$ & 28012705 & 16.494 & 2.4 & 0.14 \\
\hline $1 / 27 / 98$ & 28012705 & 16.494 & 2.4 & 0.14 \\
\hline $1 / 27 / 98$ & 28012705 & 16.494 & 3.6 & 0.40 \\
\hline $1 / 27 / 98$ & 28012708 & 21.310 & 1.1 & 0.03 \\
\hline $1 / 27 / 98$ & 28012708 & 21.310 & 1.7 & 0.22 \\
\hline $1 / 27 / 98$ & 28012708 & 21.310 & 1.7 & $0 . \overline{16}$ \\
\hline $1 / 27 / 98$ & 28012708 & 21.310 & 2.4 & 0.38 \\
\hline $1 / 27 / 98$ & 28012708 & 21.310 & 2.4 & 0.41 \\
\hline $1 / 27 / 98$ & 28012708 & 21.310 & 3.6 & 0.64 \\
\hline \multicolumn{2}{|c|}{ longterm exposure } & & 0.9 & 0.006 \\
\hline
\end{tabular}




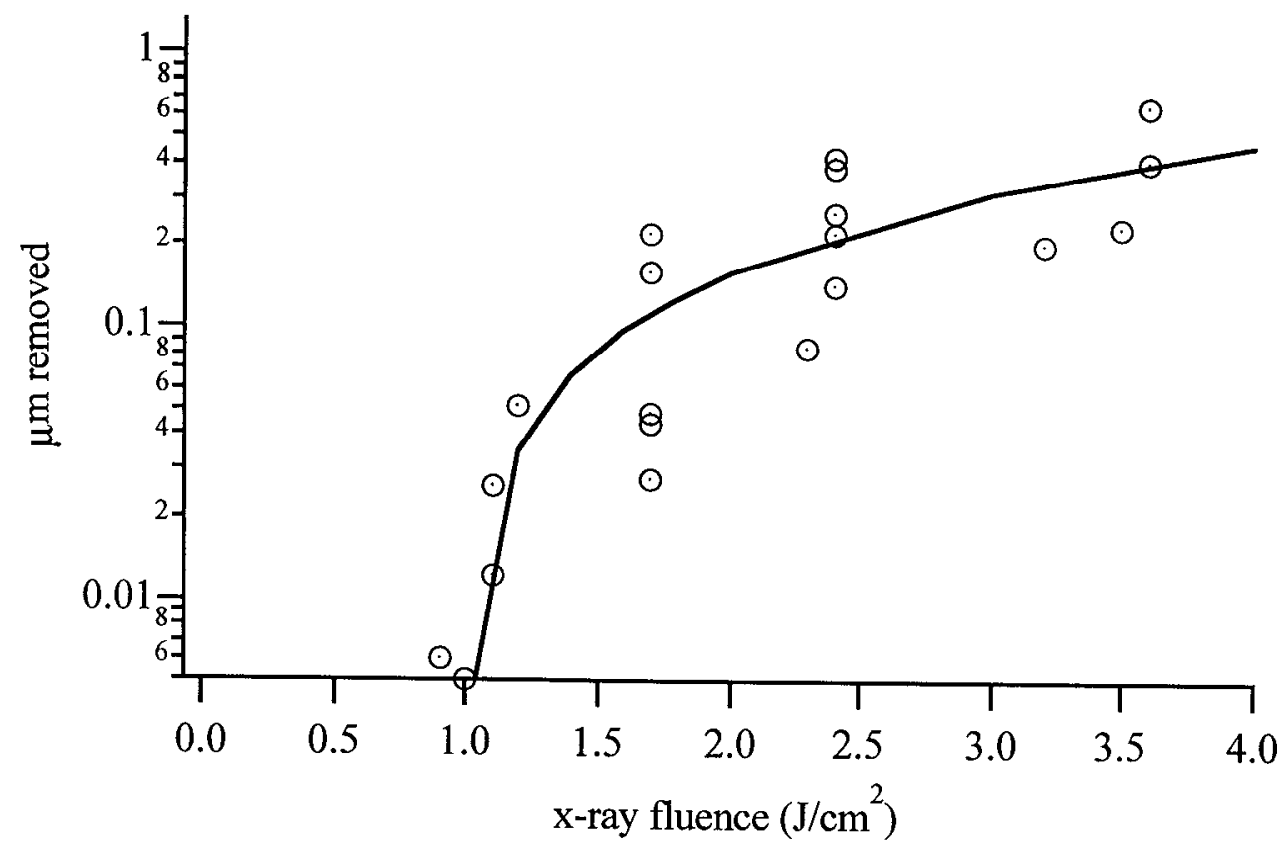

Figure 1. Graph and linear fit of fused silica response to $\mathrm{x}$ rays from NOVA scale-1 hohlraums driven by 1-ns-square pulses.

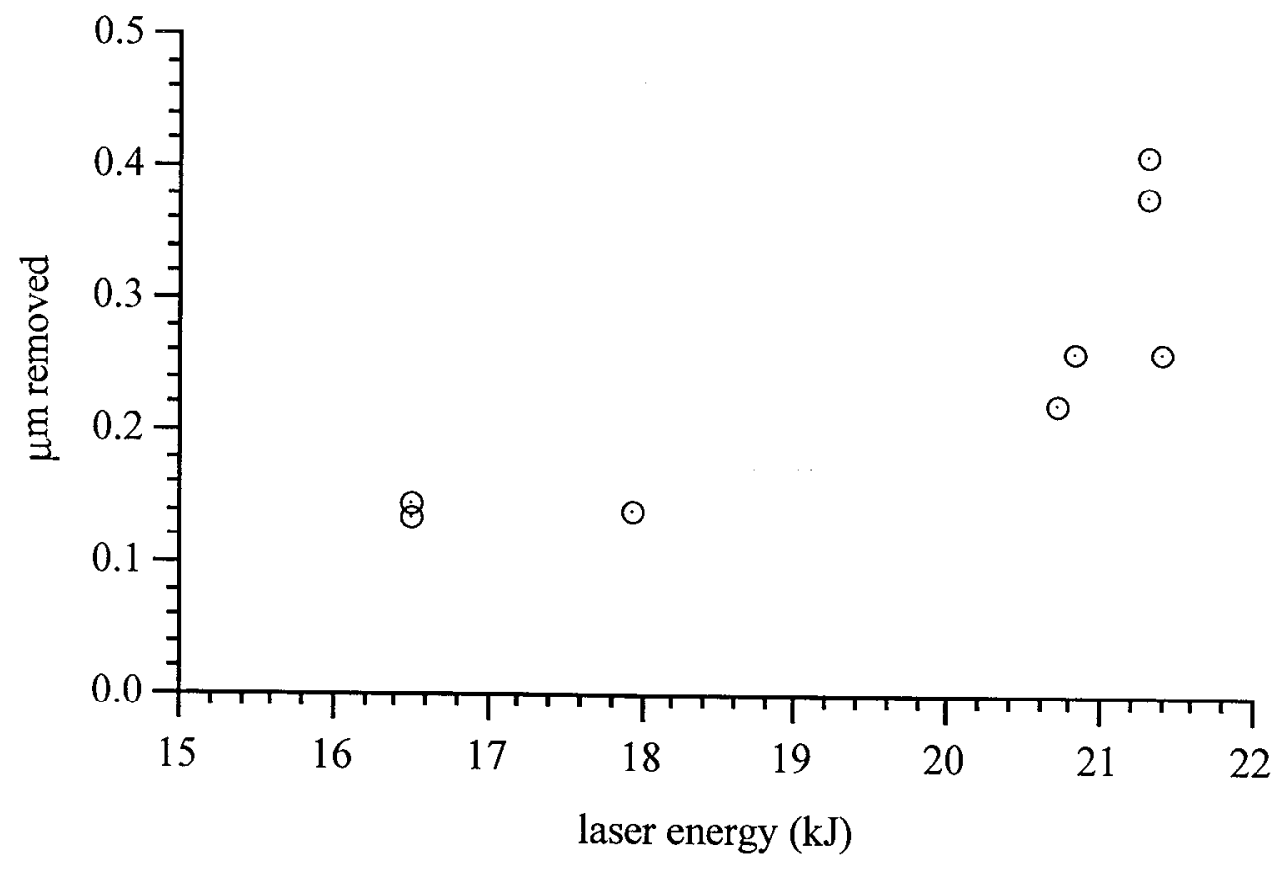


Figure 2. Fused silica removal vs laser energy for a nominal x-ray fluence of $2.4 \mathrm{~J} / \mathrm{cm}^{2}$.

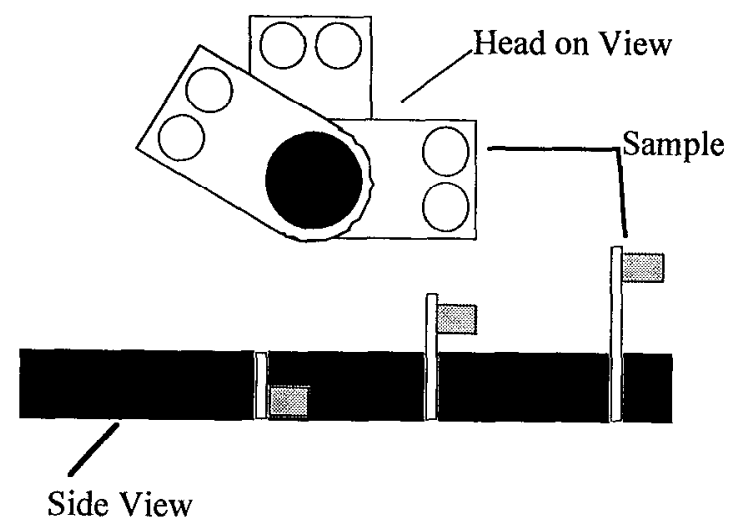

Figure 3. Head-on vicw and side view of experimental apparatus.

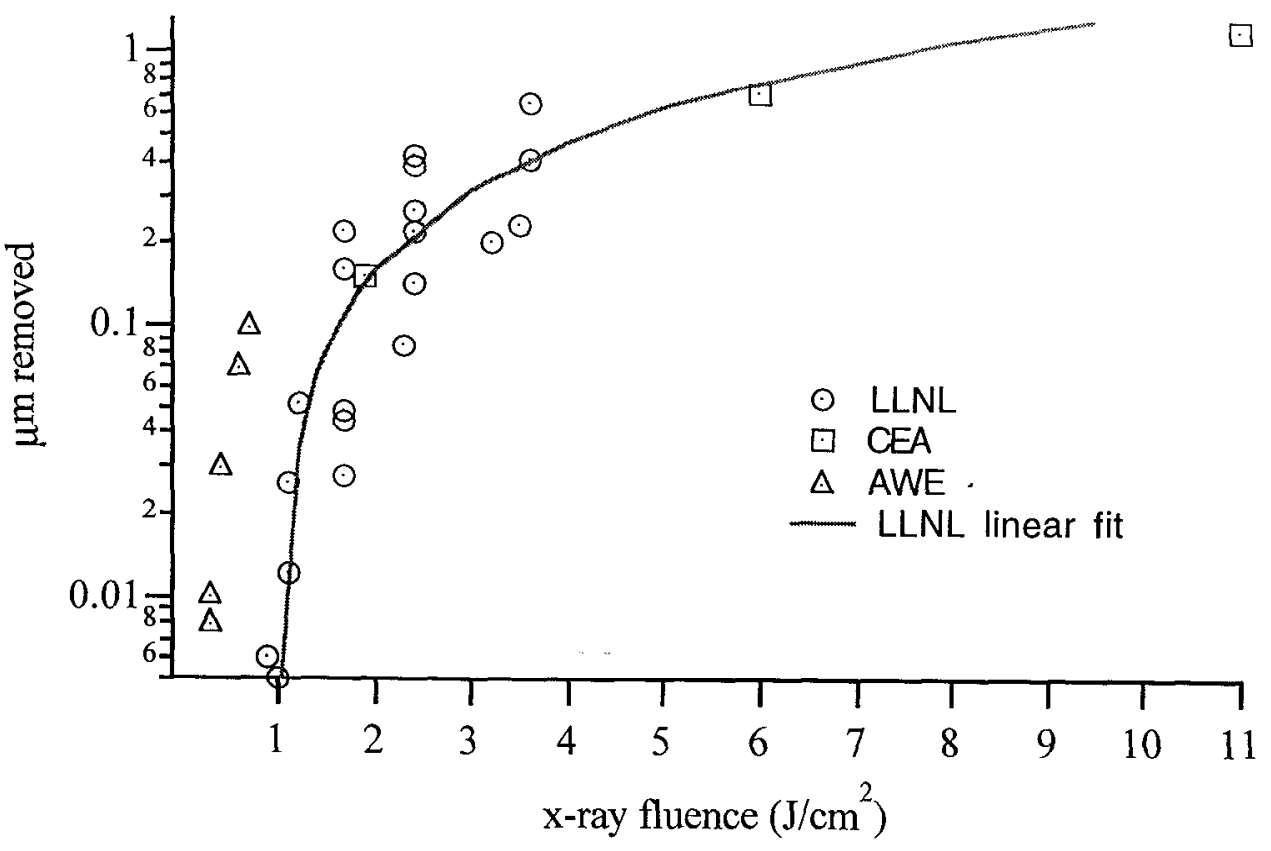

Figure 4. Comparison of LLNL data to AWE and CEA data. 


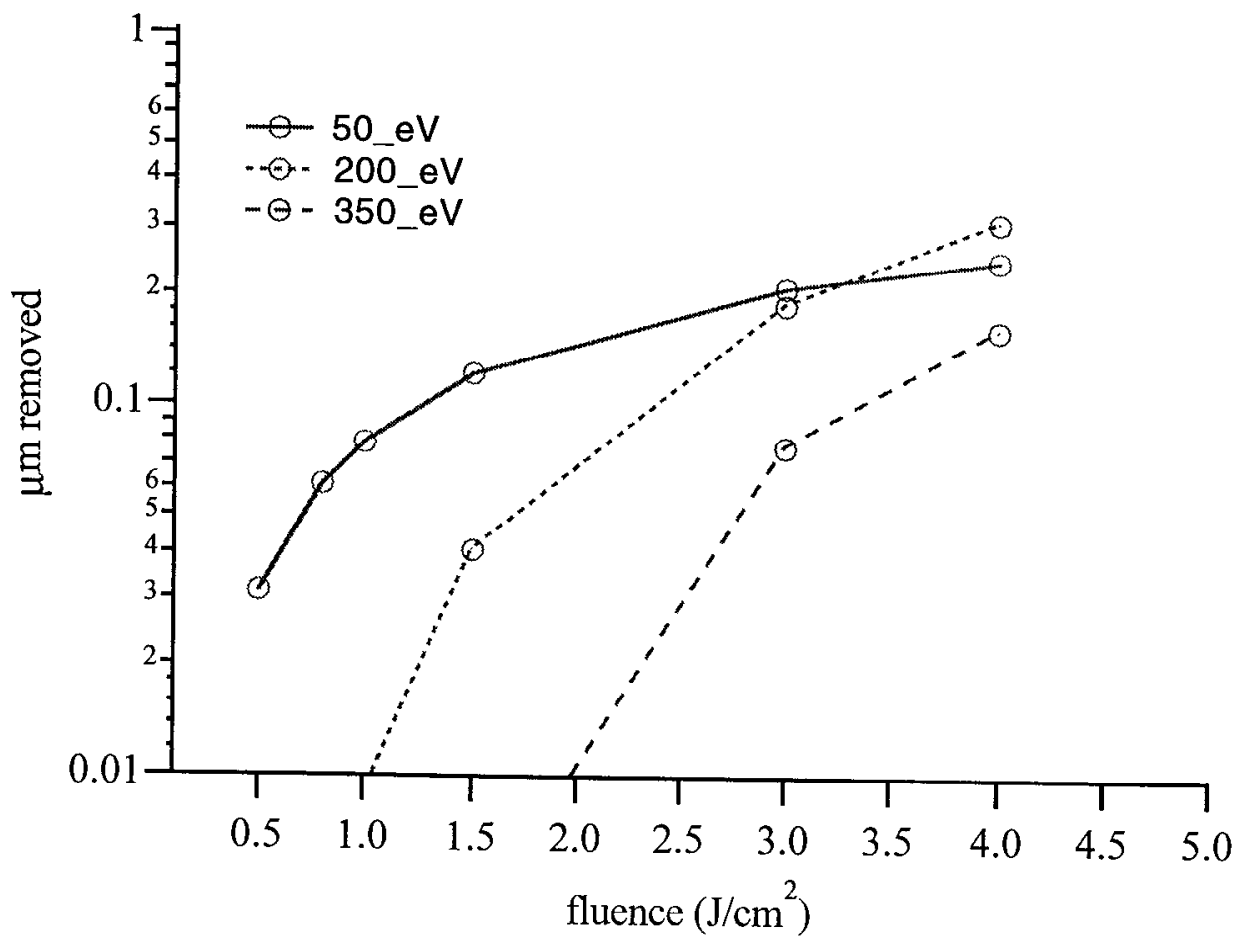

Figure 5. ABLATOR calculation comparing response of fused silica to various spectra. 


\subsection{Variation of NIF target chamber material response with $x$-ray spectrum}

Few exposure experiments conducted to evaluate $x$-ray response of candidate NIF target chamber materials on Nova were performed with scale- 1 hohlraums driven by $1 \mathrm{~ns}$ square laser pulses. These parameters remained consistent in order to maintain nearly the same conditions for each material exposure. During NIF operation, conditions will vary on a shot to shot basis, and the response of target chamber materials will vary with the laser energy, the laser pulse shape and the type of target. These parameters determine the pulse length and spectrum of the $\mathrm{x}$-ray source that target-facing materials will experience. The x-ray source affects the amount of removal from target chamber materials. This memo discusses how varying the spectrum of the $\mathrm{x}$ rays affects material response.

\section{Discussion}

The common practice for describing the $\mathrm{x}$-ray emissions from targets is to take the measured spectrum emitted from the target and fit it with a blackbody curve or with a combination of blackbody curves. The x-ray spectrum from a Nova scale- 1 hohlraum driven by a $1 \mathrm{~ns}$ square laser pulse can be described by a $200-220 \mathrm{eV}$ blackbody for the duration of the laser pulse. LASNEX calculations performed by Andy Anderson ${ }^{1}$ show that the emissions from a NIF $20 \mathrm{MJ}$ target are a combination of 350,90 , and $20 \mathrm{eV}$ blackbodies. This indicates that the performance that will be seen on NIF will vary somewhat from the experiments that have been performed on Nova. Given the same fluence deposited over the same amount of time, materials will behave differently with varying blackbody temperatures. A recent memo ${ }^{2}$ compared fused silica ablation data from Nova to data from the CEA and the AWE. Though, the blackbody temperatures for the Nova and AWE data were quoted to be the same, the results were significantly different. Since the radiation spectrum was not measured for either set of data, it is plausible that the spectrum was not the quoted value for either experiment. This resulted in two distinctly different sets of data.

Material removal varies with the blackbody spectrum because of the penetration distance of the $x$ rays into the material. The photons from a higher temperature blackbody penetrate further into the material than the photons from a lower temperature blackbody. Table 1 gives the absorption coefficient of photons vs. photon energy for aluminum. From the table we can see that higher energy photons have a lower energy absorption coefficient and hence a greater penetration distance. For the photon energies of interest $(<10 \mathrm{keV})$ the primary absorption mechanisms of photon energy is the photoelectric effect. In the photoelectric effect, an oncoming photon interacts with an atom and an electron is ejected from one of the bound shells. The interaction takes place with the atom as a whole and does not occur with free electrons. There is no one expression that describes photoelectric absorption over all ranges of $E_{\gamma}$ and $Z$ but a rough approximation is given by:

$$
\sigma=\frac{k Z^{4}}{E_{\gamma}^{3.5}}
$$


where $k$ is a constant, $Z$ is the atomic number and $E_{\gamma}$ is the photon energy. Eq. 1 shows that absorption increases with atomic number and decreases with increasing photon energy. The dependence of the absorption cross-section on $Z$ demonstrates why materials like $\mathrm{B}_{4} \mathrm{C}$ generally perform better than $\mathrm{Al}$ under the same $\mathrm{x}$-ray conditions. Aluminum with its higher $Z$ is more strongly absorbing then $\mathrm{B}_{4} \mathrm{C}$ at the same conditions.

An excellent example of penetration depth variation with photon energy is to compare $\mathrm{x}$ ray deposition with laser light deposition. A $0.35 \mu \mathrm{m}$ ( $3 \omega$ light) photon has an average penetration depth of $30 \mathrm{~nm}$ in aluminum. A $1 \mathrm{keV}$ photon (the location of the peak of a $200 \mathrm{eV}$ blackbody spectrum) has an average penetration depth of $3000 \mathrm{~nm}$. This is the reason why laser energy deposition is often modeled as a surface heating process whereas x-ray deposition modeling must account for the penetration distance. Therefore, a spatial resolution of the energy deposition is required when performing $\mathrm{x}$-ray ablation calculations.

When the NIF first becomes operational it will only have four beamlines, sometime later half the beamlines will come on-line and eventually all 192 beams will be operational. The shot schedule on NIF will ramp up in energy as more beamlines become operational and as more experience is gained with operating the facility. Initially, the capabilities of the first set of beams will be nearly equivalent to Nova, but ultimately, ignition shots will be fielded. LASNEX simulations show that a typical full energy shot without yield will have a blackbody spectrum of $\sim 250 \mathrm{eV}$ but a full yield $20 \mathrm{MJ}$ shot will have $\sim 350 \mathrm{eV}$ spectrum. Therefore, in the years before ignition, the target chamber will experience an x-ray environment similar to Nova but once ignition is achieved this will change. From eq. 1 , it is evident that a different blackbody spectrum will affect the response of materials to $\mathrm{x}$ rays because the absorption cross section is dependent on the photon energy. Fig. 1-4 are calculational results showing the effect of x-ray spectrum on the predicted response of relevant materials to the target chamber. The graphs give the expected melt and vaporization depths vs. x-ray fluence with a $1 \mathrm{~ns}$ deposition time for several blackbody spectrums . The vaporization depths provide a lower bound on material removal and the melt depths provide an upper bound.

The calculations give some indication about the effect of blackbody temperature on the response of a material at a given $x$-ray fluence. The results in fig. 1-4 demonstrate that at some fluence, more material will be removed by a higher temperature blackbody then by a lower temperature blackbody. This follows from the dependence of cross section on the photon energy. X rays from a relatively colder blackbody have a higher absorption cross section and hence a shorter mean free path in the material. They will deposit energy closer to the surface and are more efficient at removing material at lower fluences. At higher fluences, their shorter mean path limits their ability to heat the bulk of the material. As a result, they continue to heat material that has already been vaporized or melted. Higher temperature blackbody x rays have a greater mean free path. At low fluences, their energy is deposited over a larger mass of material compared to that of a lower temperature blackbody. Consequently, colder $\mathrm{x}$ rays are more efficient at removal of material at lower fluences. At high fluences, the larger mean free path of 
hotter $\mathrm{x}$ rays allows for better heating of the material bulk. More efficient heating of the bulk at higher fluences leads to greater removal of material than from a colder blackbody.

A related result is that the relative resistance of two materials to $\mathrm{x}$-ray ablation can change as a function of applied fluence if the applied spectrum changes in concert for conditions of interest for a specific application. This has a practical implication for the NIF first wall. NIF $x$ rays are strongly absorbed over the entire range of expected fluences and spectra. Further, the minor increase in ablation due to higher fluence of an ignition shot is approximately canceled by a corresponding decrease in ablation due to the hotter spectrum. In contrast, $\mathrm{B} 4 \mathrm{C}$ and $\mathrm{Al}$ are much nearer the threshold for ablation under NIF conditions, and changes in x-ray deposition depth have a profound effect on the amount of ablation. For these materials, the increase in ablation with fluence for an ignition shot is more than cancelled by a decrease due to the hotter spectrum, leading to decreased ablation for an ignition shot. Of course, these predictions need to be tempered by the fact that the spectra in both cases will be time dependent, leading to a more complicated picture.

\section{Conclusion}

The anticipated $\mathrm{x}$-ray spectrum that the NIF target chamber environment will experience during ignition shots is different from the conditions experienced by samples tested on Nova. Calculations show that material response to $\mathrm{x}$-ray exposures of a few $\mathrm{J} / \mathrm{cm}^{2}$ are dependent on the blackbody spectrum of the $x$ rays. This implies that the $\mathrm{x}$-ray response of the first wall during a yield shot will be different from its performance until the point of the first yield shots. It will bc critical to monitor the performance of the first wall during the campaign to ignition. The campaign to ignition will likely involve some low yield shots (5-10 MJ). Monitoring at this point in time is important in order to gain some predictive ability about its performance with a 20 MJ yield shot where the largest threat is posed to the first wall. Though the $\mathrm{x}$-ray spectrum from the lower yield shots will not be identical to a $20 \mathrm{MJ}$ yield shot, it will be a departure from conditions that have not been test on Nova and will provide some data beyond what is currently known.

\section{References}

1. Anderson, A. "X-ray Ablation Measurements and Modeling for ICF Applications," Lawrence Livermore National Laboratory, UCRL-LR-125352, Sept., 1996.

2. Scott, J.M., "Variability of material response to Nova X-ray emissions", Lawrence Livermore National Laboratory, NIF-0005818, Feb. 19, 1998. 
Table 1--Absorption of photon energy in aluminum.

\begin{tabular}{cc}
$\begin{array}{c}\text { Photon } \\
\text { Energy } \\
(\mathbf{k e V})\end{array}$ & $\begin{array}{c}\text { Cross } \\
\text { Section } \\
\left(\mathbf{c m}^{2} / \mathbf{g m}\right)\end{array}$ \\
\hline & \\
0.001259 & $5.38 \mathrm{E}+06$ \\
0.01259 & $5.38 \mathrm{E}+06$ \\
0.1259 & $4.51 \mathrm{E}+06$ \\
0.3162 & $8.40 \mathrm{E}+05$ \\
0.5012 & $2.99 \mathrm{E}+05$ \\
0.7943 & $9.26 \mathrm{E}+04$ \\
1.055 & $4.47 \mathrm{E}+04$ \\
5.525 & $6.49 \mathrm{E}+03$ \\
8.238 & $2.01 \mathrm{E}+03$ \\
10.06 & $1.12 \mathrm{E}+03$ \\
22.36 & $9.70 \mathrm{E}+01$ \\
49.71 & $7.80 \mathrm{E}+00$ \\
60.7 & $4.12 \mathrm{E}+00$ \\
74.11 & $2.17 \mathrm{E}+00$ \\
90.5 & $1.15 \mathrm{E}+00$
\end{tabular}

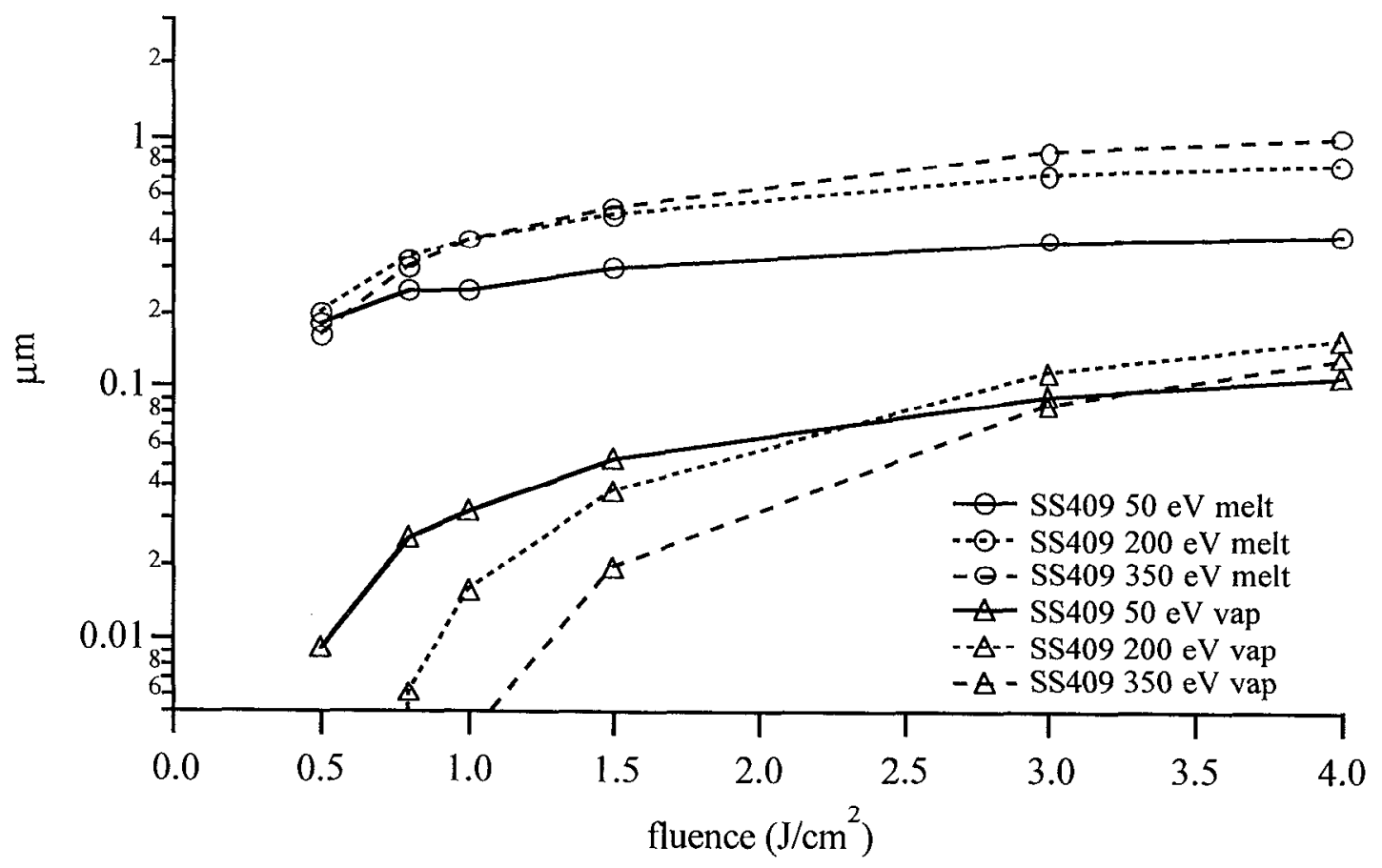

Fig. 1--Calculated x-ray response of stainless steel 409. 


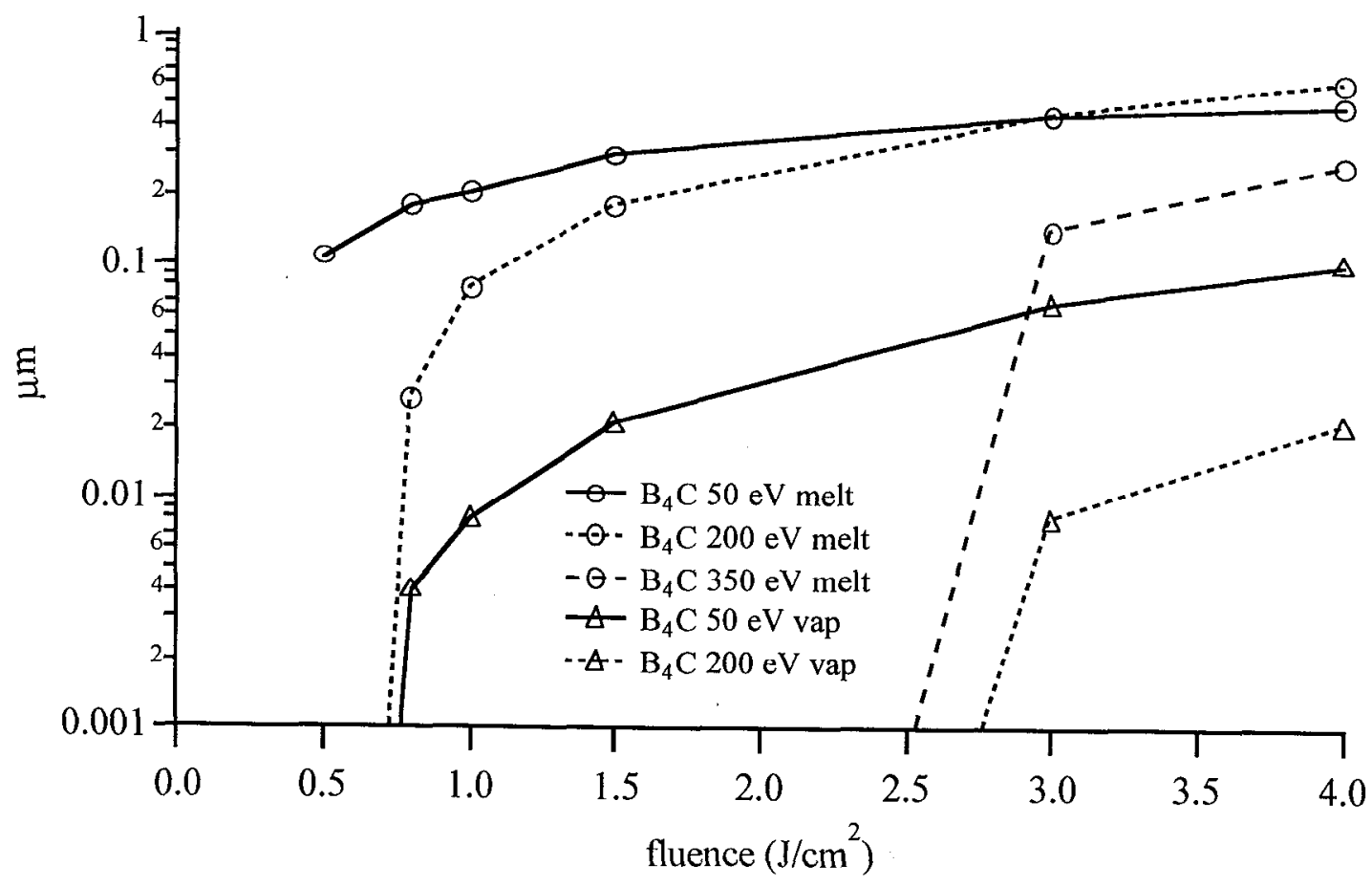

Fig. 2--Calculated x-ray response of boron carbide.

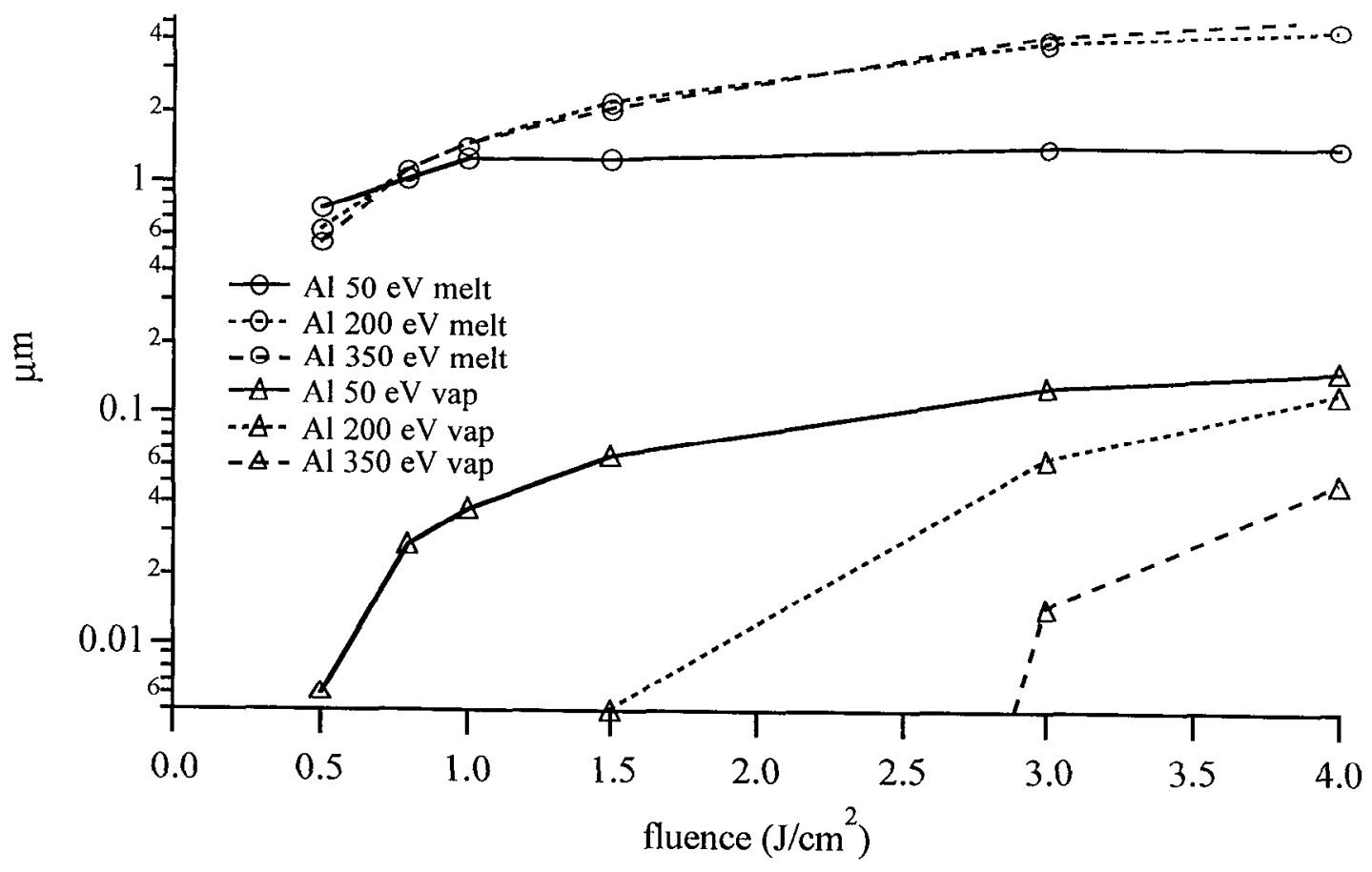

Fig. 3--Calculated x-ray response of aluminum. 


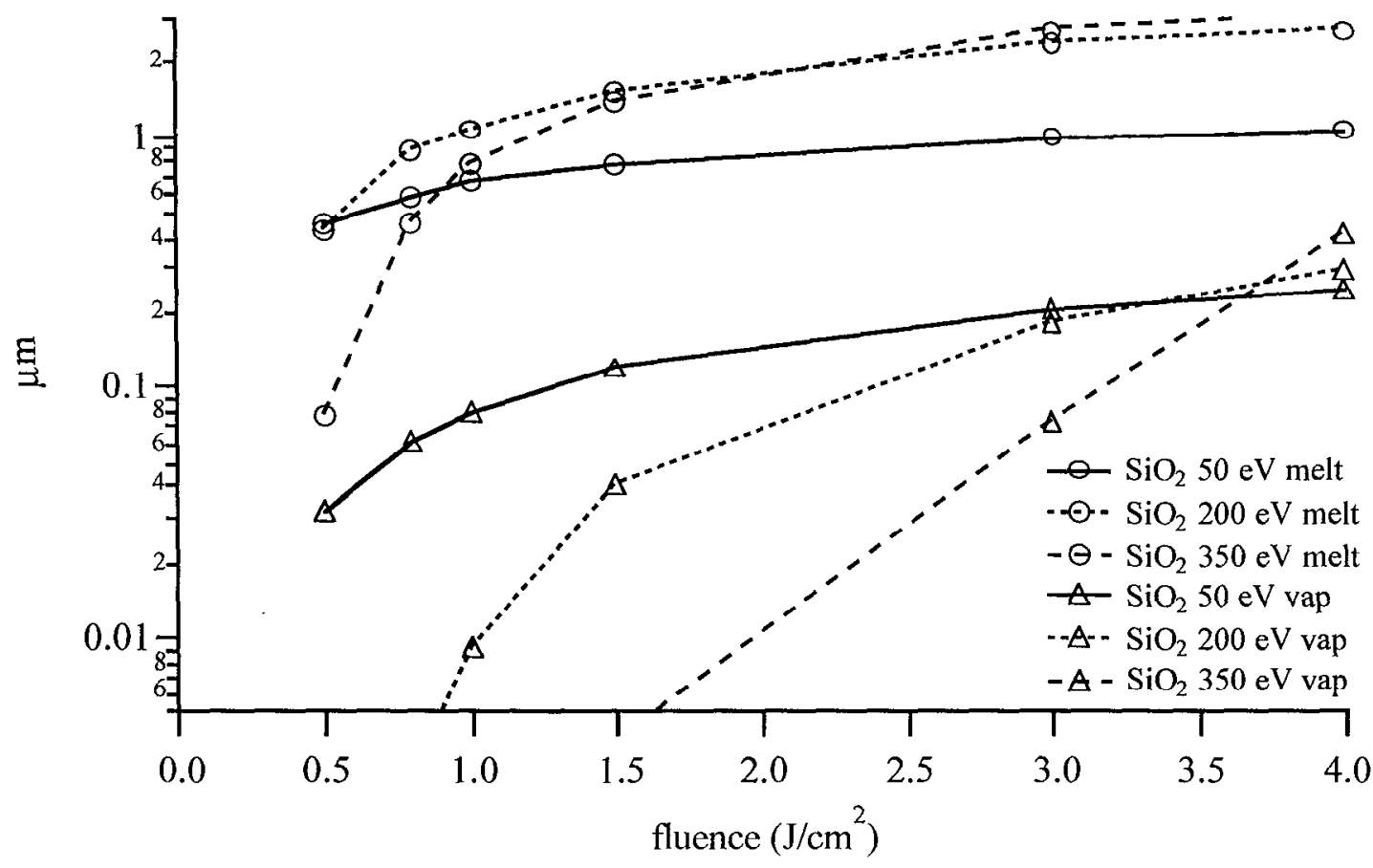

Fig. 4--Calculated $\mathrm{x}$-ray response of fused silica. 